\title{
Recent Progress on Zinc-Ion Rechargeable Batteries
}

Check for

Copdates

Cite as

Nano-Micro Lett.

(2019) 11:90

Received: 24 July 2019

Accepted: 3 October 2019

Published online: 17 October 2019

(C) The Author(s) 2019

HIGHLIGHTS

\author{
Wangwang $\mathrm{Xu}^{1}$, Ying Wang ${ }^{1} \bowtie$ \\ $\triangle$ Ying Wang, ywang@1su.edu \\ 1 Department of Mechanical and Industrial Engineering, Louisiana State University, Baton Rouge, LA 70803, \\ USA
}

- The recent progress about zinc-ion batteries was systematically summarized in detail, including the merits and limits of aqueous and nonaqueous electrolytes, various cathode materials, zinc anode, and solid-state zinc-ion batteries.

- Current challenges and perspectives to future research directions are also provided.

\begin{abstract}
The increasing demands for environmentally friendly grid-scale electric energy storage devices with high energy density and low cost have stimulated the rapid development of various energy storage systems, due to the environmental pollution and energy crisis caused by traditional energy storage technologies. As one of the new and most promising alternative energy storage technologies, zinc-ion rechargeable batteries have recently received much attention owing to their high abundance of zinc in natural resources, intrinsic safety, and cost effectiveness, when compared with the popular, but unsafe and expensive lithium-ion batteries. In particular, the use of mild aqueous electrolytes in zinc-ion batteries (ZIBs) demonstrates high potential for portable electronic applications and large-scale energy storage systems. Moreover, the development of superior electrolyte operating at either

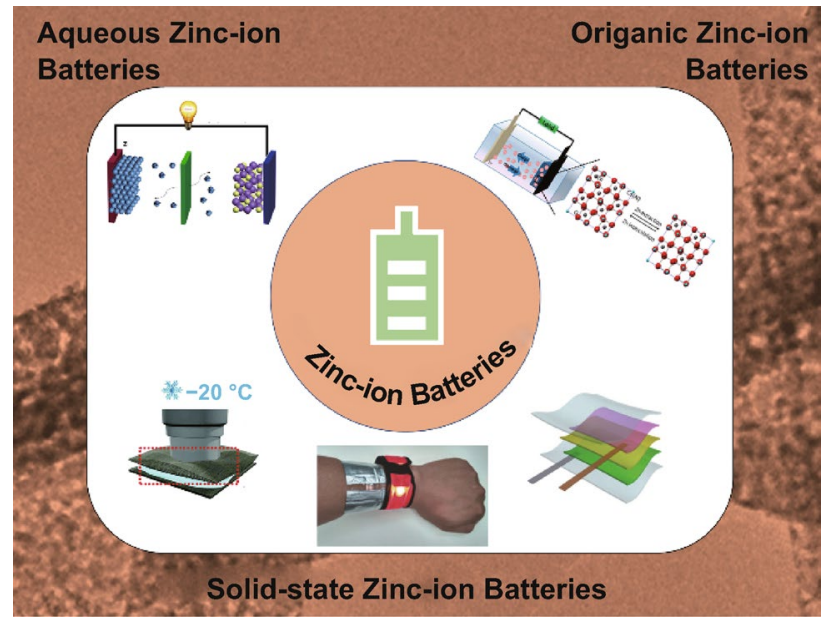
high temperature or subzero condition is crucial for practical applications of ZIBs in harsh environments, such as aerospace, airplanes, or submarines. However, there are still many existing challenges that need to be resolved. This paper presents a timely review on recent progresses and challenges in various cathode materials and electrolytes (aqueous, organic, and solid-state electrolytes) in ZIBs. Design and synthesis of zinc-based anode materials and separators are also briefly discussed.
\end{abstract}

KEYWORDS Zinc-ion batteries; Electrolyte; Cathode; Zinc anode; Flexible device

\section{Introduction}

Energy crisis and environmental pollution have become two of the most serious issues in the present time [1-4]. For hundreds of years, fossil fuels (petroleum, coal, etc.) have dominated the energy supply for the needs of humanity [5-8]. However, usage of fossil fuels can lead to numerous environmental issues, especially air pollution, which is caused by the emissions of sulfur dioxide, nitrous oxide, carbon dioxide, and other gases containing volatile organic compounds [9, 10]. Meanwhile, the development of environment-friendly energy sources such as solar cell and wind electricity is seriously restrained by their intermittent production and inability for storing energy [11, 12]. To overcome the above-mentioned challenges, electrical energy storage (EES) offers an effective way to improve the 
reliability and scalability of the grid [13-15]. In recent years, much progress has been made by developing new energy technologies, especially rechargeable batteries [16-19]. Since the first secondary cell (lead-acid battery) was invented about 150 years ago, numerous kinds of rechargeable batteries have been designed, such as nickel zinc battery, nickel metal hydride, and lithium-ion batteries (LIBs) [20, 21]. For several decades, lithium-ion batteries have been widely applied as commercial energy storage devices owing to their advantages of high efficiency in delivering energy, high voltage, and long cycling life [22, 23]. However, many issues such as high cost and safety problems seriously hinder the large-scale applications of lithium-ion batteries [24, 25]. In recent years, a lot of research work focused on aqueous rechargeable batteries using naturally abundant monovalent ions $\left(\mathrm{Na}^{+}, \mathrm{K}^{+}\right)$and multivalent cations $\left(\mathrm{Zn}^{2+}, \mathrm{Mg}^{2+}, \mathrm{Al}^{3+}\right)$ as charge carriers [26-29]. The aqueous zinc-ion batteries (ZIBs) are very appealing owing to the unique properties of zinc anode, including the low cost, rich resources of zinc metals, high chemical/physical stability, environmental friendliness, and high safety [28, 30-35].

A typical ZIB consists of a cathode for hosting $\mathrm{Zn}$ ions, zinc metal anode, electrolyte, and a separator to separate cathode and anode, which is quite similar to the structure of a LIB. Zinc ions are moving between cathode and anode during charging and discharging processes. Since Volta et al. used zinc metal as electrode in battery in 1999 for the first time, $\mathrm{Zn}$ metal has been deemed as an ideal anode material in types of primary and secondary $\mathrm{Zn}$ cells due to many excellent properties, especially high capacity of $\mathrm{Zn}$ metal anode, nontoxicity, relatively low redox potential $(-0.76 \mathrm{~V}$ vs. standard hydrogen electrode (SHE)), high safety, and low cost. Therefore, such $\mathrm{Zn}$ metal has been applied in various batteries, such as $\mathrm{Ni}-\mathrm{Zn}$ batteries, $\mathrm{MnO}_{2}-\mathrm{Zn}$ batteries, $\mathrm{Zn}$-ion batteries, and $\mathrm{Zn}$-air batteries. Among them, $\mathrm{Zn}-\mathrm{MnO}_{2}$ batteries are dominant as primary batteries owing to the properties of low cost and high energy density [36, 37]. Later effort further expands the alkaline $\mathrm{Zn}-\mathrm{MnO}_{2}$ batteries to secondary battery field, while, as electrode in rechargeable batteries, the continuous formation of zinc dendrite in zinc metal and the irreversible reaction lead to limited cycling life and low discharge capacity. Several decades ago, Yamamoto et al. first designed aqueous zinc-ion batteries by replacing the alkaline electrolyte with aqueous mild acid zinc sulfate electrolyte [38]. Unlike the case in alkaline $\mathrm{Zn}-\mathrm{MnO}_{2}$ batteries, the formation of by-products
$\left(\mathrm{ZnO}, \mathrm{Zn}(\mathrm{OH})_{2}\right.$, etc.) on zinc metal is very few. Also, compared with $\mathrm{Mg}$ metal, another advantage of zinc metal is that zinc can be dissolved more easily in electrolyte and deposited more easily on metal anode. In recent years, a lot of research work has been focused on both zinc metal anode and cathode materials, especially manganese-based oxides, vanadium-based oxides, polyanion compounds, sustainable quinone analogs, and Prussian blue analogs. This research work has made significant progress on the development of ZIBs [39-44].

Furthermore, the rapid development of various wearable electronic devices keeps promoting the exploration on portable energy storage devices with superior electrochemical performance and desirable mechanical flexibility $[45,46]$. As a promising candidate, rechargeable solid-state zinc-ion storage systems also have increasingly attracted research interests [30, 47]. It should be noted that safety problem requires serious consideration in the wearable and flexible devices while they maintain high energy storage capabilities, because these electronics may undergo continuous mechanical force or damage such as strike or being bended, and directly in contact with human body [48]. In comparison with liquid electrolytes, solid-state electrolytes show a noticeable advantage for avoiding the electrolyte leakage. Furthermore, solid-state electrolytes show high stability, desirable flexibility, and can effectively control the formation of zinc dendrite and the dissolution of active electrode materials in zinc-ion storage systems [49]. To date, electrolytes based on zinc sulfate $\left(\mathrm{ZnSO}_{4}\right)$ and zinc triflate $\left(\mathrm{Zn}\left(\mathrm{CF}_{3} \mathrm{SO}_{3}\right)_{2}\right)$ in conjunction with polymer hosts such as $\mathrm{ZnSO}_{4}$-gelatin, $\mathrm{Zn}\left(\mathrm{CF}_{3} \mathrm{SO}_{3}\right)_{2}$-polyethylene oxide, and $\mathrm{Zn}\left(\mathrm{CF}_{3} \mathrm{SO}_{3}\right)_{2}$-polyvinyl alcohol have been reported [50-53]. However, these polymer electrolytes suffer from insufficient mechanical strength, undesirable ionic conductivity, and fast degradation. By employing these electrolytes, the batteries display relatively narrow voltage window and undesirable cycling stability, posing challenges for the gel electrolyte selection and preparation method. Additionally, an intrinsically self-healable ZIB is proposed by the utilization of hydrogel electrolyte, in order to effectively enhance the recoverability of the devices against various shape deformations [51]. More importantly, the exploration of desirable solid-state electrolytes with a wide working range from subzero to high temperature is still lacking and researchers need to put more efforts to promote its development, which can boost the practical applications of flexible ZIBs used 
in airplanes, aerospace, or ocean vehicles. Consequently, the careful design on the suitable solid-state electrolytes with high stability, excellent zinc-ion conductivity, superior mechanical properties, and easy fabrication is highly required for the further development of flexible and safe rechargeable zinc-ion based energy storage devices, which could effectively prevent electrolyte leakage issue and achieve industrial production of batteries with desirable structures [30].

Recently, Fan et al. have analyzed and summarized the $\mathrm{Zn}$-ion storage mechanisms of various cathode materials [54]. And Liu et al. summarized the design strategies for vanadium-based cathodes for aqueous ZIBs [13]. Though many review articles have been published in recent years [53], few review papers discuss various electrolytes in the ZIBs in details despite that electrolyte is a crucial component in ZIBs and there have been rapid new developments concerning it lately. The main difference in this review is that we systematically present recent progresses and challenges of all the components in ZIBs in detail, including various cathode materials, aqueous and nonaqueous electrolytes, solid-state $\mathrm{ZIBs}$, and $\mathrm{Zn}$ anodes. We also provide opinions on current limitations of ZIBs and perspectives for future research directions. The review is divided into six parts: (1) research background, recent development and research progress of ZIBs based on (2) aqueous electrolytes, (3) summarization of representative cathode materials, (4) solid-state zinc-ion batteries, (5) design of zinc anodes and separators, and (6) current challenges and perspectives for future research directions.

\section{Zinc-Ion Batteries based on Aqueous Electrolytes}

Aqueous rechargeable batteries are regarded as promising candidate for large-scale energy storage due to their high safety nature, low cost, and environmental friendliness [55-57]. Moreover, compared with organic electrolyte, the aqueous electrolytes can provide two times higher ionic conductivities $\left(\sim 1 \mathrm{~S} \mathrm{~cm}^{-1}\right)$ due to the higher mobility of ions in water environment [56]. In addition, the rechargeable zincion batteries employing divalent ions can provide higher specific capacity as well as energy density than monovalent ions due to the double electrons involved in redox reactions. Because the most common anode material in ZIBs is zinc metal and the battery capacity is more limited by cathode than anode, a vast variety of cathode materials have been explored for applications in high-performance ZIBs, as detailed below.

\subsection{Manganese Oxide Cathode Materials}

For thousands of years, manganese-based materials have been widely used by humans due to their abundant resources in the crust. Manganese oxides have remarkable diversity of atomic structures and multivalent phases due to different oxidation states of $\mathrm{Mn}:+2,+3$, and +4 . Therefore, manganese oxides can be widely applied as catalysts, battery materials, and deoxidizer in steel making, etc. Moreover, manganese oxides are the first material researched and reported as cathode in the field of ZIBs due to its high valence state and specific phases which can readily accommodate inserted ions. To better understand manganese oxides and their crystal structures and the Mn-based materials applied in ZIBs, we summarize the recent studies about manganese oxides below.

\subsection{1 $\mathrm{\gamma}-\mathrm{MnO}_{2}$}

Kim et al. investigated the phase evolution in a mesoporous $\gamma-\mathrm{MnO}_{2}$ material during the intercalation of zinc ions via in situ Synchrotron XANES and XRD [58]. The results confirm that with the intercalation of zinc ions, the typical tunnel-type $\gamma-\mathrm{MnO}_{2}$ gradually transferred to spinel-type $\mathrm{ZnMn}_{2} \mathrm{O}_{4}$ and two new intermediary $\mathrm{Mn}(\mathrm{II})$ phases, namely tunnel-type $\gamma-\mathrm{Zn}_{x} \mathrm{MnO}_{2}$ and layered-type $\mathrm{L}-\mathrm{Zn}_{y} \mathrm{MnO}_{2}$. With the extraction of zinc ions, most of these phases return back to the $\gamma-\mathrm{MnO}_{2}$ phase, indicating reversible phase transformation during electrochemical reaction (Fig. 1). At the current density of $0.05 \mathrm{~mA} \mathrm{~cm}^{-2}$, the mesoporous $\gamma-\mathrm{MnO}_{2}$ cathode can deliver an initial discharge capacity of $285 \mathrm{mAh} \mathrm{cm}^{-2}$.

\subsection{2 $\alpha-\mathrm{MnO}_{2}$}

The $\alpha-\mathrm{MnO}_{2}$ is also a hot topic to be applied as cathode in ZIBs due to its large and stable $2 \times 2$ tunnels structure, which can accommodate the intercalated $\mathrm{Zn}^{2+}$ ions. The $\alpha$ $\mathrm{MnO}_{2}$ was first studied as cathode of ZIBs by Zeng et al. in 2009 with the initial capacity of $210 \mathrm{mAh} \mathrm{g}^{-1}$ [59]. The capacity can be almost $100 \%$ maintained after 100 cycles at current density of $6{ }^{\circ} \mathrm{C}$, showing reversible zinc storage and robust $2 \times 2$ tunnel structure during electrochemical 


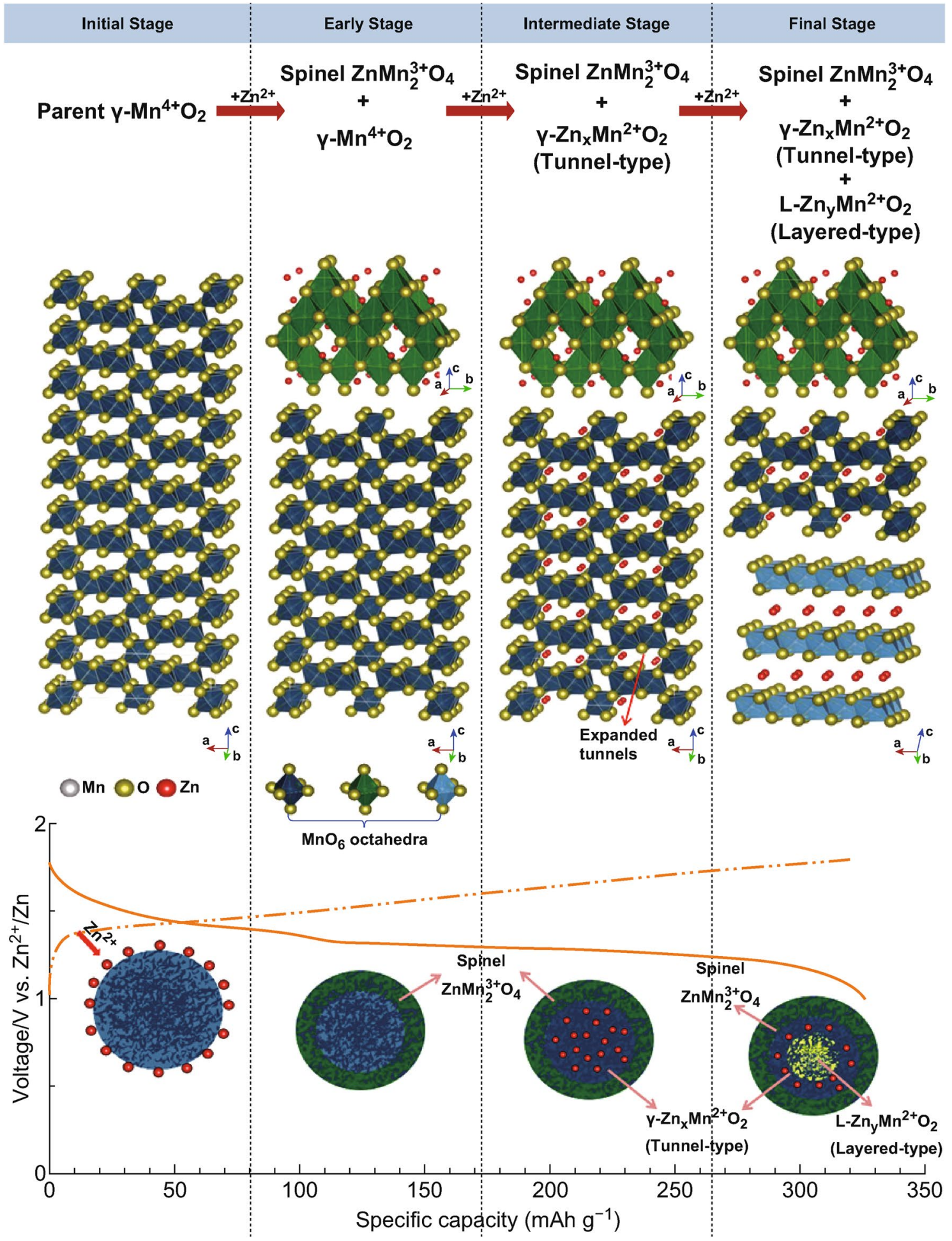

Fig. 1 Schematic illustration of the transformation process of $\gamma-\mathrm{MnO}_{2}$ cathode with $\mathrm{Zn}^{2+}$ ion insertion [58]. With permission from American Chemical Society 
reactions. However, the electrochemical reaction mechanism for $\mathrm{MnO}_{2} / \mathrm{Zn}$ batteries is still a discussion topic until now. Currently, three mechanisms are proposed in the aqueous $\alpha-\mathrm{MnO}_{2} / \mathrm{Zn}$ batteries: zinc intercalation/deintercalation, conversion reaction, and $\mathrm{H}^{+}$and $\mathrm{Zn}^{2+}$ co-insertion.

Zinc intercalation/deintercalation mechanism Due to the small radius of zinc ions, various compounds with layered or tunnel structure enable the intercalation of zinc ions. In 2012, Kang et al. investigated electrochemical mechanism of $\alpha-\mathrm{MnO}_{2} / \mathrm{Zn}$ batteries with aqueous electrolyte [32]. They confirmed that $\mathrm{ZnMn}_{2} \mathrm{O}_{4}$ was formed after the insertion of $\mathrm{Zn}^{2+}$ ion into the tunnels of $\alpha-\mathrm{MnO}_{2}$ and reversibly returned to $\alpha-\mathrm{MnO}_{2}$ after the extraction via ex situ XRD, and they proposed the zinc intercalation/deintercalation mechanism as below [32]:

Cathode: $\mathrm{Zn}^{2+}+2 \mathrm{e}^{-}+2 \alpha-\mathrm{MnO}_{2} \leftrightarrow \mathrm{ZnMn}_{2} \mathrm{O}_{4}$

Anode: $\mathrm{Zn} \leftrightarrow \mathrm{Zn}^{2+}+2 \mathrm{e}^{-}$

Afterward, some studies focus on the phase transformation after the intercalation of zinc ions in tunnels of $\alpha-\mathrm{MnO}_{2}$. For example, Oh et al. revealed that the electrochemical reaction process of $\alpha-\mathrm{MnO}_{2} / \mathrm{Zn}$ involves a reversible phase transition between tunneled $\left(\alpha-\mathrm{MnO}_{2}\right)$ and layered $\mathrm{Zn}$-buserite, instead of spinel structure $\mathrm{ZnMn}_{2} \mathrm{O}_{4}$ [33].

Conversion reaction mechanism In 2016, Liu et al. significantly improved the electrochemical performance of $\mathrm{Zn} /$ $\mathrm{MnO}_{2}$ battery by adding $\mathrm{MnSO}_{4}$ additive in mild $\mathrm{ZnSO}_{4}$ aqueous electrolyte [60]. They found that the $\mathrm{MnSO}_{4}$ additive can suppress the $\mathrm{Mn}^{2+}$ dissolution into the electrolyte, leading to improved rate performance and capacity retention capability. In addition, to understand the electrochemical behavior, they further investigated the morphology and phase evolution of $\alpha-\mathrm{MnO}_{2}$ material via TEM and STEM-EDS mapping. The results reveal that the electrochemical mechanism of $\mathrm{MnO}_{2}$ is based on the conversion reaction between $\mathrm{MnOOH}$ and $\mathrm{MnO}_{2}$ instead of $\mathrm{Zn}^{2+}$ ion intercalation/deintercalation in/out of $\mathrm{MnO}_{2}$, which is formulated as below [60]:

Cathode:

$$
\begin{aligned}
& \mathrm{H}_{2} \mathrm{O} \leftrightarrow \mathrm{H}^{+}+\mathrm{OH}^{-} \\
& \alpha-\mathrm{MnO}_{2}+\mathrm{H}^{+}+\mathrm{e}^{-} \leftrightarrow \mathrm{MnOOH} \\
& 1 / 2 \mathrm{Zn}^{2+}+\mathrm{OH}^{-}+1 / 6 \mathrm{ZnSO}_{4}+x / 6 \mathrm{H}_{2} \mathrm{O} \\
& \quad \leftrightarrow 1 / 6 \mathrm{ZnSO}_{4}\left[\mathrm{Zn}(\mathrm{OH})_{2}\right]_{3} \cdot x \mathrm{H}_{2} \mathrm{O}
\end{aligned}
$$

Anode: $1 / 2 \mathrm{Zn} \leftrightarrow 1 / 2 \mathrm{Zn}^{2+}+\mathrm{e}^{-}$

The $\mathrm{MnOOH}$ phase is confirmed by XRD at the fully discharged state. Instead of intercalation of zinc ions, the reaction is induced by the reaction between $\alpha-\mathrm{MnO}_{2}$ and inserted protons. Moreover, another electrochemical mechanism of $\mathrm{H}^{+}$and $\mathrm{Zn}^{2+}$ co-insertion was reported.

The $\mathrm{H}^{+}$and $\mathrm{Zn}^{2+}$ co-insertion mechanism $\mathrm{It}$ is possible that the open tunnel $\alpha-\mathrm{MnO}_{2}$ enables the co-insertion of $\mathrm{H}^{+}$ and $\mathrm{Zn}^{2+}$ ions. To understand the mechanism, Wang et al. [61] developed $\mathrm{Zn} / \mathrm{MnO}_{2}$ batteries and studied consequent $\mathrm{H}^{+}$and $\mathrm{Zn}^{2+}$ insertion processes by using electroanalytical technology combined with XRD, SEM, and TEM. The two insertion processes happened at two different voltage regions. The galvanostatic intermittent titration technique (GITT) results show that the $\mathrm{H}^{+}$insertion process happens at region I with low overvoltage of $0.08 \mathrm{~V}$, and the $\mathrm{Zn}^{2+}$ insertion process takes place at region II with much higher overvoltage of $0.6 \mathrm{~V}$. The significant difference of $\mathrm{H}^{+}$and $\mathrm{Zn}^{2+}$ insertion processes is mainly attributed to the different resistances for $\mathrm{H}^{+}$and $\mathrm{Zn}^{2+}$ ion diffusion. The EIS results show that the ohmic resistances of these two regions are close, while the charge transfer resistance of region II is much larger than that in region I. Moreover, the bivalent zinc ions have much larger radius and stronger electrostatic interactions with the host atoms than $\mathrm{H}^{+}$ions, leading to slower $\mathrm{Zn}^{2+}$ diffusion. It can be also observed in ZIBs with other cathodes, such as $\mathrm{V}_{2} \mathrm{O}_{5} \cdot n \mathrm{H}_{2} \mathrm{O}$ [65] and $\mathrm{NaV}_{3} \mathrm{O}_{8} \cdot 1.5 \mathrm{H}_{2} \mathrm{O}$ [78]. Despite that three different $\mathrm{Zn}^{2+}$ storage mechanisms in $\mathrm{MnO}_{2} / \mathrm{Zn}$ batteries have been proposed, more efforts are still needed to further identify the electrochemical reaction mechanism and further enhance the battery performance.

Many strategies have been applied to improve the performance of $\mathrm{MnO}_{2} / \mathrm{Zn}$ batteries. For example, to slow down the manganese dissolution during electrochemical cycling, Liang et al. introduced potassium ions and oxygen defects in $\mathrm{MnO}_{2}$ [62]. The incorporated $\mathrm{K}^{+}$ions can stabilize the $\mathrm{Mn}$ based cathodes, and the oxygen defects can improve electrical conductivity and diffusion rate for zinc ions. Therefore, the $\mathrm{K}_{0.8} \mathrm{Mn}_{8} \mathrm{O}_{16} / \mathrm{Zn}$ batteries show improved capacity at high rate. At a high current density of $1 \mathrm{~A} \mathrm{~g}^{-1}$, the $\mathrm{K}_{0.8} \mathrm{Mn}_{8} \mathrm{O}_{16} /$ $\mathrm{Zn}$ batteries can provide a high specific capacity over $300 \mathrm{mAh} \mathrm{g}^{-1}$ and a high energy density of $398 \mathrm{Wh} \mathrm{kg}^{-1}$ for over 1000 cycles, showing outstanding durability and energy density. Composite nanostructure design is another effective 
strategy to boost the performance of $\mathrm{MnO}_{2} / \mathrm{Zn}$ batteries. For example, $\mathrm{Xia}$ et al. designed the manganese dioxide with polyaniline preintercalated in the interlayer space. The intercalated polyaniline can strengthen the layered structure of manganese dioxide in nanoscale size [63]. Furthermore, the combination of PANI-reinforced layered structure and nanoscale particle size $(\sim 10 \mathrm{~nm})$ can efficiently hinder the phase transformation induced by the insertion of hydrated $\mathrm{H}^{+} / \mathrm{Zn}^{2+}$ ions, maintaining the structural stability during the electrochemical reaction. The co-insertion process of hydrated $\mathrm{H}^{+}$and $\mathrm{Zn}^{2+}$ ions was also carefully examined and clarified a self-regulating mechanism involving generation/dissolution of electrolyte (zinc hydroxide sulfate). The PANI-reinforced $\mathrm{MnO}_{2}$ achieves a high capacity of $125 \mathrm{mAh} \mathrm{g}^{-1}$ for over 5000 cycles, showing long cycling life with high capacity.

\subsection{3 $\mathrm{ZnMn}_{2} \mathrm{O}_{4}$}

Inspired by the success of $\mathrm{LiMn}_{2} \mathrm{O}_{4}$, spinel $\mathrm{MFe}_{2} \mathrm{O}_{4}$ $(\mathrm{M}=\mathrm{Zn}, \mathrm{Ni}$, or $\mathrm{Cu}), \mathrm{Co}_{3} \mathrm{O}_{4}, \mathrm{ZnCo}_{2} \mathrm{O}_{4}$, and $\mathrm{ZnMn}_{2} \mathrm{O}_{4}$ have also been explored as electrode material for batteries. Manthiram et al.'s study investigated the reaction mechanism of the insertion process of $\mathrm{Zn}^{2+}$ ions in spinel compositions $\mathrm{ZnMn}_{2-x} \mathrm{Ni}_{x} \mathrm{O}_{4}(x=0,0.5$, and 1) [64]. The zinc ions can be extracted from the structure in acid condition during the $\mathrm{Mn}^{3+}$ disproportionation reaction, while, with the increase in $\mathrm{Ni}$ content, the extraction of $\mathrm{Zn}^{2+}$ will decrease. The researching results appear that the spinel-structured materials are not quite suitable for the intercalation of zinc ions, while, with a certain content of defects (vacancies), the $\mathrm{Zn}$-ion diffusion can be much easier due the lower electrostatic repulsion. Inspired by the understanding that the creation of defects in spinel materials can open additional pathways for the transportation of divalent ions. Chen and his co-workers prepared the cation-defective $\mathrm{ZnMn}_{2} \mathrm{O}_{4}$ spinel as the host material for intercalation of $\mathrm{Zn}^{2+}$ cations [19]. They applied $\mathrm{ZnMn}_{2} \mathrm{O}_{4} /$ carbon composite as the cathode material and studied the electrochemical reaction mechanism via XRD, Raman, FTIR, NMR, and electrochemical measurements. They demonstrated that the abundant cation vacancies and small nanoscale size can facilitate the charge transfer and $\mathrm{Zn}^{2+}$ insertion into $\mathrm{ZnMn}_{2} \mathrm{O}_{4}$ spinel structures. The $\sim 100 \% \mathrm{Zn}$ plating/stripping efficiency enables long cycling life with high capacity. At high current of $500 \mathrm{~mA} / \mathrm{g}$, the $\mathrm{ZnMn}_{2} \mathrm{O}_{4}$ spinel carbon composite material can supply the specific capacity of $150 \mathrm{mAh} \mathrm{g}^{-1}$ for 500 cycles with retention of 94\%.

\subsection{Vanadium-Based Cathode Materials}

\subsection{1 $\mathrm{V}_{2} \mathrm{O}_{5}$}

Building by sharing edges and corners of square pyramids chains, the vanadium pentoxide shows square pyramidlayered structure. More importantly, square pyramid layer of $\alpha-\mathrm{V}_{2} \mathrm{O}_{5}$ can include water molecules or ions such as $\mathrm{Na}$ and $\mathrm{Zn}$ ions into the interlayers, which may change the layered structure and significantly affect the discharge/charge processes and electrochemical performances of ZIBs.

In 2018, Cheng et al. investigated the $\mathrm{Zn}$ storage mechanism in commercial $\mathrm{V}_{2} \mathrm{O}_{5}$ cathode material using $\mathrm{Zn}\left(\mathrm{CF}_{3} \mathrm{SO}_{3}\right)_{2}$ aqueous electrolyte [65]. It is reported that $\mathrm{Zn}^{2+}$ cations can reversibly insert/extract through the layered structure of commercial $\mathrm{V}_{2} \mathrm{O}_{5}$ bulks. Moreover, it is interesting to find that the bulk $\mathrm{V}_{2} \mathrm{O}_{5}$ morphology gradually develops into porous nanosheet structure after cycling, which is caused by the exfoliation during charging and discharging processes (Fig. 2). As a result, the $\mathrm{V}_{2} \mathrm{O}_{5}$ porous nanosheets can deliver a very high reversible capacity of $372 \mathrm{mAh} \mathrm{g}^{-1}$ at current density of $5 \mathrm{~A} \mathrm{~g}^{-1}$ for over 4000 cycles. In addition, the co-intercalated $\mathrm{H}_{2} \mathrm{O}$ molecules can enhance the transportation of $\mathrm{Zn}^{2+}$ ions. Subsequently, Mai et al. systematically studied the critical role of structural $\mathrm{H}_{2} \mathrm{O}$ on $\mathrm{Zn}^{2+}$ intercalation into the layered structure of $\mathrm{V}_{2} \mathrm{O}_{5} \cdot n \mathrm{H}_{2} \mathrm{O}$ [66]. They found that water molecules can dramatically work as a "lubricant" to promote the fast transportation of zinc ions. Specifically, the structural water can function like a charge screening media in redox reactions during cycling, which can not only increase the interlayer distance, but also decrease electrostatic interactions of $\mathrm{H}_{2} \mathrm{O}$-solvated $\mathrm{Zn}^{2+}$ ions in the $\mathrm{V}_{2} \mathrm{O}_{5}$ framework. This result was confirmed by the solid-state magic-angle spinning results. Benefited from the "lubricating" effect of structural water, $\mathrm{V}_{2} \mathrm{O}_{5} \cdot n \mathrm{H}_{2} \mathrm{O}$ can deliver a very high energy density of $\sim 144 \mathrm{Wh} \mathrm{kg}^{-1}$ at $0.3 \mathrm{~A} \mathrm{~g}^{-1}$, which is comparable with $\mathrm{LiCoO}_{2} /$ graphite batteries. 

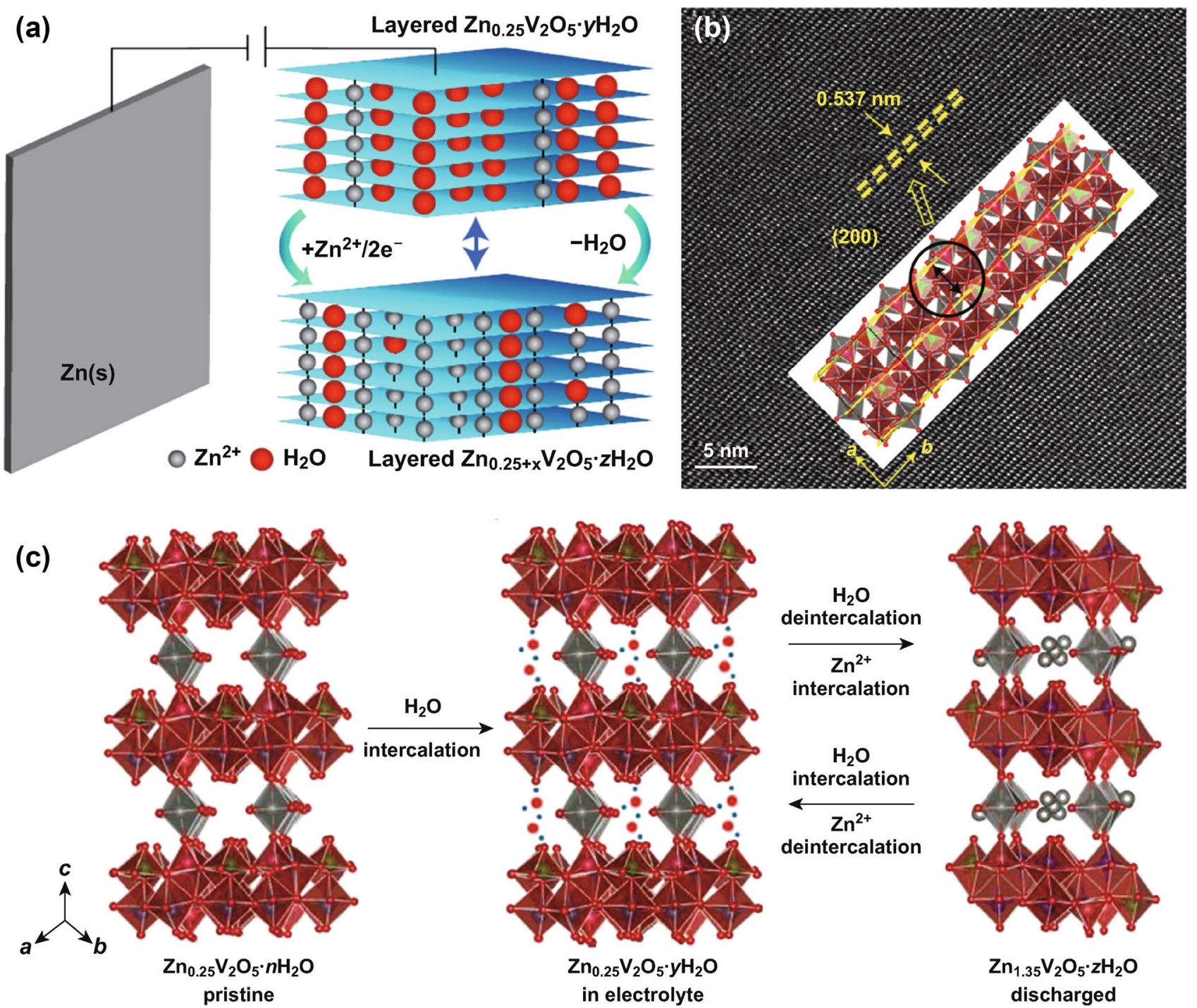

Fig. 2 a Schematic of aqueous ZIBs based on $\mathrm{Zn}_{0.25} \mathrm{~V}_{2} \mathrm{O}_{5}$ cathode. Due to the water molecules between the $\mathrm{V}_{2} \mathrm{O}_{5}$ layers, the interlayer space expands. b The related HRTEM image of the $\mathrm{Zn}_{0.25} \mathrm{~V}_{2} \mathrm{O}_{5} \cdot n \mathrm{H}_{2} \mathrm{O}$ nanobelts. $\mathbf{c}$ Schematics showing the co-intercalation of water molecules accompanying $\mathrm{Zn}^{2+}$ in/out of the interlayer space of $\mathrm{V}_{2} \mathrm{O}_{5}$ layers during charging and discharging process [67]. With permission from Springer Nature

The critical role of structural water molecules and interlayer-doped ions is also verified by many researchers. For example, Linda et al. first studied $\mathrm{Zn}_{0.25} \mathrm{~V}_{2} \mathrm{O}_{5} \cdot n \mathrm{H}_{2} \mathrm{O}$ as the positive electrode for $\mathrm{Zn}$ cells in 2016 (Fig. 2a) [67]. They found that water molecules intercalated in the interlayers can buffer the high charge density of zinc ions and reduce the activation energy for charge transfer at the interface of cathode material (Fig. 2b). The indigenous $\mathrm{Zn}$ ions in $\mathrm{Zn}_{0.25} \mathrm{~V}_{2} \mathrm{O}_{5} \cdot n \mathrm{H}_{2} \mathrm{O}$ crystals can stabilize the layered structure, leading to the long cycling stability. Moreover, the stable layered structure can release the stress generated by the insertion/extraction of zinc ions during charging/discharging process and also short the pathways for the transportation of zinc ions (Fig. 2c). At the rate of $1{ }^{\circ} \mathrm{C}$, the $\mathrm{Zn}_{0.25} \mathrm{~V}_{2} \mathrm{O}_{5} \cdot n \mathrm{H}_{2} \mathrm{O}$ can provide the capacity up to $300 \mathrm{mAh} \mathrm{g}^{-1}$, with energy density of $\sim 450 \mathrm{Wh}^{-1}$ and capacity retention of more than $80 \%$ for over 1000 cycles.

\subsection{2 $V_{x} O_{y}$ Cathode Materials}

Constructed by distorted $\mathrm{VO}_{6}$ octahedra by sharing corners and edges, vanadium dioxide has a special tunnel-like framework. The big tunnel-like framework can facilitate the 
transportation for the diffusion of inserted ions. In recent years, $\mathrm{VO}_{2}(\mathrm{~B})$ has been widely studied as potential electrode material in organic electrolytes with monovalent ions, while the investigation of $\mathrm{VO}_{2}(\mathrm{~B})$ in divalent/multivalent ion batteries is almost blank. In 2018, Yang et al. first introduced $\mathrm{VO}_{2}(\mathrm{~B})$ as cathode material in aqueous ZIBs [68]. They investigated the electrochemical mechanism by in situ XRD combined electrochemical analyses. And the results demonstrate that $\mathrm{VO}_{2}(\mathrm{~B})$ nanofibers have an intercalation pseudocapacitance behavior. The pseudocapacitance behavior is owing to the unique tunnel-like framework, which can not only provide efficient pathways for transporting $\mathrm{Zn}^{2+}$ ions, but also has strong mechanical stability during the intercalation/deintercalation of $\mathrm{Zn}^{2+}$ ions. Therefore, the $\mathrm{VO}_{2}(\mathrm{~B})$ nanofibers show remarkable electrochemical performance. At the high current density of $300{ }^{\circ} \mathrm{C}, \mathrm{VO}_{2}$ (B) nanofibers show the reversible capacity as high as $171 \mathrm{mAh} \mathrm{g}^{-1}$, high energy density of $297 \mathrm{Wh} / \mathrm{kg}$, and power densities of $180 \mathrm{~W} \mathrm{~kg}^{-1}$. In addition, Niu et al. designed the freestanding reduced graphene oxide/vanadium dioxide (RGO/ $\mathrm{VO}_{2}$ ) composite films to further improve the performance of $\mathrm{VO}_{2}$ as cathode for zinc-ion batteries. $\mathrm{Zn} / \mathrm{RGO} / \mathrm{VO}_{2}$ batteries exhibit an energy density of $65 \mathrm{Wh} \mathrm{kg}^{-1}$ even at a high power density of $7.8 \mathrm{~kW} \mathrm{~kg}^{-1}$ (Fig. 3). The superior
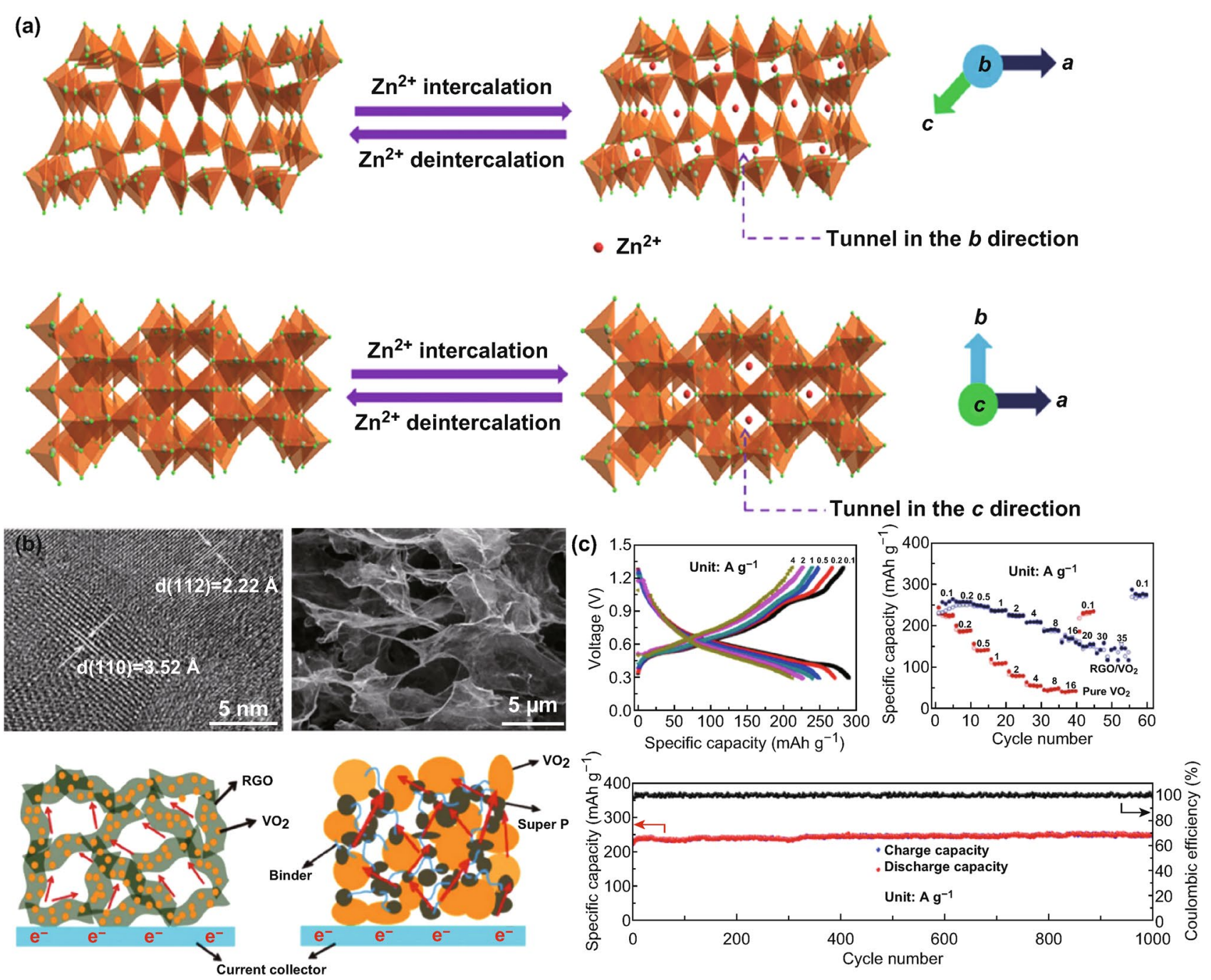

Fig. 3 a Schematic illustration of $\mathrm{Zn}^{2+}$ intercalation/deintercalation in $\mathrm{VO}_{2}$ crystals. b HRTEM and SEM images of $\mathrm{RGO}^{\mathrm{V}} \mathrm{O}_{2}$; schematic view of the pathways for electron transportation in different samples (RGO- $\mathrm{VO}_{2}$ and $\mathrm{VO}_{2}$-super $\left.\mathrm{P}\right)$. $\mathbf{c}$ Electrochemical performance of $\mathrm{RGO}-\mathrm{VO}_{2}$ composite film, including charge/discharge profiles, rate capability, and long-term cycling test at $4 \mathrm{~A} \mathrm{~g}^{-1}$ [67]. With permission from Elsevier and Wiley 
performance attributes to the porous structure of $\mathrm{RGO} / \mathrm{VO}_{2}$ composite film, which can provide efficient transportation of electrons and ions during cycling. Moreover, porous network can also release the stress and accommodate the volume change during the intercalation/deintercalation of $\mathrm{Zn}^{2+}$ into/ from the $\mathrm{VO}_{2}$ crystals. In recent years, Wang et al. found an interesting phase transformation phenomenon during electrochemical process of $\mathrm{VO}_{2}$ [69]. They demonstrated that the monoclinic $\mathrm{VO}_{2}$ gradually transfers to bilayered $\mathrm{V}_{2} \mathrm{O}_{5} \cdot n \mathrm{H}_{2} \mathrm{O}$, which is induced by the initial insertion/extraction of zinc ions in $\mathrm{VO}_{2}$ during cycling. The phase transformation leads to significantly enlarged interlayer spacing and enhanced structural stability, enabling an improved battery performance: at the current density of $100 \mathrm{~mA} \mathrm{~g}^{-1}$ (corresponding to a specific energy density of $271.8 \mathrm{Wh} \mathrm{kg}^{-1}$ ), it can deliver a capacity of $274 \mathrm{mAh} \mathrm{g}^{-1}$ with an excellent capacity retention of $79 \%$ for over 10,000 cycles, showing a promising application as cathode material of ZIBs.

Interlayer-expanded $\mathrm{V}_{6} \mathrm{O}_{13} \cdot n \mathrm{H}_{2} \mathrm{O}(\mathrm{H}-\mathrm{VO})$ nanosheets were also prepared and evaluated as cathode material for aqueous ZIBs [70]. Benefiting from the enlarged interplanar spacing with abundant accessible channels and the ultrathin nanosheet architecture with short diffusion pathway for $\mathrm{Zn}^{2+}$ migration, the $\mathrm{H}-\mathrm{VO}$ cathode presents superior electrochemical property (Fig. 4). The as-synthesized H-VO nanosheets exhibit a very high and reversible capacity of $395 \mathrm{mAh} \mathrm{g}^{-1}$ at a current density of $0.1 \mathrm{~A} \mathrm{~g}^{-1}$, an exceptionally high rate capability up to $20 \mathrm{~A} \mathrm{~g}^{-1}$ with a decent capacity of $97 \mathrm{mAh} \mathrm{g}^{-1}$, and over $87 \%$ capacity retention after 1000 cycles, while the annealed $\mathrm{V}_{6} \mathrm{O}_{13}$ (VO) without lattice water shows much inferior electrochemical behaviors. This demonstrates the essential role of crystalline water in enhancing the electrochemical performances of vanadium compounds as cathode in aqueous ZIBs.

Choi et al. further elucidated the importance of water coinsertion with $\mathrm{Zn}^{2+}$ by the combination of density functional theory (DFT) calculations and experiments, rendering the high performance of $\mathrm{V}_{6} \mathrm{O}_{13}$ material as aqueous ZIB cathode [71]. Such intercalation mechanism showed that the coinserted water can facilitate $\mathrm{Zn}^{2+}$ diffusion through reducing effective charge and thus provide electrostatic shielding. Benefiting from the hydrated intercalation, $\mathrm{V}_{6} \mathrm{O}_{13}$ presented a reversible capacity of $360 \mathrm{mAh} \mathrm{g}^{-1}$ at $0.2 \mathrm{~A} \mathrm{~g}^{-1}$, high rate capability up to $24 \mathrm{~A} \mathrm{~g} \mathrm{~g}^{-1}$ with a decent capacity of 145 $\mathrm{mAh} \mathrm{g}^{-1}$, and satisfactory cycling stability with $92 \%$ capacity retention after 2000 cycles.

Orthorhombic-structured $\mathrm{V}_{3} \mathrm{O}_{7} \cdot \mathrm{H}_{2} \mathrm{O}$ nanowires were also studied as the cathode for ZIBs. Wei et al. designed aqueous ZIBs that composed with $\mathrm{V}_{3} \mathrm{O}_{7} \cdot \mathrm{H}_{2} \mathrm{O} / \mathrm{rGO}$ composite as the cathode and $\mathrm{Zn}$-coated rGO as the anode [72]. The reduced (a)

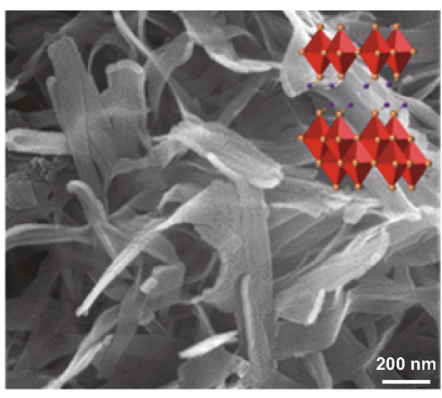

(b)

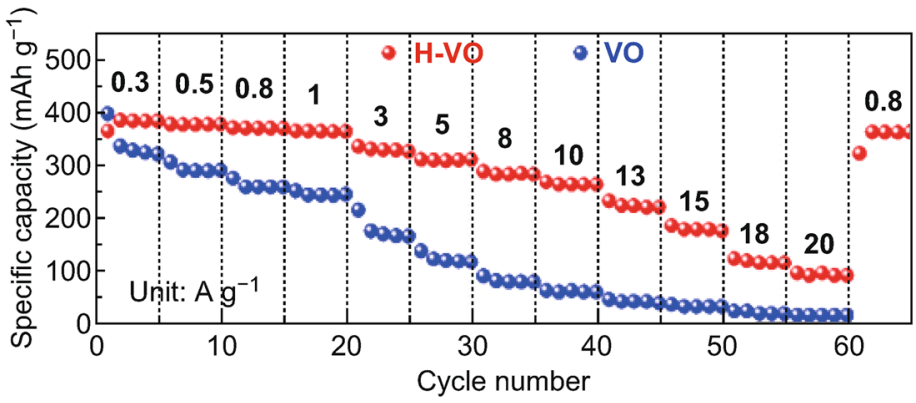

(c)

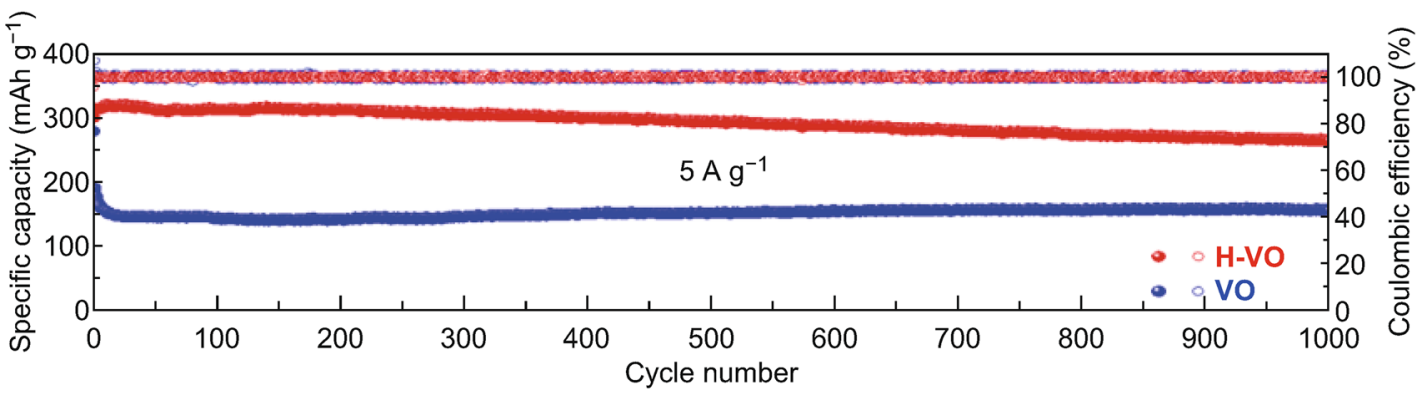

Fig. 4 a SEM image of $\mathrm{V}_{6} \mathrm{O}_{13} \cdot n \mathrm{H}_{2} \mathrm{O}$ (insert: the corresponding atomic structure). b Rate capabilities of $\mathrm{V}_{6} \mathrm{O}_{13} \cdot n \mathrm{H}_{2} \mathrm{O}$ and $\mathrm{V}_{6} \mathrm{O}_{13}$ electrodes. c Long-term cycling performances of $\mathrm{V}_{6} \mathrm{O}_{13} \cdot n \mathrm{H}_{2} \mathrm{O}$ and $\mathrm{V}_{6} \mathrm{O}_{13}$ cathodes at $5 \mathrm{~A} \mathrm{~g}^{-1}$ [70]. With permission from American Chemical Society 
graphene boosts the conductivity of both cathode and anode materials, leading to excellent electrochemical performance. It can deliver a high power density of $8400 \mathrm{~W} \mathrm{~kg}^{-1}$ at energy density of $77 \mathrm{Wh} \mathrm{kg}^{-1}$.

\subsection{3 $M_{x} V_{y} O_{z}$ Vanadate Cathode Materials}

Enlarging the interlayer spacing via preintercalation of cations is an effective way to improve the electrochemical performance of electrodes for aqueous ZIBs. In recent years, vanadium-based nanowires intercalated with different cations ( $\mathrm{M}_{x} \mathrm{~V}_{y} \mathrm{O}_{z}, \mathrm{M}=\mathrm{H}, \mathrm{Li}, \mathrm{Na}, \mathrm{K}, \mathrm{Zn}, \mathrm{Ca}, \mathrm{Ag}, \mathrm{Mn}$, etc.) have been widely studied. For example, Mai et al. designed the aqueous ZIBs based on $\mathrm{H}_{2} \mathrm{~V}_{3} \mathrm{O}_{8}$ nanowire cathode. $\mathrm{H}_{2} \mathrm{~V}_{3} \mathrm{O}_{8}$ nanowires can deliver a high capacity of $423.8 \mathrm{mAh} \mathrm{g}^{-1}$ at $0.1 \mathrm{~A} \mathrm{~g}^{-1}$, with capacity retention as high as $94.3 \%$ for over 1000 cycles [73]. The remarkable performance is owing to the layered structure of $\mathrm{H}_{2} \mathrm{~V}_{3} \mathrm{O}_{8}$ with large interlayer spacing, which facilitates the transportation of zinc ions due to lower resistance and enables the intercalation/deintercalation of zinc ions with a slight change on structure. Moreover, Wang et al. further enhance the performance via designing $\mathrm{H}_{2} \mathrm{~V}_{3} \mathrm{O}_{8}$ nanowires/GO composite [74]. The composite exhibits superior zinc-ion storage capability. At the current density of $1 / 3{ }^{\circ} \mathrm{C}$, the composite shows a high capacity of $394 \mathrm{mAh} \mathrm{g}^{-1}$. At the high rate of $20{ }^{\circ} \mathrm{C}$, the composite can deliver the capacity of $270 \mathrm{mAh} \mathrm{g}^{-1}$ (high power density of $2215 \mathrm{~W} \mathrm{~kg}^{-1}$ ) with a retention of $87 \%$ for over 2000 cycles, exhibiting remarkable performance at high rate. The excellent performance is owing to the synergistic merits of $\mathrm{H}_{2} \mathrm{~V}_{3} \mathrm{O}_{8}$ nanowires and highly conductive graphene framework.

Lithium-ion intercalation is also an effective way to improve the electrochemical performance of $\mathrm{V}_{2} \mathrm{O}_{5}$. Liang et al. synthesized $\mathrm{Li}_{x} \mathrm{~V}_{2} \mathrm{O}_{5} \cdot n \mathrm{H}_{2} \mathrm{O}$ by the chemical intercalation of $\mathrm{Li}^{+}$into the interlayer of $\mathrm{V}_{2} \mathrm{O}_{5} \cdot n \mathrm{H}_{2} \mathrm{O}$ through the combination of hydrothermal and annealing processes [75]. The $\mathrm{Li}^{+}$ions in $\mathrm{V}_{2} \mathrm{O}_{5} \cdot n \mathrm{H}_{2} \mathrm{O}$ enlarge its interlayer spacing, thus facilitating the $\mathrm{Zn}^{2+}$ ion diffusion. Therefore, compared with the poor performance of the $\mathrm{V}_{2} \mathrm{O}_{5} \cdot n \mathrm{H}_{2} \mathrm{O}$ electrode without preintercalation of lithium ions, the $\mathrm{Li}^{+}$ intercalated $\mathrm{V}_{2} \mathrm{O}_{5} \cdot \mathrm{nH}_{2} \mathrm{O}$ electrode can deliver a high initial capacity of $304 \mathrm{mAh} \mathrm{g}^{-1}$ at current density of $5 \mathrm{~A} \mathrm{~g}^{-1}$, with stable retained capacity of $232 \mathrm{mAh} \mathrm{g}^{-1}$ after 500 cycles. Another material, $\mathrm{Li}_{1+x} \mathrm{~V}_{3} \mathrm{O}_{8}$ (LVO), is also an interesting candidate to facilitate the intercalation/deintercalation of multivalent ions with large radius owing to the layered-type structure and vanadium in high oxidation states. Kim and his co-workers first applied the layered-type $\mathrm{LiV}_{3} \mathrm{O}_{8}$ as cathode for ZIBs and studied the detailed phase evolution during the intercalation of $\mathrm{Zn}$ ions via simulation techniques, in situ XRD and electrochemistry analysis [76]. The results reveal that after the intercalation of zinc ions, $\mathrm{ZnLiV}_{3} \mathrm{O}_{8}$ phase gradually transferred to reversible solid-solution $\mathrm{Zn}_{y} \mathrm{LiV}_{3} \mathrm{O}_{8}(y>1)$ phase. The unique phenomenon leads to improved electrochemical performance. At the current density of $133 \mathrm{~mA} \mathrm{~g}^{-1}$, it can deliver a high specific capacity of $172 \mathrm{mAh} \mathrm{g}^{-1}$ for over 65 cycles with $75 \%$ capacity retention and $100 \%$ Coulombic efficiency. Another similar material, $\mathrm{K}_{2} \mathrm{~V}_{6} \mathrm{O}_{16} \cdot 2.7 \mathrm{H}_{2} \mathrm{O}(\mathrm{KVO})$, was also investigated by $\mathrm{Kim}$ and his group members. They studied the $\mathrm{K}_{2} \mathrm{~V}_{6} \mathrm{O}_{16} \cdot 2.7 \mathrm{H}_{2} \mathrm{O}$ nanorods as cathode materials in ZIBs for the first time [77]. The $\mathrm{K}_{2} \mathrm{~V}_{6} \mathrm{O}_{16} \cdot 2.7 \mathrm{H}_{2} \mathrm{O}$ compound has a unique structural arrangement of $\mathrm{V}_{3} \mathrm{O}_{8}$ layers of $\mathrm{VO}_{6}$ and $\mathrm{V}_{2} \mathrm{O}_{8}$ units with interstitial hydrated $\mathrm{K}$ ions. Moreover, ex situ XRD and XPS results showed that the diffusion behavior of $\mathrm{Zn}^{2+}$ ions in and out of the layered KVO structure is dominated by the redox reaction of vanadium. At the specific power of $72 \mathrm{~W} \mathrm{~kg}^{-1}$, the KVO nanorods can deliver a reversible high specific energy of $172.1 \mathrm{Wh} \mathrm{kg}^{-1}$ with $\sim 82 \%$ capacity retention for over 500 cycles, indicating high energy density and long-term cyclability.

$\mathrm{Na}_{0.33} \mathrm{~V}_{2} \mathrm{O}_{5}$ is composed by quadruple octahedra chains, which are linked by double chains of square pyramids via sharing their corners [78]. Due to the limited space for intercalated $\mathrm{Zn}^{2+}$ ions, $\mathrm{Na}_{0.33} \mathrm{~V}_{2} \mathrm{O}_{5}$ framework suffers a huge structural stress after the intercalation of $\mathrm{Zn}^{2+}$ ions. After the intercalation of zinc ions, a new $\mathrm{Zn}_{x} \mathrm{Na}_{0.33} \mathrm{~V}_{2} \mathrm{O}_{5}$ phase appeared due to the crystal distortion with $\mathrm{Zn}^{2+}$ intercalation. Therefore, a large capacity fading for about $100 \mathrm{mAh}$ $\mathrm{g}^{-1}$ was observed during the initial two cycles due to the "dead sites" for inserted zinc ions. Sodium ions in sodium vanadium oxides are believed to act as pillars to stabilize the framework to keep the reversible phase transform during cycling. In the most recent years, many researchers focused on the development of sodium vanadium oxides with stable ion storage properties. For example, Chen and his coworkers further studied the electrochemical mechanism of $\mathrm{NaV}_{3} \mathrm{O}_{8} \cdot 1.5 \mathrm{H}_{2} \mathrm{O}$ by ex situ Fourier transform infrared spectroscopy and nuclear magnetic resonance [79]. Their results confirm that accompanying with insertion/extraction of zinc ion, simultaneous proton insertion/extraction also exists 
during the electrochemical processes, which is different from conventional rechargeable batteries. This unique cointercalation behavior ensures the remarkable electrochemical performance. At the current density of $50 \mathrm{~mA} \mathrm{~g}^{-1}$, it can deliver a high reversible specific capacity of $380 \mathrm{mAh} \mathrm{g}^{-1}$ (corresponding to energy density of $300 \mathrm{Wh} \mathrm{kg}^{-1}$ ) with capacity retention of $82 \%$ for over 1000 cycles, showing excellent zinc storage capability.

The significant role of structured water in $\mathrm{Na}_{2} \mathrm{~V}_{6} \mathrm{O}_{16}$ enhancing the electrochemical performances is further confirmed by Mai et al. [80] They designed a highly durable zinc-ion battery system with a $\mathrm{Na}_{2} \mathrm{~V}_{6} \mathrm{O}_{16} \cdot 1.63 \mathrm{H}_{2} \mathrm{O}$ nanowire cathode with an aqueous $\mathrm{Zn}\left(\mathrm{CF}_{3} \mathrm{SO}_{3}\right)_{2}$ electrolyte. Compared with only $17 \%$ of capacity retention of $\mathrm{NaV}_{3} \mathrm{O}_{8}$ nanowires at $5000 \mathrm{~mA} \mathrm{~g}^{-1}$ after 4000 cycles, the $\mathrm{Na}_{2} \mathrm{~V}_{6} \mathrm{O}_{16} \cdot 1.63 \mathrm{H}_{2} \mathrm{O}$ nanowires exhibit a capacity retention of $90 \%$ for over 6000 cycles at current density of $5000 \mathrm{~mA} \mathrm{~g}^{-1}$. Moreover, they assembled a single-nanowire-based zinc-ion battery to investigate the intrinsic $\mathrm{Zn}^{2+}$ storage mechanism at nanoscale (Fig. 5). The single-nanowire zinc-ion battery verifies the high electrical conductivity and current carrying capacity of $\mathrm{Na}_{2} \mathrm{~V}_{6} \mathrm{O}_{16} \cdot 1.63 \mathrm{H}_{2} \mathrm{O}$. The layered structure of $\mathrm{Na}_{1.1} \mathrm{~V}_{3} \mathrm{O}_{7.9} @ \mathrm{rGO}$ is firstly employed as cathode for aqueous zinc-ion battery by Liang et al. [81]. The designed pilotaxitic $\mathrm{Na}_{1.1} \mathrm{~V}_{3} \mathrm{O}_{7.9}$ nanoribbons/graphene composite shows improved performance. In addition, to confirm the structural stability of $\mathrm{Na}_{0.33} \mathrm{~V}_{2} \mathrm{O}_{5}$ nanowires after long cycles, He et al. performed TEM characterization on the electrodes after cycling. Figure 5e, f shows the SAED pattern, HRTEM image of $\mathrm{Na}_{0.33} \mathrm{~V}_{2} \mathrm{O}_{5}$ electrode after 100 cycles. The results confirm that the nanowire morphology and single crystalline structure are well maintained after long cycles. Another cation, $\mathrm{Mn}(\mathrm{II})$, can also act as robust structural pillars to stabilize the layered structure of hydrated vanadate [82]. Cao et al. reported manganese expanded hydrated vanadate as a cathode for ZIBs. The chemical insertion of Mn(II) cations can expand the interplanar spacing to $12.9 \AA$, leading to the reduced electrostatic interactions. In addition, the expanded interplanar spacing can facilitate fast intercalation of $\mathrm{Zn}$ ions at higher current densities, leading to significantly enhanced reversibility and cycling stability. At a specific current of $4 \mathrm{~A} \mathrm{~g}^{-1}$, manganese expanded hydrated vanadate can deliver a high specific capacity of $260 \mathrm{mAh} \mathrm{g}^{-1}$ for over 2000 cycles with a high capacity retention of $92 \%$.

Alshareef et al. first reported another new material, layered $\mathrm{Ca}_{0.24} \mathrm{~V}_{2} \mathrm{O}_{5}$ bronze, as the cathode material for aqueous
ZIBs [83]. The prepared $\mathrm{Ca}_{0.24} \mathrm{~V}_{2} \mathrm{O}_{5}$ is very suitable as cathode material for stable aqueous $\mathrm{Zn}^{2+}$ ion storage. At $0.2 \mathrm{C}$, the $\mathrm{Ca}_{0.24} \mathrm{~V}_{2} \mathrm{O}_{5}$ structure can deliver a high capacity of $340 \mathrm{mAh} \mathrm{g}^{-1}$. At power density of $53.4 \mathrm{~W} \mathrm{~kg}^{-1}$, the $\mathrm{Zn} / \mathrm{Ca}_{0.24} \mathrm{~V}_{2} \mathrm{O}_{5}$ cells show a remarkable energy density of $267 \mathrm{Wh} \mathrm{kg}^{-1}$ for over 5000 cycles, exhibiting very high energy density and long cycling stability. Also, the low cost of $\mathrm{Ca}, \mathrm{Zn}, \mathrm{V}$ enables $\mathrm{Ca}_{0.24} \mathrm{~V}_{2} \mathrm{O}_{5}$ a viable cathode for aqueous ZIBs in large-scale applications. Another novel material, $\mathrm{Ag}_{0.4} \mathrm{~V}_{2} \mathrm{O}_{5}$, was synthesized by Liang et al. and first applied as cathode for ZIBs. They studied the phase evolution after the discharging process and demonstrated the displacement/intercalation mechanism [84]. Specifically, after the initial discharging, most of $\mathrm{Ag}^{+}$in $\mathrm{Ag}_{0.4} \mathrm{~V}_{2} \mathrm{O}_{5}$ is replaced by $\mathrm{Zn}^{2+}$, forming $\mathrm{Zn}_{2}\left(\mathrm{~V}_{3} \mathrm{O}_{8}\right)_{2}$. The formed $\mathrm{Zn}_{2}\left(\mathrm{~V}_{3} \mathrm{O}_{8}\right)_{2}$ can accommodate more inserted $\mathrm{Zn}^{2+}$ ions. The generated highly conductive $\mathrm{Ag}^{0}$ matrix within the material can support high electronic conductivity. Therefore, the prepared $\mathrm{Ag}_{0.4} \mathrm{~V}_{2} \mathrm{O}_{5}$ material exhibits good rate capability and long cycling stability. At the high rate of $20 \mathrm{~A} \mathrm{~g}^{-1}$, it can still provide the stable capacity of $144 \mathrm{mAh} \mathrm{g}^{-1}$ for over 4000 cycles.

A series of layered ammonium vanadates, including $\mathrm{NH}_{4} \mathrm{~V}_{4} \mathrm{O}_{10}, \mathrm{NH}_{4} \mathrm{~V}_{3} \mathrm{O}_{8}$, and $\left(\mathrm{NH}_{4}\right)_{2} \mathrm{~V}_{3} \mathrm{O}_{8}$ with corresponding interlayer distance of $0.98,0.79$, and $0.56 \mathrm{~nm}$, respectively, were examined as cathode materials for aqueous ZIBs [85]. Owing to the largest interlayer spacing of $0.98 \mathrm{~nm}$ and intercalated $\mathrm{NH}_{4}{ }^{+}$as strong "pillars," $\mathrm{NH}_{4} \mathrm{~V}_{4} \mathrm{O}_{10}$ showed high energy density of $374.3 \mathrm{Wh} \mathrm{kg}^{-1}$ with the power density of $9000 \mathrm{~W} \mathrm{~kg}^{-1}$, and negligible capacity loss over 1000 cycles at $10 \mathrm{~A} \mathrm{~g}^{-1}$. Notably, the cycling stability of $\mathrm{NH}_{4} \mathrm{~V}_{4} \mathrm{O}_{10}$ cathode was tested under high $\left(50{ }^{\circ} \mathrm{C}\right)$ and low temperature $\left(0{ }^{\circ} \mathrm{C}\right)$ at $5 \mathrm{~A} \mathrm{~g} \mathrm{~g}^{-1}$, exhibiting a high reversible capacity of $377 \mathrm{mAh} / \mathrm{g}$ at $50{ }^{\circ} \mathrm{C}$ and decent capacity of $179 \mathrm{mAh} \mathrm{g}^{-1}$ at $0{ }^{\circ} \mathrm{C}$, indicating impressive electrochemical properties working in a wide temperature range.

\subsection{Prussian Blue Materials}

Prussian blue is a kind of prototype material with open framework structure, which contains zeolitic water and possesses special physical and chemical properties. In the typical Prussian blue material $\left(\mathrm{KFe}^{3+} \mathrm{Fe}^{2+}(\mathrm{CN})_{6}\right)$, the $\mathrm{Fe}^{3+}$ ions and $\mathrm{Fe}^{2+}$ ions are octahedrally connected with the nitrogen ends and carbon ends of the $\mathrm{CN}^{-}$groups, respectively. One half of the open sites in framework structure are occupied 

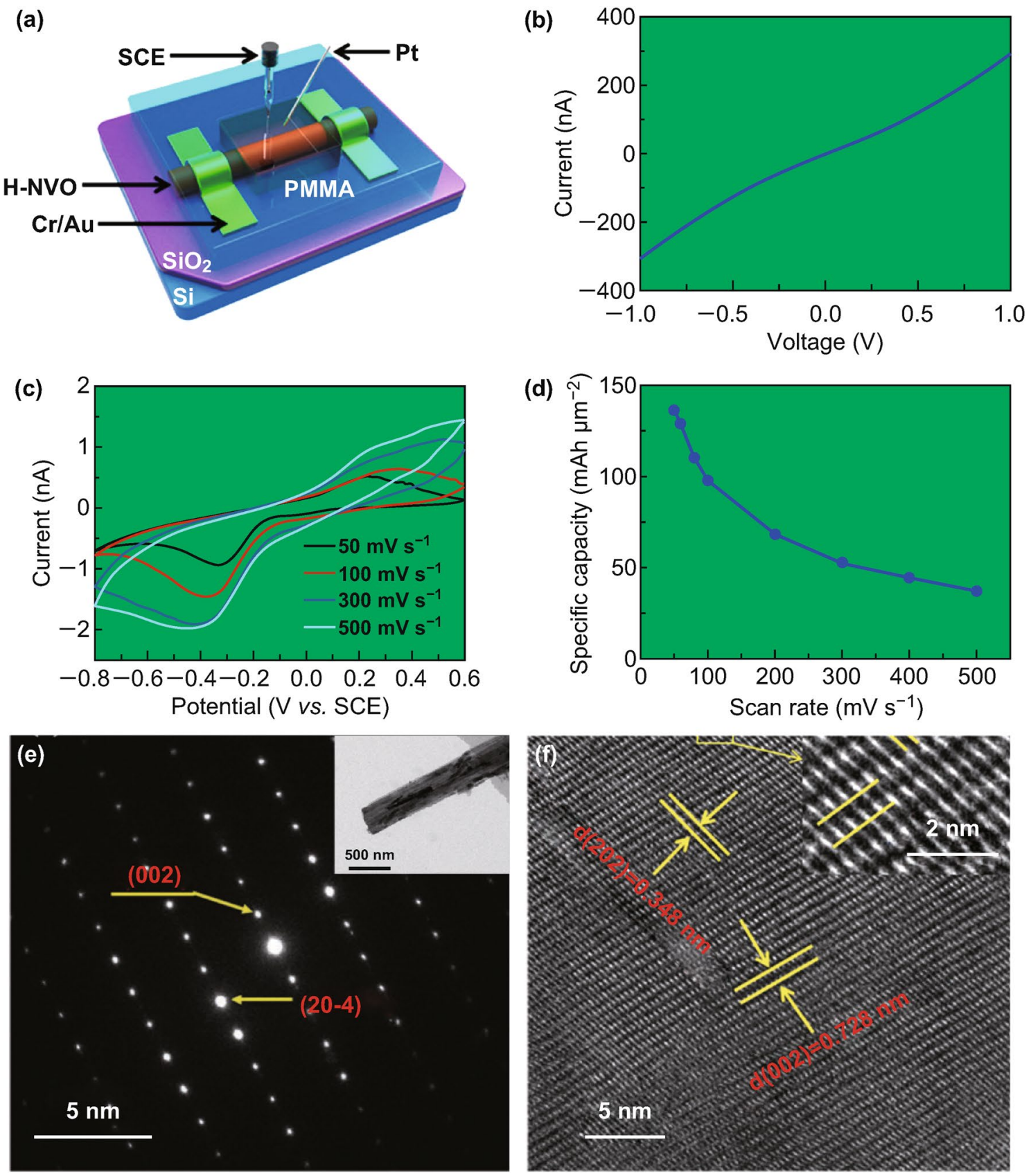

Fig. 5 a Schematic view of single-nanowire ZIB, b the transport property, $\mathbf{c}$ the $\mathrm{CV}$ curves tested at different scan rates ranging from 50 to $500 \mathrm{mV} \mathrm{s}^{-1}$, $\mathbf{d}$ the specific capacitances at different scan rates [80], e the SAED pattern; the inset shows the TEM image and $\mathbf{f}$ HRTEM image of $\mathrm{Na}_{0.33} \mathrm{~V}_{2} \mathrm{O}_{5}$ electrode after 100 cycles [78]. With permission from American Chemical Society and Wiley

by $\mathrm{K}^{+}$ions. With the intercalation of more $\mathrm{K}^{+}$ions, some of the $\mathrm{Fe}^{3+}$ ions are reduced to $\mathrm{Fe}^{2+}$. The color changes from blue to colorless. The yielded product is called Everitt's salt. With the $\mathrm{K}^{+}$ions extracted from Prussian blue, $\mathrm{Fe}^{2+}$ ions are oxidized. The color turns to yellow, and the product is called Prussian yellow.

\subsubsection{CuHCF and ZnHCF Cathode Materials}

As a typical Prussian blue analog-based material (PBA), copper hexacyanoferrate (CuHCF) has a well-studied open framework. Mantia et al. first applied $\mathrm{CuHCF}$ as a positive electrode in aqueous ZIBs. They found that CuHCF can provide an extremely high average potential of $1.73 \mathrm{~V}$. At 
a current density of $1{ }^{\circ} \mathrm{C}$, CuHCF can supply $90 \%$ of the theoretical capacity for 100 cycles with retention of $96.3 \%$ [86]. The battery also shows a high rate capability, delivering $96.1,90$, and $78 \mathrm{mAh} \mathrm{g}^{-1}$ at current density of $2.5,5$, and $10^{\circ} \mathrm{C}$, respectively. Moreover, Wang et al. prepared $\mathrm{CuHCF}$ nanocubes for application as cathode electrode in aqueous ZIBs [87]. They found that the intercalation/deintercalation of $\mathrm{Zn}^{2+}$ ions were controlled by the solid-phase diffusion of $\mathrm{Zn}^{2+}$ in/out of the CuHCF electrode. Mantia et al. further studied the long-term cycling stability of CuHCF in kinds of zinc-ion electrolytes [88]. They discovered that the anions and the concentration of zinc ions played a significant role for the stability of the cathode electrode. Basically, the stability of $\mathrm{CuHCF}$ electrode is higher with the lower concentration of electrolyte. This is due to the phase transition of the $\mathrm{CuHCF}$, instead of the dissolution of the active material.

Liu et al. carefully studied the effect of different insertion cations $\left(\mathrm{Na}^{+}, \mathrm{K}^{+}\right.$, and $\left.\mathrm{Zn}^{2+}\right)$ on the electrochemical reaction of ZnHCF [89]. ZnHCF can exist stably in the condition of aqueous $\mathrm{ZnSO}_{4}$ electrolyte, while $\mathrm{ZnHCF}$ would be dissolved in aqueous $\mathrm{Na}_{2} \mathrm{SO}_{4} / \mathrm{K}_{2} \mathrm{SO}_{4}$ electrolytes. Meanwhile, they discovered that the intercalation potential was highly dependent on ionic radius. Specifically, larger ionic radii can lead to higher charging/discharging potential. The ZnHCFbased ZIBs show an extremely high average operation voltage of $1.7 \mathrm{~V}$, leading to a high specific energy density of $100 \mathrm{Wh} \mathrm{kg}^{-1}$.

\subsection{Other Cathode Materials}

The large family of polyanionic materials has been widely studied as cathodes for monovalent metal ion batteries $\left(\mathrm{Li}^{+}\right.$and $\mathrm{Na}^{+}$ion batteries), due to their high redox voltage, plenty of vacancies to accommodate the inserted metal ions, as well as stable framework that is favorable for long cycling performance. In 2018, Wang et al. first designed a $\mathrm{Zn} / \mathrm{LiV}_{2}\left(\mathrm{PO}_{4}\right)_{3}$ battery and verified that the robust polyanion crystal structure could also enable the reversible intercalation of $\mathrm{Zn}^{2+}$ ions (Fig. 6) [91]. They demonstrated that the intercalated $\mathrm{Zn}^{2+}$ ions can be delocalized by multiple atoms through the $p-d$ hybridization between the $\mathrm{V}-d$ and $\mathrm{O}-p$ orbitals. The $\mathrm{Zn} / \mathrm{LiV}_{2}\left(\mathrm{PO}_{4}\right)_{3}$ batteries can deliver the high voltage of $1.7 \mathrm{~V}$ and support both high power density and high energy density for over 4000 cycles. Huang et al. first introduced $\mathrm{Na}_{3} \mathrm{~V}_{2}\left(\mathrm{PO}_{4}\right)_{3}$ as cathode material for ZIBs in 2016 [43, 91]. They fabricated $\mathrm{Na}_{3} \mathrm{~V}_{2}\left(\mathrm{PO}_{4}\right)_{3}$ with carbon nanosheets wrapped around as intercalation host for zinc cations. The $\mathrm{Zn} / \mathrm{Na}_{3} \mathrm{~V}_{2}\left(\mathrm{PO}_{4}\right)_{3}$ batteries exhibited excellent rate capability and long cycling life. At a current density of $0.5^{\circ} \mathrm{C}, \mathrm{Na}_{3} \mathrm{~V}_{2}\left(\mathrm{PO}_{4}\right)_{3}$ can deliver the capacity of $97 \mathrm{mAh} \mathrm{g}^{-1}$ for over 100 cycles. They claimed an ion occupying variation mechanism for the intercalation of zinc ions in polyanion crystal structure, which is also confirmed by CV and XRD results. Moreover, Chen et al. studied the electrochemical reaction mechanism of both $\mathrm{Li}_{3} \mathrm{~V}_{2}\left(\mathrm{PO}_{4}\right)_{3}$ and $\mathrm{Na}_{3} \mathrm{~V}_{2}\left(\mathrm{PO}_{4}\right)_{3}$ as cathodes materials in ZIBs [92]. They found that the crystal structure of both $\mathrm{Li}_{3} \mathrm{~V}_{2}\left(\mathrm{PO}_{4}\right)_{3}$ and $\mathrm{Na}_{3} \mathrm{~V}_{2}\left(\mathrm{PO}_{4}\right)_{3}$ is very stable in zinc-ion electrolyte. They further studied the effects of the $\mathrm{pH}$ value of aqueous electrolyte on electrochemical performance. They discovered that aqueous electrolyte with weak acidic $\mathrm{pH}$ value (4.0-4.5) can support the optimized electrochemical performance. Jiang et al. further investigated the electrochemical performance of $\mathrm{Na}_{3} \mathrm{~V}_{2}\left(\mathrm{PO}_{4}\right)_{2} \mathrm{~F}_{3}$ as cathode electrode in ZIBs [93]. To avoid the formation of dendrite on $\mathrm{Zn}$ anode, they coated the zinc metal with a thin carbon film. The designed $\mathrm{Zn} / \mathrm{Na}_{3} \mathrm{~V}_{2}\left(\mathrm{PO}_{4}\right)_{2} \mathrm{~F}_{3}$ batteries can support a high average potential $(1.62 \mathrm{~V})$, high energy density $\left(97.5 \mathrm{Wh} \mathrm{kg}^{-1}\right)$ and a long cycling life for over 4000 cycles with capacity retention of $95 \%$.

There have also been some studies on Mo-based electrode materials in ZIBs. For instance, $\mathrm{MoO}_{3}$ and $\mathrm{MoS}_{2}$ cathodes were found to deliver high initial discharge specific capacities up to 200 and $110 \mathrm{mAh} \mathrm{g}^{-1}$, respectively [94]. Inspired by the work of Mo-based electrodes in lithium-ion batteries, Xu et al. adopted electrochemical activation method to prepare the $\mathrm{MoO}_{2} / \mathrm{Mo}_{2} \mathrm{~N}$ composite nanobelts [95]. They discovered that the $\mathrm{MoO}_{2}$ grains gradually in situ formed in the $\mathrm{Mo}_{2} \mathrm{~N}$ matrix during the continually electrochemical activation cycling. The combination of $\mathrm{MoO}_{2}$ and $\mathrm{Mo}_{2} \mathrm{~N}$ can overcome the intrinsic low conductivity and structural degradation of Mo-based materials (Fig. 7a). Specifically, the $\mathrm{Mo}_{2} \mathrm{~N}$ matrix can protect the inner $\mathrm{MoO}_{2}$ grains from structural degradation during the intercalation of zinc ions. And the small $\mathrm{MoO}_{2}$ grains can accommodate more intercalated zinc ions. The synergic effects of $\mathrm{MoO}_{2}$ and $\mathrm{Mo}_{2} \mathrm{~N}$ lead to significantly improved electrochemical performance. At the high rate of $1 \mathrm{~A} \mathrm{~g}^{-1}$, the formed $\mathrm{MoO}_{2} / \mathrm{Mo}_{2} \mathrm{~N}$ composite nanobelts can still deliver a high discharge capacity of $113 \mathrm{mAh} \mathrm{g}^{-1}$ for over 1000 cycles, exhibiting excellent performance at high 
(a)
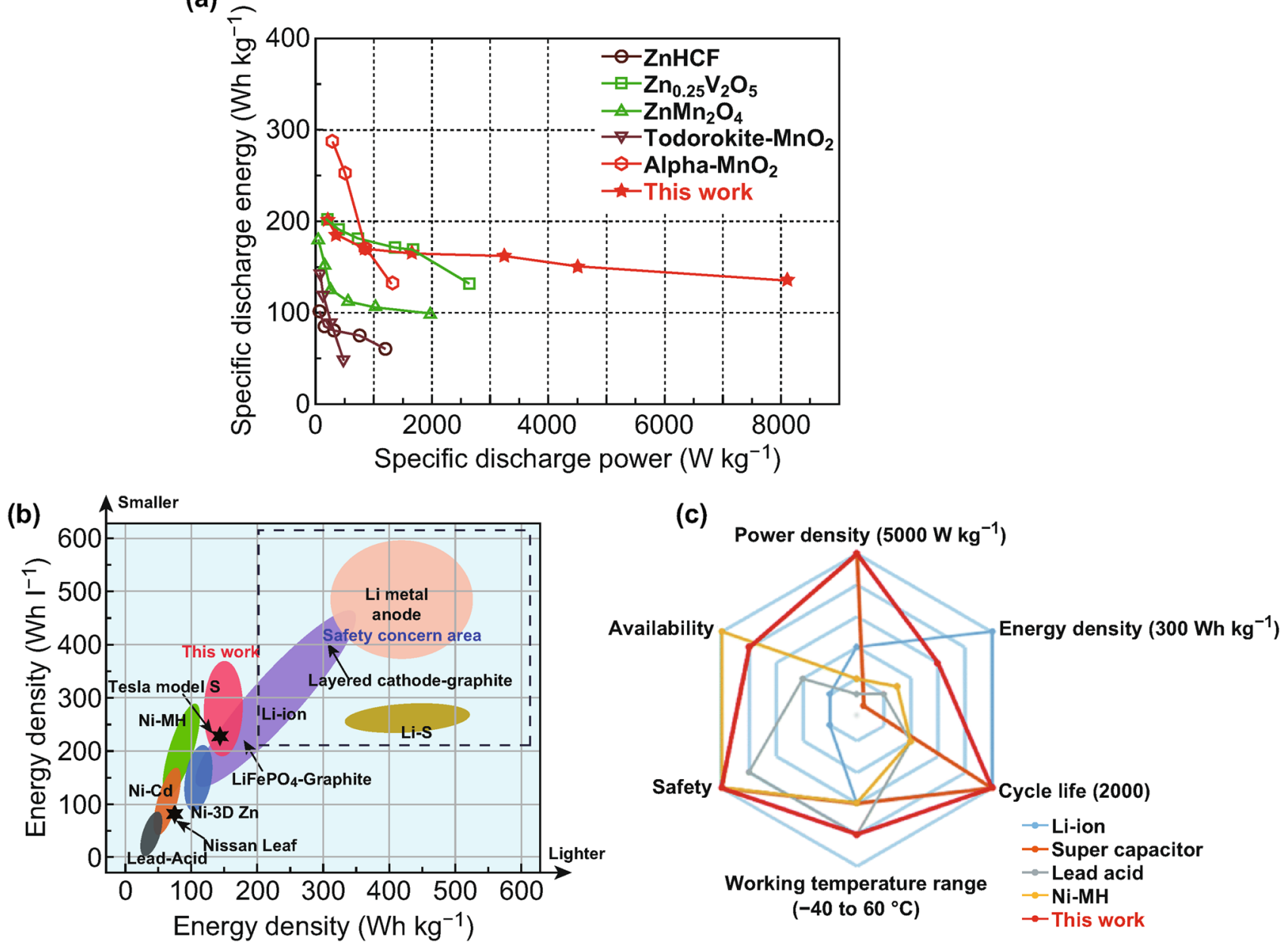

Fig. 6 Comprehensive electrochemical performance for $\mathrm{LiV}_{2}\left(\mathrm{PO}_{4}\right)_{3}$. a Comparison of $\mathrm{LiV}_{2}\left(\mathrm{PO}_{4}\right)_{3}$ cathode with other researched cathode materials for ZIBs. b Gravimetric $\left(\mathrm{Wh} \mathrm{kg}^{-1}\right)$ and volumetric $\left(\mathrm{Wh} \mathrm{L}^{-1}\right)$ energy densities for different battery systems. $\mathbf{c}$ The spider chart for the itemized comparison of $\mathrm{Zn} / \mathrm{LiV}_{2}\left(\mathrm{PO}_{4}\right)_{3}$ cell with other commercial systems [90]. With permission from The Royal Society of Chemistry
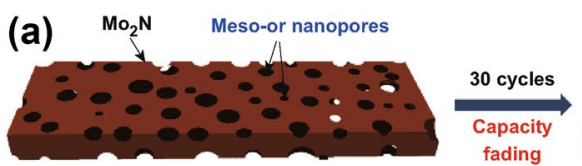

(b)

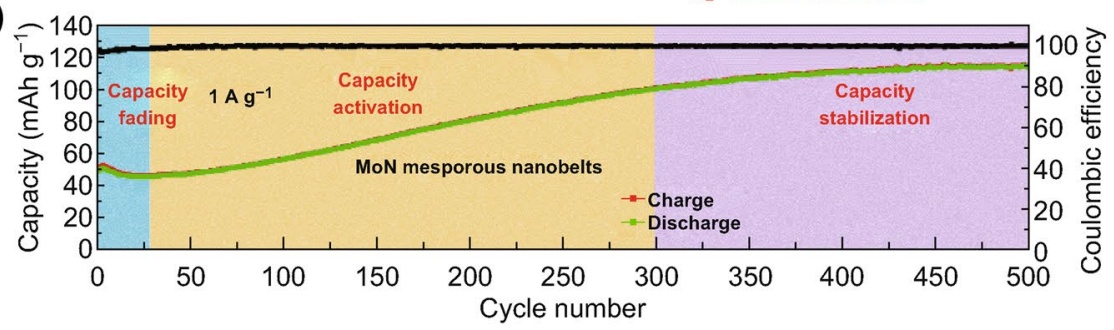

Cracks
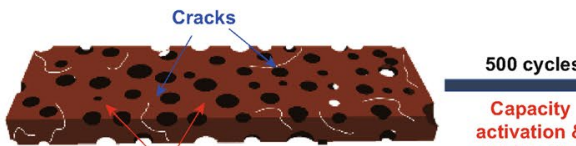
activation \& bilization

(c)

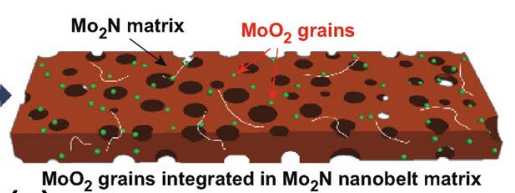

c)

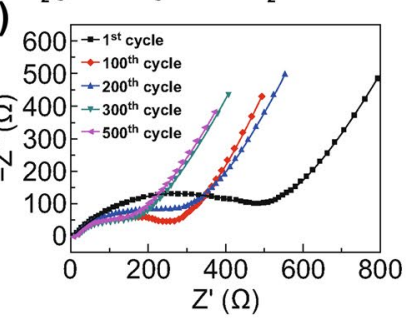

Fig. 7 a Schematic of formation of $\mathrm{MoO}_{2} / \mathrm{Mo}_{2} \mathrm{~N}$ composite materials during the electrochemical activation process. b The capacity during the electrochemical activation cycling process. $\mathbf{c}$ The Nyquist plots at different cycling times [95]. With permission from Elsevier 
rate (Fig. 7b, c). Moreover, the electrochemical activation phenomenon was also observed in MnO-based ZIBs. As reported by Kang et al., the charging process leads to gradual formation of porous $\mathrm{MnO}_{2}$ nanosheets surrounding $\mathrm{MnO}$ particles [96]. The activated layered $\mathrm{MnO}_{2}$ nanosheets show significantly improved electrochemical performance. At a specific current of $0.1 \mathrm{~A} \mathrm{~g}^{-1}$, the specific capacity of the electrode can be enhanced to $330 \mathrm{mAh} \mathrm{g}^{-1}$.

$\mathrm{Xu}$ et al. further studied $\mathrm{MoS}_{2}$ with defects induced for application as cathode material in ZIBs with both experimental and theoretical methods [97]. They found that $\mathrm{MoS}_{2-x}$ nanosheets with tremendous sulfur vacancies can accommodate preferential intercalation of $\mathrm{Zn}^{2+}$ ions, showing much higher capacity than the $\mathrm{MoS}_{2}$ without defects. Material characterization and theoretical modeling results revealed that interlayer sulfur vacancies and edge sites of $\mathrm{MoS}_{2}$ nanosheets can accommodate the intercalated $\mathrm{Zn}^{2+}$ ions, leading to a significantly enhanced capacity than $\mathrm{MoS}_{2}$ without defects. At the current density of $1 \mathrm{~A} \mathrm{~g}^{-1}$, the defect-engineered $\mathrm{MoS}_{2-x}$ can deliver a high capacity of $88.6 \mathrm{mAh} \mathrm{g}^{-1}$ for over 1000 cycles (capacity retention of $87.8 \%$ ). Subsequently, Zhi et al. prepared $\mathrm{MoS}_{2}$ with expanded interlayer spacing as promising cathode for flexible ZIBs [98]. They investigated the $\mathrm{Zn}^{2+}$ intercalation/deintercalation process via XRD and Raman techniques. At the current density of $0.1 \mathrm{~A} \mathrm{~g}^{-1}$, the E-MoS $\mathrm{S}_{2}$ electrode can deliver a high specific capacity of $202.6 \mathrm{mAh} \mathrm{g}^{-1}$ for 600 cycles. Moreover, they further developed a quasi-solid $\mathrm{Zn} / \mathrm{E}-\mathrm{MoS}_{2}$ battery by using polyacrylamide (PAM) polymer as electrolyte. The quasi-solid $\mathrm{Zn} / \mathrm{E}-\mathrm{MoS}_{2}$ battery exhibits good performance under kinds of deformations, demonstrating potential to be applied in next-generation flexible devices. Recently, aqueous zinc-iodine batteries are emerging as an attractive electrochemical energy storage technology due to their low cost, abundant resource, and high energy density [99-102]. Similar to the widely studied lithium-sulfur batteries, zinc-iodine batteries have the similar problems of low reversibility and limited cycling, which is caused by the poor conductivity and soluble active species in the electrolytes. To address these issues, many efforts have been devoted to design iodine/carbon composite materials. For example, Pan et al. prepared microporous carbon with iodine encapsulated inside via solid-liquid conversion reactions [99]. The resulted zinc-iodine/C battery can provide a high capacity of $174.4 \mathrm{mAh} \mathrm{g}^{-1}$ at $1 \mathrm{C}$ for over
3000 cycles. Yuan et al. designed the composite material with $\mathrm{I}_{2}$ confined in porous carbon cloth. With fully utilizing the active $\mathrm{I}_{2}$ material in the composite architecture, the zinc-iodine batteries yield a high energy density of $\sim 151 \mathrm{Wh} \mathrm{kg}^{-1}$ with long cycling life for 1500 cycles [100].

\subsection{Zinc-Ion Batteries based on Nonaqueous Electrolytes}

Initially, there was research focused on using room temperature ionic liquid electrolytes (trifluoromethanesulfonic imide, trifluoromethanesulfonic imide, etc.) as electrolytes in zinc-ion batteries owing to their very low vapor pressure, extremely high chemical/physical stability, and high ionic transportation. However, the discharge capacities and cycling lifetime of batteries based on these electrolytes are not satisfactory. To achieve an ideal electrolyte with good electrode compatibility, much work concerning acetonitrile electrolytes has been carried out [103-106]. For example, $\mathrm{Zn}\left(\mathrm{ClO}_{4}\right)_{2}$ acetonitrile electrolyte was employed together with $\mathrm{NiHCF}$ as cathode in ZIBs [103]. At a rate of $0.2{ }^{\circ} \mathrm{C}$, the battery can deliver a discharge capacity of $55.6 \mathrm{mAh} \mathrm{g}^{-1}$ with an average potential of $1.19 \mathrm{~V}$. Gewirth et al. then explored a new series of spinels, $\mathrm{ZnNi}_{x} \mathrm{Mn}_{x} \mathrm{Co}_{2-2 x} \mathrm{O}_{4}$, as cathode electrodes for ZIBs with organic electrolyte [104]. The full cells were fabricated with these spinels paired with zinc metal anode. At a specific current of $42 \mathrm{~mA} \mathrm{~g}^{-1}$, the batteries can supply a specific capacity of $174 \mathrm{mAh} \mathrm{g}^{-1}$ for 200 cycles, corresponding to an energy density as high as $305 \mathrm{Wh} \mathrm{kg}^{-1}$. The XRD and EDS results verified the reversible intercalation/deintercalation of $\mathrm{Zn}^{2+}$ ions in spinel materials. Meanwhile, the ex situ XPS results confirmed that the reversible conversion between $\mathrm{Mn}^{4+}$ / $\mathrm{Mn}^{3+}, \mathrm{Ni}^{4+} / \mathrm{Ni}^{3+} / \mathrm{Ni}^{2+}, \mathrm{Co}^{4+} \mathrm{Co}^{3+}$ oxidation states took place in spinel cathodes during the electrochemical process. All the results indicate that co-substitution of $\mathrm{Mn}$ and $\mathrm{Ni}$ for $\mathrm{Co}$ in $\mathrm{ZnCo}_{2} \mathrm{O}_{4}$ is an efficient way to promote the intercalation of zinc ions and improve the capacity. As such, the acetonitrile- $\mathrm{Zn}\left(\mathrm{CF}_{3} \mathrm{SO}_{3}\right)_{2}$ electrolyte shows a high anodic stability and relatively low overpotential, leading to an excellent Coulombic efficiency of the $\mathrm{Zn}$ anode, while V-based materials usually show low specific capacity and poor rate performance in organic electrolytes 
[106]. This is because the insertion of $\mathrm{Zn}$ ions needs a desolvation penalty at the electrode/electrolyte interface. In the water-based solution, the co-intercalation of water molecules can effectively facilitate the insertion of $\mathrm{Zn}$ ions and the penalty is very low. However, the co-intercalation with $\mathrm{Zn}^{2+}$ ions in nonaqueous solutions is difficult to be realized due to large radius of the solvation molecules, which is the main reason that ZIBs consisting of nonaqueous electrolytes often show poor kinetics.

\section{Summarization of Representative Cathode Materials}

Table 1 summarizes recent developments of some representative cathode materials, including the electrolyte components, testing voltage and current, discharge capacity, and cycling life. And Fig. 8 displays the specific capacity versus the discharge potential for various cathodes. As we can see in Table 1 and Fig. 8, manganese oxides show high operation voltages and acceptable rate capabilities. However, manganese oxides suffer from limited cycling life, due to the dissolution of $\mathrm{Mn}^{2+}$ ions during cycling caused by the Jahn-Teller effect during the phase transformation with the intercalation of zinc ions. $\mathrm{Mn}^{2+}$ additives in the electrolyte can hinder the dissolution of $\mathrm{MnO}_{2}$ electrodes. But appropriate concentration still needs to be examined to balance the $\mathrm{Mn}^{2+}$ dissolution and the re-oxidation. Compared with manganese oxides, vanadium oxides exhibit much lower discharge potential, but show enhanced rate performance and prolonged cycling life. The stable layered framework and structural water molecules in the V-based cathodes facilitate fast diffusion of zinc ions, leading to their high rate capability and long cycling life. However, the average operation voltage of vanadium oxides is only about $0.8 \mathrm{~V}$ in aqueous ZIBs, which seriously restricts its practical applications. The discharge potential of vanadium oxides can be increased by introducing polyanions or fluorines. For example, $\mathrm{M}_{3} \mathrm{~V}_{2}\left(\mathrm{PO}_{4}\right)_{3}(\mathrm{M}=\mathrm{Li}, \mathrm{Na})$ and $\mathrm{Na}_{3} \mathrm{~V}_{2}\left(\mathrm{PO}_{4}\right)_{2} \mathrm{~F}_{3}$ show much higher discharge potential of about $1.5 \mathrm{~V}$. However, these additional groups lead to increased molecular mass and decreased specific capacities (only $113.5 \mathrm{mAh} \mathrm{g}^{-1}$ for $\mathrm{M}_{3} \mathrm{~V}_{2}\left(\mathrm{PO}_{4}\right)_{3}(\mathrm{M}=\mathrm{Li}, \mathrm{Na})$, and 50 $\mathrm{mAh} \mathrm{g}{ }^{-1}$ for $\left.\mathrm{Na}_{3} \mathrm{~V}_{2}\left(\mathrm{PO}_{4}\right)_{2} \mathrm{~F}_{3}\right)$. Therefore, further explorations should be focused on enhancing both the operating voltage and specific capacity for vanadium-based cathodes. Compared with manganese oxides and vanadium-based cathodes, the electrochemical performance of PBAs is poor. Even though the PBAs can support a high average operation voltage up to $1.5 \mathrm{~V}$ [89], they suffer low specific capacities (50-80 $\mathrm{mAh} \mathrm{g}^{-1}$ ) and limited cycling life ( 200 cycles). The poor performance of PBAs is attributed to the randomly distributed $\mathrm{Fe}(\mathrm{CN})_{6}$ vacancies that can break the electronic conduction between $\mathrm{Fe}-\mathrm{CN}-\mathrm{M}$ bonds and thus result in poor rate capability. Therefore, it is important to reduce the lattice defects to improve the performance. Moreover, herein we also summarize the ZIBs with aqueous and nonaqueous electrolytes. The anions and solvents in the electrolytes are significant for the diffusion of charge carriers and stabilizing electrode materials. $\mathrm{ZnSO}_{4}$ and $\mathrm{Zn}\left(\mathrm{CF}_{3} \mathrm{SO}_{3}\right)_{2}$ solutions are commonly used as electrolytes in aqueous ZIBs due to their excellent electrochemical performances. However, the acidic condition may damage the long-term stability of the Zn metal anode. Compared to ZIBs with aqueous electrolytes, ZIBs with organic electrolytes exhibit higher operation voltages and moderate discharge capacities, but they show much poorer rate performance and limited cycling life, which probably attributes to faster ionic diffusion rate, and higher reversibility of metal deposition/dissolution in mild aqueous electrolytes.

\section{Solid-state Zinc-Ion Batteries}

The ever-increasing demands for portable and wearable electronics have stimulated research interests in flexible rechargeable batteries with excellent electrochemical performances and low cost. As a promising new energy storage system, solid-state zinc-ion batteries (SZIBs) exhibit a series of noticeable advantages, such as high safety without electrolyte leakage, good flexibility, and low cost. Though much work has been done on zinc-ion batteries with liquid electrolytes, progress on SZIBs is still limited due to the lack of high zinc-ion conducting solid-state electrolytes. Therefore, it is imperative to explore the physicochemical properties of suitable solid-state electrolytes and the zinc-ion migration mechanism inside the solid-state electrolytes, which may provide more insight into the realizations of practical SZIBs [30].

In 2017, Tong et al. first developed flexible quasi-solidstate $\mathrm{Zn}-\mathrm{MnO}_{2} / \mathrm{PEDOT}$ battery with high performance via using $\mathrm{PVA} / \mathrm{ZnCl}_{2} / \mathrm{MnSO}_{4}$ gel electrolyte and $\mathrm{MnO}_{2} /$ PEDOT cathode (Fig. 9a, b) [107]. The as-fabricated 
Table 1 Summary of electrochemical properties of cathode materials for ZIBs

\begin{tabular}{|c|c|c|c|c|c|c|}
\hline Cathode & Electrolyte & Operating voltage $(\mathrm{V})$ & Current rate & Capacity $\left(\mathrm{mAh} \mathrm{g}^{-1}\right)$ & Cycle performance & Refs. \\
\hline$\alpha-\mathrm{MnO}_{2}$ nanorods & Aqueous $\mathrm{Zn}\left(\mathrm{CF}_{3} \mathrm{SO}_{3}\right)_{2}$ & $0.8-1.8$ & $5 \mathrm{~A} / \mathrm{g}$ & 115.9 & $\begin{array}{l}97.7 \% \text { retention after } \\
4000 \text { cycles }\end{array}$ & [35] \\
\hline$\alpha-\mathrm{MnO}_{2} / \mathrm{rGO}$ & Aqueous $\mathrm{ZnSO}_{4}$ & $1.0-1.9$ & $3 \mathrm{~A} / \mathrm{g}$ & 145.3 & $\begin{array}{l}94 \% \text { retention after } \\
3000 \text { cycles }\end{array}$ & [40] \\
\hline$\gamma-\mathrm{MnO}_{2}$ & Aqueous $\mathrm{ZnSO}_{4}$ & $1.0-1.8$ & $0.5 \mathrm{~mA} / \mathrm{cm}^{2}$ & $158 \mathrm{mAh} / \mathrm{cm}^{2}$ & $\begin{array}{l}37 \% \text { retention after } \\
40 \text { cycles }\end{array}$ & [58] \\
\hline$\alpha-\mathrm{MnO}_{2}$ nanofibers & Aqueous $\mathrm{ZnSO}_{4}$ & $1.0-1.85$ & $1520 \mathrm{~mA} / \mathrm{g}$ & 160 & $\begin{array}{l}92 \% \text { retention after } \\
5000 \text { cycles }\end{array}$ & {$[60]$} \\
\hline $\mathrm{MnO}_{2}$ & Aqueous $\mathrm{ZnSO}_{4}$ & $1.0-1.8$ & $1885 \mathrm{~mA} / \mathrm{g}$ & $50-70$ & 10,000 cycles & {$[61]$} \\
\hline $\begin{array}{l}\text { PANI-intercalated } \\
\mathrm{MnO}_{2}\end{array}$ & Aqueous $\mathrm{ZnSO}_{4}$ & $1.0-1.8$ & $2 \mathrm{~A} / \mathrm{g}$ & 125 & 5000 cycles & {$[63]$} \\
\hline $\mathrm{V}_{2} \mathrm{O}_{5}$ & Aqueous $\mathrm{Zn}\left(\mathrm{CF}_{3} \mathrm{SO}_{3}\right)_{2}$ & $0.2-1.6$ & $5 \mathrm{~A} / \mathrm{g}$ & 372 & $\begin{array}{l}91.1 \% \text { retention after } \\
4000 \text { cycles }\end{array}$ & {$[65]$} \\
\hline Bilayer $\mathrm{V}_{2} \mathrm{O}_{5} \cdot n \mathrm{H}_{2} \mathrm{O}$ & aqueous $\mathrm{Zn}\left(\mathrm{CF}_{3} \mathrm{SO}_{3}\right)_{2}$ & $0.2-1.6$ & $6 \mathrm{~A} / \mathrm{g}$ & $\sim 200$ & $\begin{array}{l}71 \% \text { retention after } \\
900 \text { cycles }\end{array}$ & {$[66]$} \\
\hline $\begin{array}{l}\mathrm{Zn}_{0.25} \mathrm{~V}_{2} \mathrm{O}_{5} \cdot \mathrm{nH}_{2} \mathrm{O} \\
\text { nanobelts }\end{array}$ & Aqueous $\mathrm{ZnSO}_{4}$ & $0.5-1.4$ & $2400 \mathrm{~mA} / \mathrm{g}$ & 260 & $\begin{array}{l}80 \% \text { retention after } \\
1000 \text { cycles }\end{array}$ & [67] \\
\hline $\mathrm{VO}_{2}(\mathrm{~B})$ & Aqueous $\mathrm{Zn}\left(\mathrm{CF}_{3} \mathrm{SO}_{3}\right)_{2}$ & $0.3-1.5$ & $100 \mathrm{~mA} / \mathrm{g}$ & 357 & 50 cycles & [68] \\
\hline $\mathrm{VO}_{2}$ & Aqueous $\mathrm{Zn}\left(\mathrm{CF}_{3} \mathrm{SO}_{3}\right)_{2}$ & $0.7-1.7$ & $10 \mathrm{~A} / \mathrm{g}$ & 133 & $\begin{array}{l}79 \% \text { retention after } \\
10,000 \text { cycles }\end{array}$ & [69] \\
\hline $\mathrm{V}_{6} \mathrm{O}_{13} \cdot n \mathrm{H}_{2} \mathrm{O}$ & Aqueous $\mathrm{Zn}\left(\mathrm{CF}_{3} \mathrm{SO}_{3}\right)_{2}$ & $0.2-1.4$ & $5 \mathrm{~A} / \mathrm{g}$ & $\sim 150$ & 1000 cycles & [70] \\
\hline $\mathrm{V}_{6} \mathrm{O}_{13}$ & Aqueous $\mathrm{Zn}\left(\mathrm{CF}_{3} \mathrm{SO}_{3}\right)_{2}$ & $0.2-1.5$ & $4 \mathrm{~A} / \mathrm{g}$ & $\sim 240$ & $\begin{array}{l}92 \% \text { retention after } \\
2000 \text { cycles }\end{array}$ & [71] \\
\hline $\mathrm{V}_{3} \mathrm{O}_{7} \cdot \mathrm{H}_{2} \mathrm{O} / \mathrm{rGO}$ & Aqueous $\mathrm{ZnSO}_{4}$ & $0.3-1.5$ & $1500 \mathrm{~mA} / \mathrm{g}$ & 245 & $\begin{array}{l}79 \% \text { retention after } \\
1000 \text { cycles }\end{array}$ & [72] \\
\hline $\mathrm{VO}_{2} / \mathrm{rGO}$ & Aqueous $\mathrm{Zn}\left(\mathrm{CF}_{3} \mathrm{SO}_{3}\right)_{2}$ & $0.3-1.3$ & $4 \mathrm{~A} / \mathrm{g}$ & 240 & $\begin{array}{l}99 \% \text { retention after } \\
1000 \text { cycles }\end{array}$ & {$[42]$} \\
\hline $\mathrm{VS}_{2}$ flake & Aqueous $\mathrm{ZnSO}_{4}$ & $0.4-1.0$ & $200 \mathrm{~mA} / \mathrm{g}$ & 125 & $\begin{array}{l}99.7 \% \text { retention after } \\
250 \text { cycles }\end{array}$ & {$[47]$} \\
\hline $\mathrm{H}_{2} \mathrm{~V}_{3} \mathrm{O}_{8}$ nanowires & Aqueous $\mathrm{Zn}\left(\mathrm{CF}_{3} \mathrm{SO}_{3}\right)_{2}$ & $0.2-1.6$ & $5 \mathrm{~A} / \mathrm{g}$ & 173.6 & $\begin{array}{l}94.3 \% \text { retention after } \\
1000 \text { cycles }\end{array}$ & [73] \\
\hline $\begin{array}{l}\mathrm{H}_{2} \mathrm{~V}_{3} \mathrm{O}_{8} \text { nanowires/ } \\
\mathrm{GO}\end{array}$ & Aqueous $\mathrm{Zn}\left(\mathrm{CF}_{3} \mathrm{SO}_{3}\right)_{2}$ & $0.2-1.6$ & $6 \mathrm{~A} / \mathrm{g}$ & 270 & $\begin{array}{l}87 \% \text { retention after } \\
2000 \text { cycles }\end{array}$ & {$[74]$} \\
\hline $\begin{array}{l}\mathrm{Li}^{+} \text {intercalated } \\
\mathrm{V}_{2} \mathrm{O}_{5} \cdot n \mathrm{H}_{2} \mathrm{O}\end{array}$ & Aqueous $\mathrm{ZnSO}_{4}$ & $0.4-1.4$ & $10 \mathrm{~A} / \mathrm{g}$ & 192 & 1000 cycles & {$[75]$} \\
\hline $\mathrm{LiV}_{3} \mathrm{O}_{8}$ & Aqueous $\mathrm{ZnSO}_{4}$ & $0.6-1.2$ & $133 \mathrm{~mA} / \mathrm{g}$ & $\sim 140$ & 65 cycles & {$[76]$} \\
\hline $\begin{array}{l}\mathrm{K}_{2} \mathrm{~V}_{6} \mathrm{O}_{16} \cdot 2.7 \mathrm{H}_{2} \mathrm{O} \\
\text { nanorod }\end{array}$ & Aqueous $\mathrm{Zn}\left(\mathrm{CF}_{3} \mathrm{SO}_{3}\right)_{2}$ & $0.4-1.4$ & $6 \mathrm{~A} / \mathrm{g}$ & 188 & $\begin{array}{l}82 \% \text { retention after } \\
500 \text { cycles }\end{array}$ & [77] \\
\hline $\mathrm{Na}_{0.33} \mathrm{~V}_{2} \mathrm{O}_{5}$ & Aqueous $\mathrm{Zn}\left(\mathrm{CF}_{3} \mathrm{SO}_{3}\right)_{2}$ & $0.2-1.6$ & $1.0 \mathrm{~A} / \mathrm{g}$ & 218.4 & $\begin{array}{l}93 \% \text { retention after } \\
1000 \text { cycles }\end{array}$ & {$[78]$} \\
\hline $\mathrm{NaV}_{3} \mathrm{O}_{8}$ & Aqueous $\mathrm{ZnSO}_{4}$ & $0.3-1.25$ & $4 \mathrm{~A} / \mathrm{g}$ & 165 & $\begin{array}{l}82 \% \text { retention after } \\
1000 \text { cycles }\end{array}$ & [79] \\
\hline $\mathrm{Na}_{2} \mathrm{~V}_{6} \mathrm{O}_{16} \cdot 1.63 \mathrm{H}_{2} \mathrm{O}$ & Aqueous $\mathrm{Zn}\left(\mathrm{CF}_{3} \mathrm{SO}_{3}\right)_{2}$ & $0.2-1.6$ & $5 \mathrm{~A} / \mathrm{g}$ & 158 & $\begin{array}{l}90 \% \text { retention after } \\
6000 \text { cycles }\end{array}$ & {$[80]$} \\
\hline $\mathrm{Na}_{1.1} \mathrm{~V}_{3} \mathrm{O}_{7.9} @ \mathrm{rGO}$ & Aqueous $\mathrm{Zn}\left(\mathrm{CF}_{3} \mathrm{SO}_{3}\right)_{2}$ & $0.4-1.4$ & $300 \mathrm{~mA} / \mathrm{g}$ & 171 & 100 cycles & {$[81]$} \\
\hline $\mathrm{Ca}_{0.25} \mathrm{~V}_{2} \mathrm{O}_{5} \cdot n \mathrm{H}_{2} \mathrm{O}$ & Aqueous $\mathrm{ZnSO}_{4}$ & $0.6-1.6$ & $\sim 20 \mathrm{~A} / \mathrm{g}$ & $\sim 70$ & $\begin{array}{l}96 \% \text { retention after } \\
3000 \text { cycles }\end{array}$ & {$[83]$} \\
\hline $\mathrm{Ag}_{0.4} \mathrm{~V}_{2} \mathrm{O}_{5}$ & Aqueous $\mathrm{ZnSO}_{4}$ & $0.4-1.4$ & $20 \mathrm{~A} / \mathrm{g}$ & 144 & 4000 cycles & {$[84]$} \\
\hline $\mathrm{NH}_{4} \mathrm{~V}_{4} \mathrm{O}_{10}$ & Aqueous $\mathrm{ZnSO}_{4}$ & $0.4-1.4$ & $10 \mathrm{~A} / \mathrm{g}$ & 255.5 & 1000 cycles & {$[85]$} \\
\hline $\mathrm{ZnHCF}$ & Aqueous $\mathrm{ZnSO}_{4}$ & $0.8-1.9$ & $300 \mathrm{~mA} / \mathrm{g}$ & 68 & $\begin{array}{l}85 \% \text { retention after } \\
200 \text { cycles }\end{array}$ & {$[41]$} \\
\hline CuHCF & Aqueous $\mathrm{ZnSO}_{4}$ & $0.45-1.4$ & $60 \mathrm{~mA} / \mathrm{g}$ & $\sim 50$ & 100 cycles & {$[86]$} \\
\hline
\end{tabular}


Table 1 (continued)

\begin{tabular}{|c|c|c|c|c|c|c|}
\hline Cathode & Electrolyte & Operating voltage (V) & Current rate & Capacity $\left(\mathrm{mAh} \mathrm{g}^{-1}\right)$ & Cycle performance & Refs. \\
\hline $\mathrm{CuHCF}$ & Aqueous $\mathrm{ZnSO}_{4}$ & $0.2-1.1$ & $10 \mathrm{C}$ & $\sim 40$ & $\begin{array}{l}\sim 80 \% \text { retention after } \\
1000 \text { cycles }\end{array}$ & [88] \\
\hline $\mathrm{ZnHCF}$ & Aqueous $\mathrm{ZnSO}_{4}$ & $0.8-1.9$ & $300 \mathrm{~mA} / \mathrm{g}$ & 52.5 & $\begin{array}{l}81 \% \text { retention after } \\
100 \text { cycles }\end{array}$ & [89] \\
\hline $\mathrm{LiV}_{2}\left(\mathrm{PO}_{4}\right)_{3}$ & Aqueous $\mathrm{Zn}(\mathrm{OTf})_{2}$ & $0.2-1.9$ & $1500 \mathrm{~mA} / \mathrm{g}$ & $\sim 110$ & $\begin{array}{l}78.8 \% \text { retention after } \\
4000 \text { cycles }\end{array}$ & [90] \\
\hline $\begin{array}{l}\mathrm{Na}_{3} \mathrm{~V}_{2}\left(\mathrm{PO}_{4}\right)_{3} / \mathrm{C} \\
\text { cathode }\end{array}$ & $\mathrm{CH}_{3} \mathrm{COOLi}+\mathrm{Zn}\left(\mathrm{CH}_{3} \mathrm{COO}\right)_{2}$ & $0.8-1.7$ & $50 \mathrm{~mA} / \mathrm{g}$ & 84 & $\begin{array}{l}68 \% \text { retention after } \\
200 \text { cycles }\end{array}$ & [91] \\
\hline $\begin{array}{c}\mathrm{M}_{3} \mathrm{~V}_{2}\left(\mathrm{PO}_{4}\right)_{3} / \mathrm{Zinc} \\
(\mathrm{M}=\mathrm{Li}, \mathrm{Na})\end{array}$ & $\begin{array}{l}\mathrm{Li}_{2} \mathrm{SO}_{4}-\mathrm{ZnSO}_{4} \text { aqueous } \\
\text { electrolyte }\end{array}$ & $0.7-2.1$ & $0.2^{\circ} \mathrm{C}$ & 113.5 & $\begin{array}{l}84.1 \% \text { retention after } \\
200 \text { cycles }\end{array}$ & [92] \\
\hline $\mathrm{Na}_{3} \mathrm{~V}_{2}\left(\mathrm{PO}_{4}\right)_{2} \mathrm{~F}_{3}$ & Aqueous $\mathrm{Zn}\left(\mathrm{CF}_{3} \mathrm{SO}_{3}\right)_{2}$ & $0.8-1.9$ & $1 \mathrm{~A} / \mathrm{g}$ & 50 & 4000 cycles & [93] \\
\hline $\mathrm{Na}_{3} \mathrm{~V}_{2}\left(\mathrm{PO}_{4}\right)_{3} / \mathrm{C}$ & Aqueous $\mathrm{Zn}\left(\mathrm{CF}_{3} \mathrm{SO}_{3}\right)_{2}$ & $0.8-1.7$ & $50 \mathrm{~mA} / \mathrm{g}$ & 97 & $\begin{array}{l}74 \% \text { retention after } \\
100 \text { cycles }\end{array}$ & [43] \\
\hline $\begin{array}{l}\mathrm{MoO}_{2} / \mathrm{Mo}_{2} \mathrm{~N} \text { nano- } \\
\text { belts }\end{array}$ & Aqueous $\mathrm{Zn}\left(\mathrm{CF}_{3} \mathrm{SO}_{3}\right)_{2}$ & $0.25-1.35$ & $1 \mathrm{~A} / \mathrm{g}$ & 113 & $\begin{array}{l}78.8 \% \text { retention after } \\
1000 \text { cycles }\end{array}$ & [95] \\
\hline $\mathrm{MoS}_{2}$ & Aqueous $\mathrm{Zn}\left(\mathrm{CF}_{3} \mathrm{SO}_{3}\right)_{2}$ & $0.25-1.25$ & $1 \mathrm{~A} / \mathrm{g}$ & 88.6 & $\begin{array}{l}87.8 \% \text { retention after } \\
1000 \text { cycles }\end{array}$ & [97] \\
\hline $\mathrm{MoS}_{2}$ & Aqueous $\mathrm{ZnSO}_{4}$ & $0.3-1.5$ & $1 \mathrm{~A} / \mathrm{g}$ & 161.7 & $\begin{array}{l}97.7 \% \text { retention after } \\
500 \text { cycles }\end{array}$ & [98] \\
\hline Quinones & Aqueous $\mathrm{Zn}\left(\mathrm{CF}_{3} \mathrm{SO}_{3}\right)_{2}$ & $0.2-1.8$ & $500 \mathrm{~mA} / \mathrm{g}$ & About 120 & $\begin{array}{l}87 \% \text { retention after } \\
1000 \text { cycles }\end{array}$ & [44] \\
\hline Polyaniline & Aqueous $\mathrm{Zn}\left(\mathrm{CF}_{3} \mathrm{SO}_{3}\right)_{2}$ & $0.5-1.5$ & $5 \mathrm{~A} / \mathrm{g}$ & 82 & $\begin{array}{l}92 \% \text { retention after } \\
3000 \text { cycles }\end{array}$ & {$[52]$} \\
\hline $\mathrm{NiHCF}$ & $\begin{array}{l}\mathrm{Zn}\left(\mathrm{ClO}_{4}\right)_{2} \text { acetonitrile elec- } \\
\text { trolyte }\end{array}$ & $0.7-1.8$ & $11.2 \mathrm{~mA} / \mathrm{g}$ & $\sim 56$ & 20 cycles & [103] \\
\hline $\begin{array}{l}\mathrm{ZnNi}_{\mathrm{x}} \mathrm{Mn}_{\mathrm{x}} \mathrm{Co}_{2-2 \mathrm{x}} \mathrm{O}_{4} \\
\text { Spinel }\end{array}$ & $\mathrm{Zn}(\mathrm{OTf})_{2}$ in $\mathrm{MeCN}$ & $0.8-2.15$ & $42 \mathrm{~mA} / \mathrm{g}$ & 180 & $\begin{array}{l}81.66 \% \text { retention } \\
\text { after } 200 \text { cycles }\end{array}$ & [104] \\
\hline $\mathrm{ZnAl}_{0.67} \mathrm{Co}_{1.33} \mathrm{O}_{4}$ & $\mathrm{Zn}(\mathrm{OTf})_{2}$ in $\mathrm{MeCN}$ & $1.4-2.2$ & $32 \mathrm{~mA} / \mathrm{g}$ & 134 & $\begin{array}{l}85.1 \% \text { retention after } \\
100 \text { cycles }\end{array}$ & [105] \\
\hline $\mathrm{V}_{3} \mathrm{O}_{7} \cdot \mathrm{H}_{2} \mathrm{O}$ nanobelts & ZnOTf) in acetonitrile & $0.5-1.8$ & $3000 \mathrm{~mA} / \mathrm{g}$ & $\sim 270$ & $\begin{array}{l}80 \% \text { retention after } \\
200 \text { cycles }\end{array}$ & [106] \\
\hline
\end{tabular}

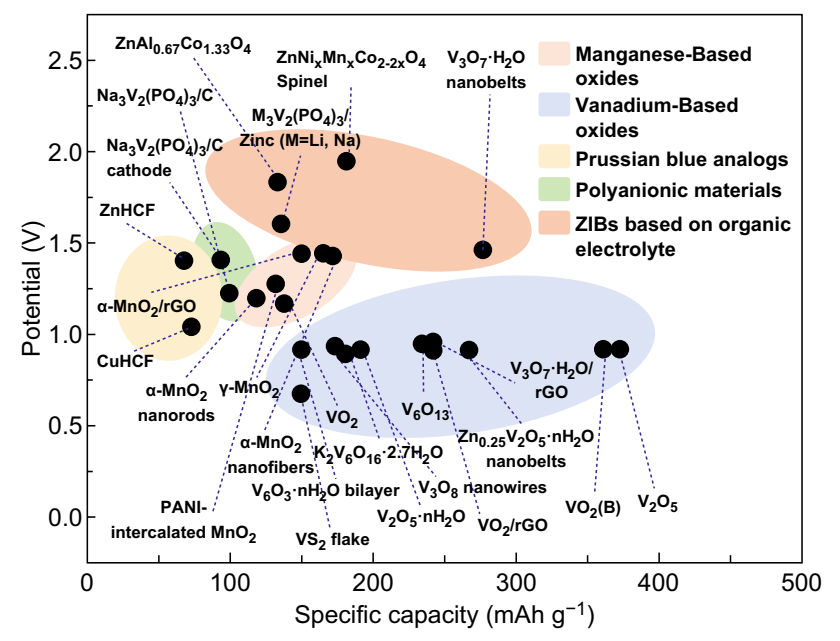

Fig. 8 Specific capacity versus discharge potential of various cathode materials for ZIBs battery exhibits a high capacity of $282.4 \mathrm{mAh}^{-1}$ at $0.37 \mathrm{~A} \mathrm{~g}^{-1}$, durable cycling up to 300 cycles with capacity retention of $77.7 \%$, and a decent energy density of $504.9 \mathrm{Wh} \mathrm{kg}^{-1}$ with a power density of $8.6 \mathrm{~kW} \mathrm{~kg}^{-1}$. Moreover, this flexible battery can maintain similar discharge properties and show no capacity loss under bending or twisting, demonstrating excellent mechanical strength. However, it should be noted that the quasi-solid-state battery usually presents relatively lower rate capability compared to the aqueous system, attributed to the low ionic conductivity and high charge transfer resistance of the $\mathrm{PVA} / \mathrm{ZnCl}_{2} / \mathrm{MnSO}_{4}$ gel electrolyte.

Zhi et al. also developed a wearable solid-state zinc-ion battery with high safety via utilizing novel gelatin-PAMbased solid-state polymer electrolyte with $\mathrm{ZnSO}_{4}$ and $\mathrm{MnSO}_{4}, \alpha-\mathrm{MnO}_{2} @ \mathrm{CNT}$ cathode, and flexible $\mathrm{Zn}$ foil anode (Fig. 9c) [108]. The solid-state polymer electrolyte was 


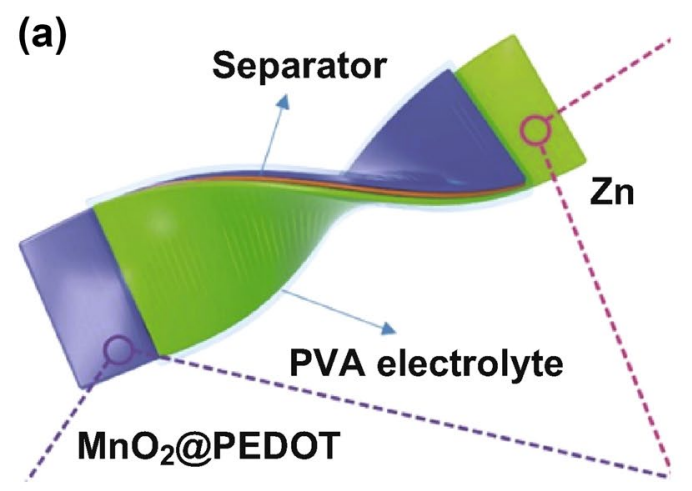

(c)

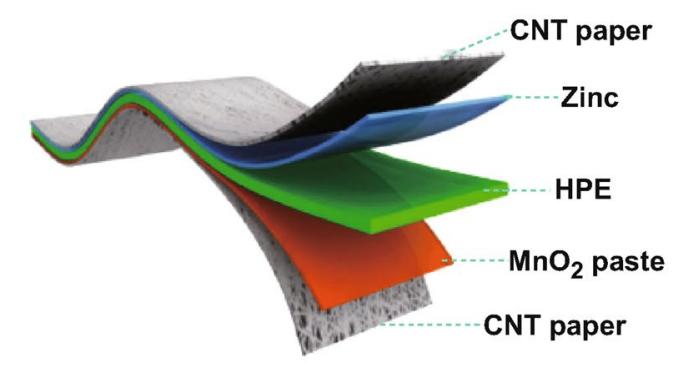

(e)

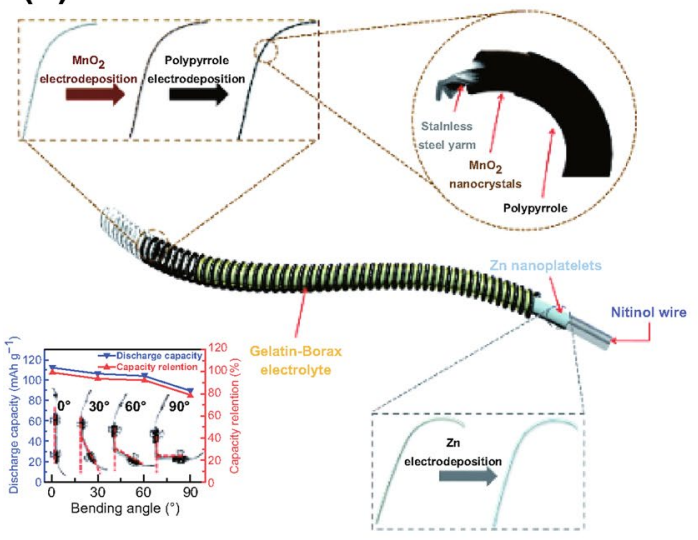

(b)

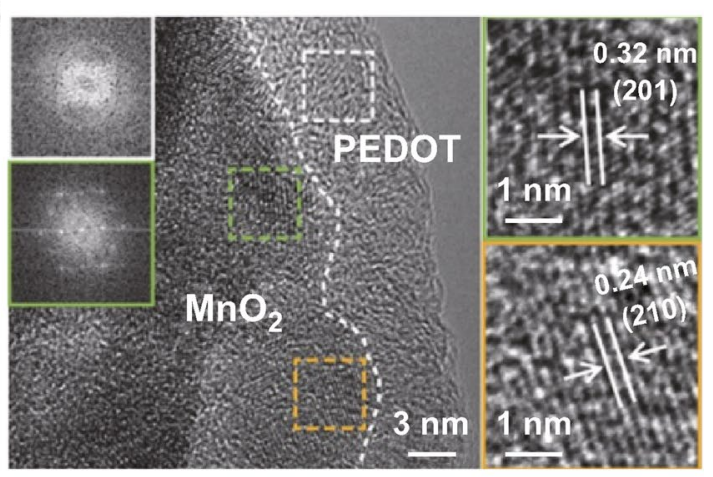

(d)
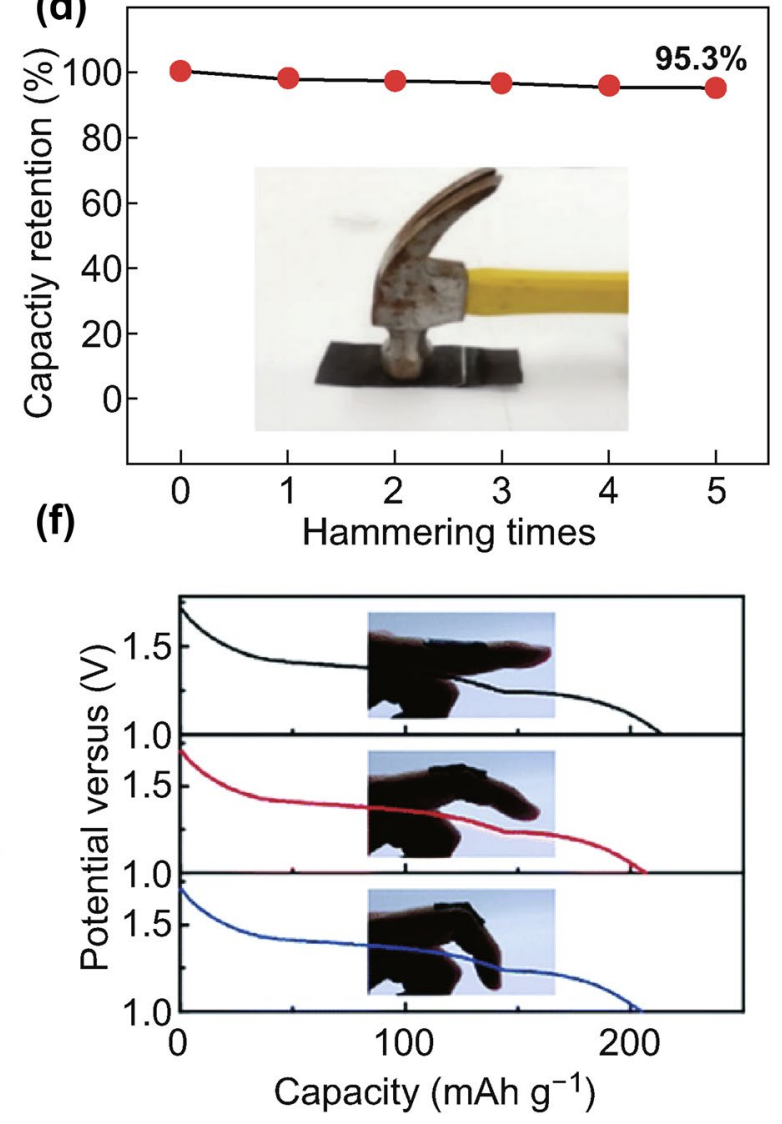

Fig. 9 a Schematic showing the flexible quasi-solid-state $\mathrm{Zn}-\mathrm{MnO}_{2} @$ PEDOT batteries. b HRTEM images of $\mathrm{MnO}_{2} @$ PEDOT sample [107]. c Schematic illustration of the structure of the solid-state ZIB and $\mathbf{d}$ the hammering test [108]. e Schematic illustration of the structure of the wire battery, inset showing the charging-discharging curves corresponding to the wire batteries bending at different angles [109]. f Galvanostatic discharge curves of $\mathrm{Zn}-\mathrm{MnO}_{2}$ batteries bending at different curvatures [110]. With permission from The Royal Society of Chemistry

prepared by filling gelatin-PAM chains in the PAN fiber network. Such highly porous interconnected framework of the solid-state polymer electrolyte displays an extremely high ionic conductivity of $1.762 \times 10^{-2} \mathrm{~S} \mathrm{~cm}^{-1}$ and desirable mechanical strength of $7.76 \mathrm{MPa}$. Benefiting from the solid-state electrolyte with high ionic conductivity, the zinc-ion battery cell exhibits an impressive reversible capacity of $306 \mathrm{mAh} \mathrm{g}^{-1}$ at a specific current of $61.6 \mathrm{~mA} \mathrm{~g}^{-1}$ and decent capacity retention of $97 \%$ up to 1000 cycles at $2772 \mathrm{~mA} \mathrm{~g}^{-1}$. Even under various severe conditions such as bending, hammering (Fig. 9d), cutting, washing, combustion, weight loading, sewing, and drilling, the designed 
solid-state zinc-ion batteries show desirable electrochemical behavior and high stability, demonstrating great potential as new generation energy storage system to power flexible and wearable electronics.

Zhi et al. further designed a smart wire-shaped flexible zinc-ion battery with shape memory function. The designed batteries show improved electrochemical performances with unique shape memory function by utilizing the temperature-initiated shape memory effect (Fig. 9e) [109]. The gel polymer electrolyte is fabricated by employing gelatin and borax in aqueous solution of $\mathrm{ZnSO}_{4} / \mathrm{MnSO}_{4}$, and it presents higher ionic conductivity of $2.0 \times 10^{-2} \mathrm{~S} \mathrm{~cm}^{-1}$ compared to the bare gelatin gel electrolyte with $1.39 \times 10^{-2} \mathrm{~S} \mathrm{~cm}^{-1}$. Owing to the introduction of borax as a cross-linker into the gelatin gel electrolyte, the ionic conductivity, water retention capability, and mechanical strength of the gelatin-borax gel electrolyte are effectively improved, thereby enhancing the electrochemical performances of the zinc-ion battery. Such flexible wire battery exhibits a specific capacity of 174.2 $\mathrm{mAh} \mathrm{g}^{-1}$ at $0.5^{\circ} \mathrm{C}$ and durable cycling performance up to 1000 cycles with corresponding Coulombic efficiencies over 99\%. Additionally, its electrochemical performance can be well preserved when bent to $90^{\circ}$ or consecutively bent to $45^{\circ}$ for over 500 cycles, indicating its superior resistance against mechanical deformation.

Searching for a stable sulfate-tolerant polymer electrolyte without polymer precipitation, Li et al. explored a xanthan biopolymer in combination with aqueous $\mathrm{ZnSO}_{4} / \mathrm{MnSO}_{4}$ solution to fabricate a very stable gum bio-electrolyte, which was then assembled in a rechargeable $\mathrm{Zn} / \mathrm{MnO}_{2}$ battery for electrochemical characterizations [110]. Owing to its favorable molecular structure composed of $\alpha, \beta$-1,4-linked glucan backbone with trisaccharide side chains connected with backbone residues by $\alpha-1,3$ linkages, the xanthan gum shows high salt tolerance stability. The gum bio-electrolyte is highly conductive $\left(1.46 \times 10^{-2} \mathrm{~S} \mathrm{~cm}^{-1}\right.$ at room temperature and $2.5 \times 10^{-3} \mathrm{~S} \mathrm{~cm}^{-1}$ at $-8{ }^{\circ} \mathrm{C}$ ), and its ionic conductivity remains unchanged even after 1 -year storage, indicating its ability of working in a wide temperature range for the long term. As a result, this battery presented a specific capacity of $260 \mathrm{mAh} \mathrm{g}^{-1}$ at $1{ }^{\circ} \mathrm{C}$, high rate capability, good cycling performance with $90 \%$ capacity retention after 330 cycles at $1{ }^{\circ} \mathrm{C}$, and even maintained a decent capacity of $127 \mathrm{mAh} \mathrm{g}^{-1}$ up to 1000 cycles at $5^{\circ} \mathrm{C}$. Moreover, the battery cell exhibits outstanding durability under bending and twisting (Fig. 9f) and effectively prohibits the zinc dendrite growth during continuous charge-discharge cycles, suggesting that the gum bio-electrolyte is a very promising candidate for flexible energy storage systems.

Inspired by Zhi et al.'s work above, Chen et al. investigated $\mathrm{a} \mathrm{Zn} / \mathrm{NaV}_{3} \mathrm{O}_{8} \cdot 1.5 \mathrm{H}_{2} \mathrm{O}(\mathrm{NVO})$ cell by using a quasi-solid-state electrolyte that consists of gelatin and aqueous $\mathrm{ZnSO}_{4}$ solution (Fig. 10a) [50]. Although the preparation method is simple, the gel electrolyte shows degraded ionic conductivity compared to the corresponding aqueous part. Even so, the flexible quasi-solid-state $\mathrm{Zn} / \mathrm{NVO}$ battery still delivers a good rate capability of $288,228,160,115$, and $80 \mathrm{mAh} \mathrm{g}^{-1}$ at $0.1,0.2,0.5,1$, and $2 \mathrm{~A} \mathrm{~g}^{-1}$, respectively. Furthermore, such flexible energy storage system can maintain the capacities under various bending states during charge-discharge process with only a slight capacity loss, indicating high stability of the quasi-solid-state cell (Fig. 10c). In addition, two quasisolid-state $\mathrm{Zn} / \mathrm{NVO}$ cells under bending condition in series can light up the LED array of 52 bulbs, suggesting that they can be great candidates for practical flexible energy storage devices, as shown in Fig. 10b.

Chen et al. also developed a flexible quasi-solid-state batteries by using polyaniline (PANI) as cathode, PVA/ $\mathrm{Zn}\left(\mathrm{CF}_{3} \mathrm{SO}_{3}\right)_{2}$ gel as electrolyte, and $\mathrm{Zn}$ metal as anode (Fig. 10d-f) [52]. Such soft-packaged quasi-solid-state Zn/ PANI battery delivers a reversible capacity $109 \mathrm{mAh} \mathrm{g}^{-1}$ in the first cycle at $0.5 \mathrm{~A} \mathrm{~g}^{-1}$ and $91.7 \%$ capacity can be retained after 200 cycles, while the cable-type battery displays a capacity of $106 \mathrm{mAh} \mathrm{g}^{-1}$ for the first discharge process at $0.5 \mathrm{~A} \mathrm{~g}^{-1}$ and $91.5 \%$ capacity retention can be achieved over 200 cycles (Fig. 10d). The highly stable electrochemical performances of both soft-packaged and cabletype Zn/PANI batteries under different bending states hold great promise for flexible electronic applications. Moreover, two soft-packaged and two cable-type flexible cells can successfully light up a wristwatch and an LED array under bending condition, respectively (Fig. 10e, f).

There has been another report concerning quasi-solidstate zinc-ion battery with high rate capability using a layered zinc orthovanadate array as cathode, a $\mathrm{Zn}$ array as anode, and a gel electrolyte composed of fumed silica with aqueous $\mathrm{ZnSO}_{4}$ solution [111]. This battery displays superior electrochemical behaviors and ultra-stable flexibility. Specifically, the flexible cell exhibits a highly reversible capacity of $204 \mathrm{mAh} \mathrm{g}^{-1}$ with an initial high Coulombic efficiency of $95 \%$ at $0.5{ }^{\circ} \mathrm{C}$, corresponding to the two-electron transfer process. Due to the nanoarray structure in both 


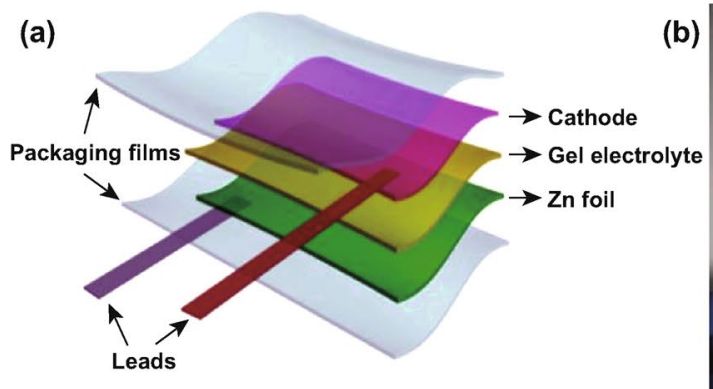

(b)

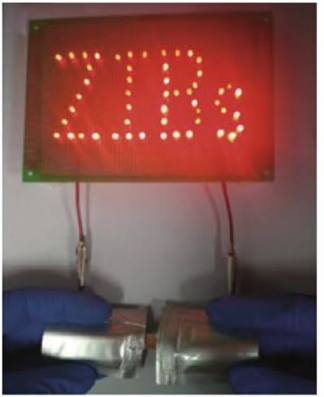

(c)

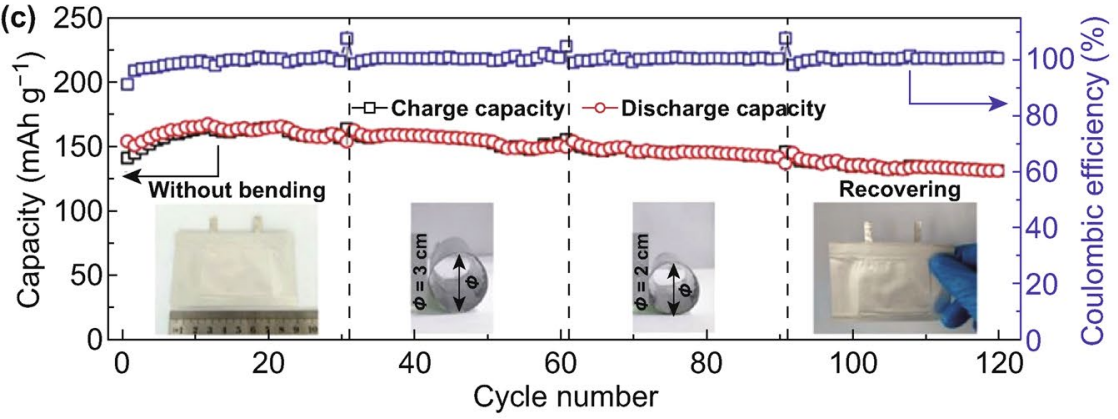

(d)

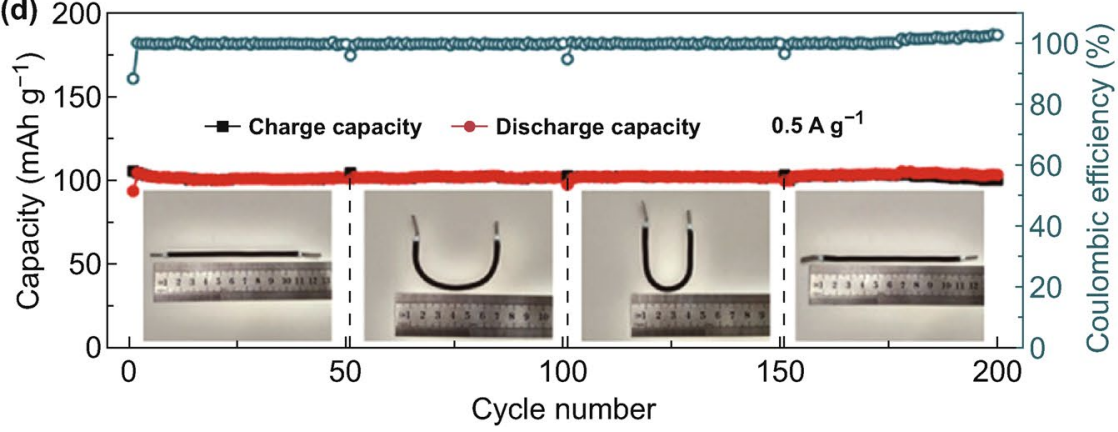

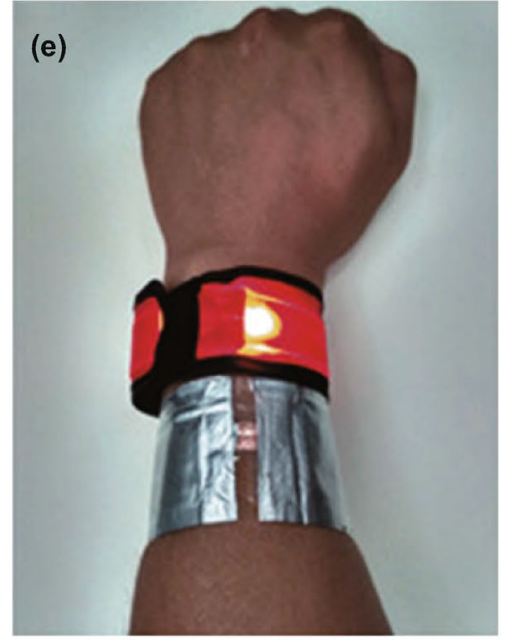

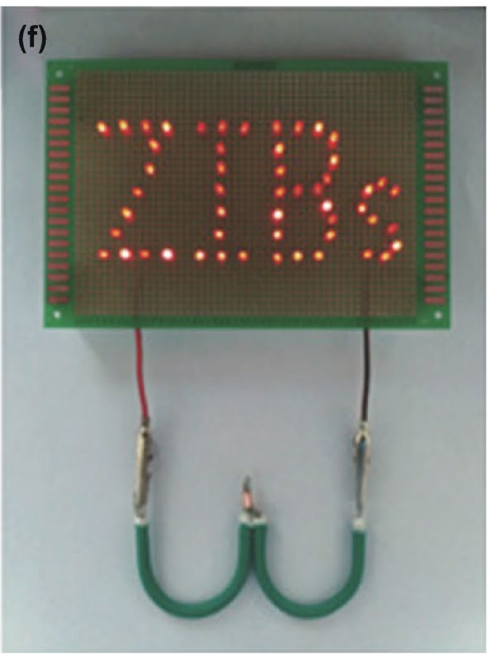

Fig. 10 a Schematic diagram of a quasi-solid-state Zn/NVO battery [50], b LED array with 52 bulbs powered by two quasi-solid-state Zn/NVO battery under bending condition, $\mathbf{c}$ cycling performance under various bending states at $0.5 \mathrm{~A} \mathrm{~g}^{-1}$ of the flexible quasi-solid-state Zn/NVO battery. d cycling performance of soft-packaged and cable-type quasi-solid-state batteries under various bending states at $0.5 \mathrm{~A} \mathrm{~g}^{-1}$. e $\mathrm{A}$ wrist strap powered by two soft-packaged quasi-solid-state batteries in series, $\mathbf{f}$ an LED array powered by two cable-type quasi-solid-state batteries in series [52]. With permission from Elsevier and The Royal Society of Chemistry

electrodes providing short fast ion migration pathways and introduced insertion pesudocapacitance, the quasi-solid-state battery delivers an excellent rate capability of $160 \mathrm{mAh} \mathrm{g}^{-1}$ at $10{ }^{\circ} \mathrm{C}$ and $101 \mathrm{mAh} \mathrm{g}^{-1}$ even at $50{ }^{\circ} \mathrm{C}$. Furthermore, the quasi-solid-state ZIB shows long-term cycling stability for 2000 cycles at $20{ }^{\circ} \mathrm{C}$ and considerable energy density of $115 \mathrm{Wh} \mathrm{kg}^{-1}$ with a power density of $5.1 \mathrm{~kW} \mathrm{~kg}^{-1}$ based on the total masses of cathode, anode, and current collectors. Additionally, the battery reveals no obvious capacity fading with over $96 \%$ capacity retention under continuous 100 bending cycles, showing its high tolerance of bending without deterioration of the discharge performance.
Recently, Zhi et al. obtained a flexible self-healing solidstate aqueous rechargeable $\mathrm{NiCo} / \mathrm{Zn}$ battery by employing NiCo hydroxide as cathode, flexible $\mathrm{Zn} /$ carbon cloth as anode, and $\mathrm{Fe}^{3+}$-cross-linking sodium polyacrylate (PANa$\mathrm{Fe}^{3+}$ ) hydrogel as solid-state electrolyte [112]. This self-healing electrolyte displays enhanced healing property and good ionic conductivity owing to the $\mathrm{Fe}^{3+}$ cross-linkers forming ionic bonds between the PANa chains, as well as the favorable compatibility of PANa- $\mathrm{Fe}^{3+}$ with aqueous solution of $\mathrm{Zn}\left(\mathrm{CH}_{3} \mathrm{COO}\right)_{2}+\mathrm{KOH}$. Hence, the assembled $\mathrm{NiCo} / \mathrm{Zn}$ batteries with such intrinsically self-healing PANa- $\mathrm{Fe}^{3+}$ electrolytes show autonomically self-healing ability with over $87 \%$ capacity retention after four cycles of cutting/healing. When 
the two broken parts of the cell were brought to connect, the watch was on again without weakening the brightness, indicating excellent healing performance and high potential applications in broken electronics. Moreover, a flexible $\mathrm{Zn}$ / $\mathrm{MnO}_{2}$ battery with exceptionally electrochemical performances has been achieved and can operate at subzero temperatures (Fig. 11) [113]. Hydrogel electrolytes are attractive for flexible ZIBs by virtue of their safety and high physical/ chemical stability. However, the freezing issue of hydrogel electrolytes under subzero temperatures would lead to severe capacity fading and elasticity degradation, in addition to loss of mechanical robustness and flexibility under cold condition. In this work, a strong hydrogen bonding with water anchored the water units within the polymer electrolyte was designed, rendering superior anti-freezing property even at $-20^{\circ} \mathrm{C}$.
The constructed $\mathrm{Zn} / \mathrm{MnO}_{2}$ flexible battery maintained high electrochemical performances, impressive durability, and flexibility even being compressed, bent, or washed in an ice bath at $-20^{\circ} \mathrm{C}$ (Fig. 11e-i). Such an excellent polymer electrolyte allows flexible ZIBs to be used under extreme conditions, such as aerospace or submarines.

\section{Design of Zinc Anodes and Separators}

Most studies in ZIBs employ commercial zinc foil as the anode for investigation of ZIBs. Although zinc metal is considered as a promising anode for aqueous ZIBs owing to its intrinsic safety, low toxicity, and high theoretical capacity, metallic zinc inevitably suffers from passivation, (a)

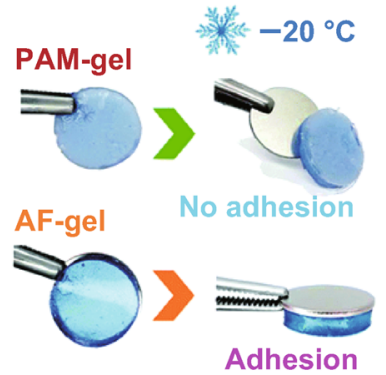

(b)

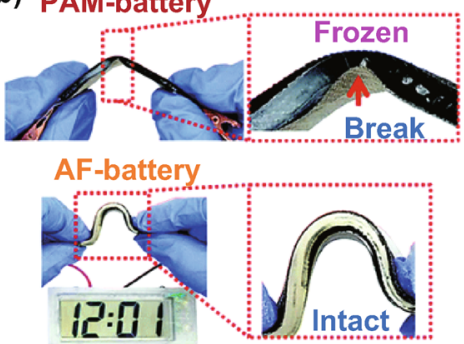

(d)

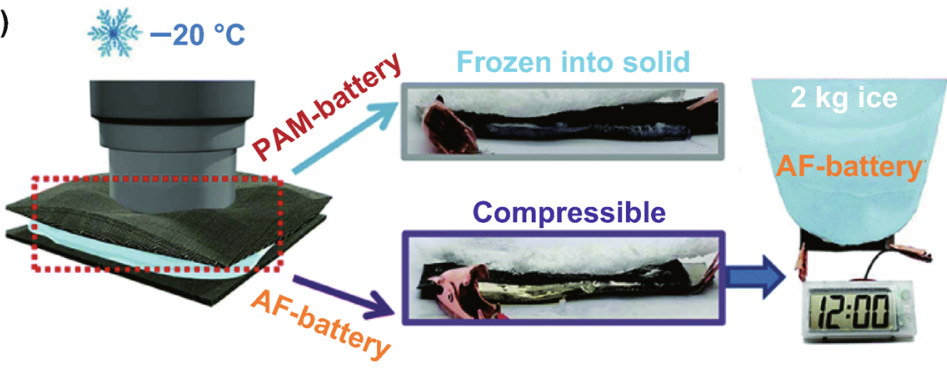

(f)

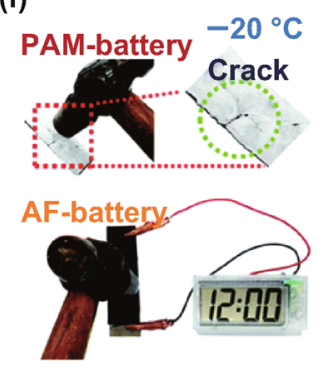

(g)

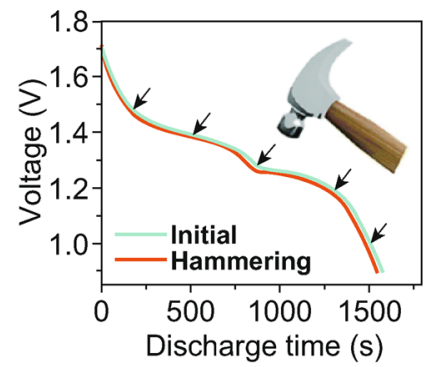

(h)

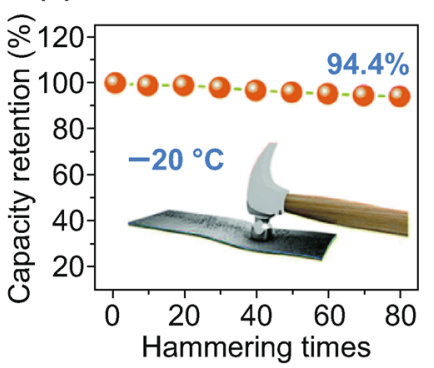

(c)
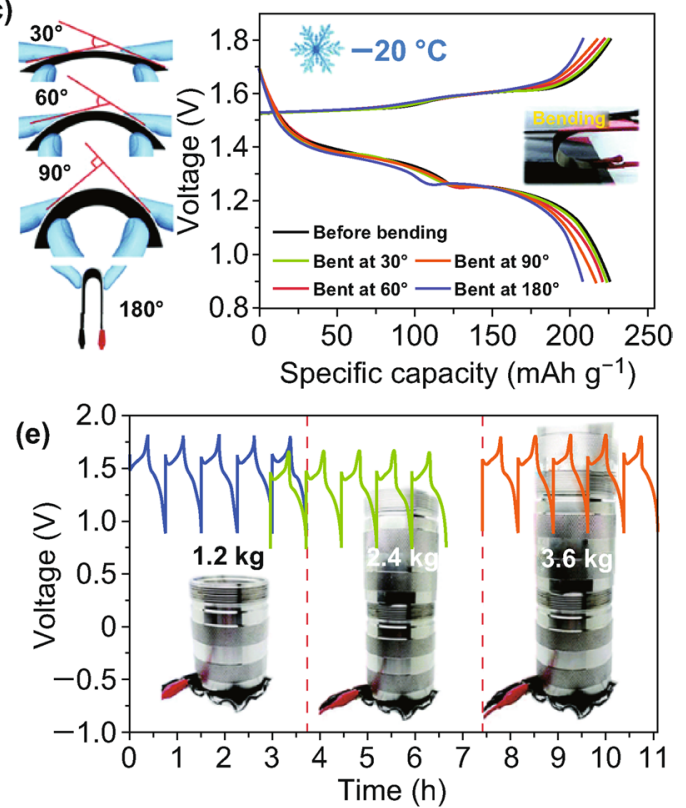

(i)

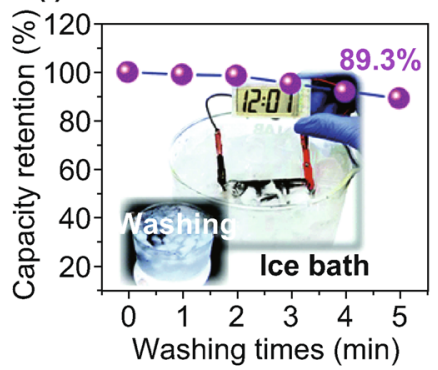

Fig. 11 a Comparisons of the adhesion force of the PAM gel and $\mathrm{AF}$ gel at $-20{ }^{\circ} \mathrm{C}$. b Bending test of the PAM battery and AF battery at $-20{ }^{\circ} \mathrm{C}$. c Charge-discharge profile of the AF battery under bending test at $0.2 \mathrm{~A} \mathrm{~g}^{-1}$. d PAM battery and AF battery holding an ice block; the AF battery can still power an electrical watch at $-20{ }^{\circ} \mathrm{C}$. e Cycling test of the AF battery under various heavy loads at $-20{ }^{\circ} \mathrm{C}$. f $\mathrm{Hammering}$ tests of the PAM battery and AF battery after 1 day of cooling at $-20{ }^{\circ} \mathrm{C}$. $\mathbf{g}$ Discharge curves and $\mathbf{h}$ cycling test of the AF battery under hammering tests. i Capacity retention of the AF battery washing in an ice bath [113]. With permission from The Royal Society of Chemistry 
irreversibility, corrosion, and growth of dendrite during plating/stripping. Especially in alkaline aqueous electrolytes, passivation problems caused by the formation of $\mathrm{ZnO}$ layer can limit the surface contact between electrolyte and zinc anode and seriously reduce the conductivity of the anode $[114,115]$. Moreover, the growth of zinc dendrites can continuously consume water during cycling and irreversibly produce by-products $\left(\mathrm{Zn}(\mathrm{OH})_{4}^{2-}\right.$, etc.), leading to very low Coulombic efficiency, poor capacity, limited cycling life of ZIBs. Zinc dendrite still tends to form especially at high current densities. It is believed that the formation of zinc dendrite is due to the uneven $\mathrm{Zn}^{2+}$ distribution on flat metallic $\mathrm{Zn}$ foil. The sharp end of dendrite tips can act as a charge center in the electric field, supporting further growth of dendrites [54]. Moreover, with the growth of zinc dendrite, the surface area of zinc anode increases, while the corrosion and other surface-dependent reactions increase with the larger surface area of zinc anode, leading to continuously consuming of zinc anode and a faster fading of the battery performance. To overcome these problems, many efforts have been devoted to designing the composite nanostructure of the $\mathrm{Zn}$ metal anode, adding additives in electrolyte, or changing the concentration of zinc salts in electrolyte.

Composite nanostructure design is deemed as an effective strategy to restrict dendrite growth, suppress the formation of by-products, and constrain the corrosion of zinc anode [116]. For example, Yan et al. designed lasagna-like nanostructured $\mathrm{Zn}$ anode, in which $\mathrm{ZnO}$ nanoparticles are wrapped with graphene oxide nanosheets [117]. The composite anode can provide much higher volumetric capacity and capacity retention when compared with pure $\mathrm{ZnO}$. Moreover, Wang et al. deposited zinc on conductive graphite felt via electrodeposition method [118]. The graphite felt substrate can facilitate fast electron transport and efficient zinc plating in various specific directions, leading to enhanced cycling stability.

In addition to the above composite nanostructure design of $\mathrm{Zn}$ anodes, adding additives in electrolyte is also an important strategy to constrain the corrosion and dendrite formation of $\mathrm{Zn}$ metal anode. For instance, as reported by Mantia et al., the electrolyte's additive can decrease the grain growth rate and thus affect the morphology of zinc electrodeposition and suppress the formation of dendrites [119]. Unfortunately, at the same time, it can also decrease the kinetics of reaction and cycling stability of ZIBs due to induced higher overpotential. Mantia and his co-workers studied the effect of branched polyethyleneimine (BPEI) as an electrolyte's additive [119]. They found that the introduction of BPEI can adjust the morphology of the deposited $\mathrm{Zn}$ and decrease the size of the crystals, leading to the improved efficiency and stability. Moreover, Chen and his co-workers found that the addition of $\mathrm{Na}_{2} \mathrm{SO}_{4}$ in $\mathrm{ZnSO}_{4}$ aqueous electrolyte can effectively hinder the growth of $\mathrm{Zn}$ dendrites [79]. This is because sodium ions with a lower reduction potential can form a positively charged electrostatic shield on $\mathrm{Zn}$ ions, avoiding the growth of $\mathrm{Zn}$ dendrites. In addition, Chen's group systemically studied the additives in gel electrolyte [120]. They first applied fumed silica as additive in gel electrolyte and found that the fumed silica can significantly reduce dendrite formation. However, the adding of fumed silica can also increase the corrosion on $\mathrm{Zn}$ anode. Therefore, they further introduce pyrazole in electrolyte and found that the pyrazole can serve as a good additive to inhibit both zinc corrosion and dendrite growth. The optimized composition 5\% fumed silica $+0.2 \%$ pyrazole finally exhibits improved performance with enhanced open-circuit voltage, rate capability, and cycling stability.

Highly concentrated neutral $\mathrm{Zn}$-ion electrolyte is another effective method to suppress the dendrite growth. To completely eliminate the formation of $\mathrm{Zn}$ dendrites, Wang et al. developed a unique aqueous electrolyte at high concentrations composed of $1 \mathrm{M} \mathrm{Zn(TFSI})_{2}$ and $20 \mathrm{M} \mathrm{LiTFSI}$, proved to achieve $100 \%$ Coulombic efficiency and no dendrite formation during Zn plating/stripping [121]. In addition, Chen and his co-workers developed $\mathrm{Zn} / \mathrm{VOPO}_{4}$ batteries using a water-in-salt electrolyte to realize reversible oxygen redox chemistry in a high voltage region [122]. Since Zn metal anodes show high corrosion current and low positive corrosion potential in $1 \mathrm{M} \mathrm{Zn(Tr})_{2}$ electrolyte, they applied highly concentrated $21 \mathrm{M} \mathrm{LiTFSI} / 1 \mathrm{M} \mathrm{Zn(Tr})_{2}$ water-in-salt electrolyte in ZIBs, which can suppress the corrosion of zinc and also constrain the dissolution of $\mathrm{VOPO}_{4}$ cathode due to the limited activity of water. The water-in-salt electrolyte facilitates the reversible oxygen redox reaction in $\mathrm{Zn} /$ $\mathrm{VOPO}_{4}$ batteries, leading to increased discharge potential to $1.56 \mathrm{~V}$ and significantly improved power density from 160 to $217 \mathrm{Wh} \mathrm{kg}^{-1}$, which is comparable with lithium-ion batteries. This work of water-in-salt electrolyte is scientifically enlightening for future research. However, the electrolyte 
with high $\mathrm{Zn}$ and Li salts is quite expensive and largely hinders its potential for grid-scale production.

It is known that the passivation and dendrite growth on zinc anode surface could be reduced in acidic electrolyte [61]. However, acidic electrolytes will cause the corrosion on $\mathrm{Zn}$ anode, seriously affecting long-term cyclability. Surface coating on zinc metal foil is an effective way to alleviate the corrosion of zinc anode and thus improve the performance. As shown in Fig. 12a, b, stable coating layer on zinc anode can slow down zinc dissolution and dendrite growth. For example, Zhao et al. applied atomic layer deposition method to coat the zinc metal plate with thin $\mathrm{TiO}_{2}$ layer to prevent corrosion during electrochemical reactions [123]. They demonstrated that $\mathrm{TiO}_{2}$ layer can effectively protect the inner zinc from corrosion and suppress $\mathrm{Zn}(\mathrm{OH})_{2}$ byproduct formation, leading to improved capacity retention and prolonged cycling life. In addition, $\mathrm{Zhi}$ et al. coated $\mathrm{Zn}$ anode with a uniform porous nano- $\mathrm{CaCO}_{3}$ layer to enhance the electrostripping/electroplating stability [124]. The porous uniform coatings can guide the $\mathrm{Zn}$ plating reaction on the entire $\mathrm{Zn}$ anode surface, effectively avoiding the corrosion and the growth of large protrusions/dendrites. Liu et al. coated zinc metal anode with graphene oxide (GO) nanosheets via casting method (Fig. 12c, d) [125]. The GO nanosheets can not only prevent the $\mathrm{Zn}$ intermediates from dissolving into aqueous electrolyte, but also improve the surface electron conductivity, leading to the prolonged cycling life and rate capability. Moreover, synthesis of zinc anode with organic additives is another strategy to reduce corrosion. For example, Chen et al. prepared novel zinc anode via electroplating with various organic additives [126]. They found that organic additives can change the surface crystallographic orientation, surface density, and texture of the produced zinc anode. Based on the linear polarization results, compared with the commercial pure zinc metal, the corrosion rate of the prepared Zn-SDS is 30 times lower, showing significantly improved corrosion tolerance. However, there are still very few studies on mechanisms of suppressing corrosion and passivation of zinc anode by now. Therefore, more research efforts should be made to manipulate the $\mathrm{Zn}^{2+}$ chemistry based on the $\mathrm{Zn}$ anode to overcome the abovementioned corrosion and dendrite growth problems.

Separator is also critical in ZIBs for practical applications, serving to prevent short circuit by separating the cathode
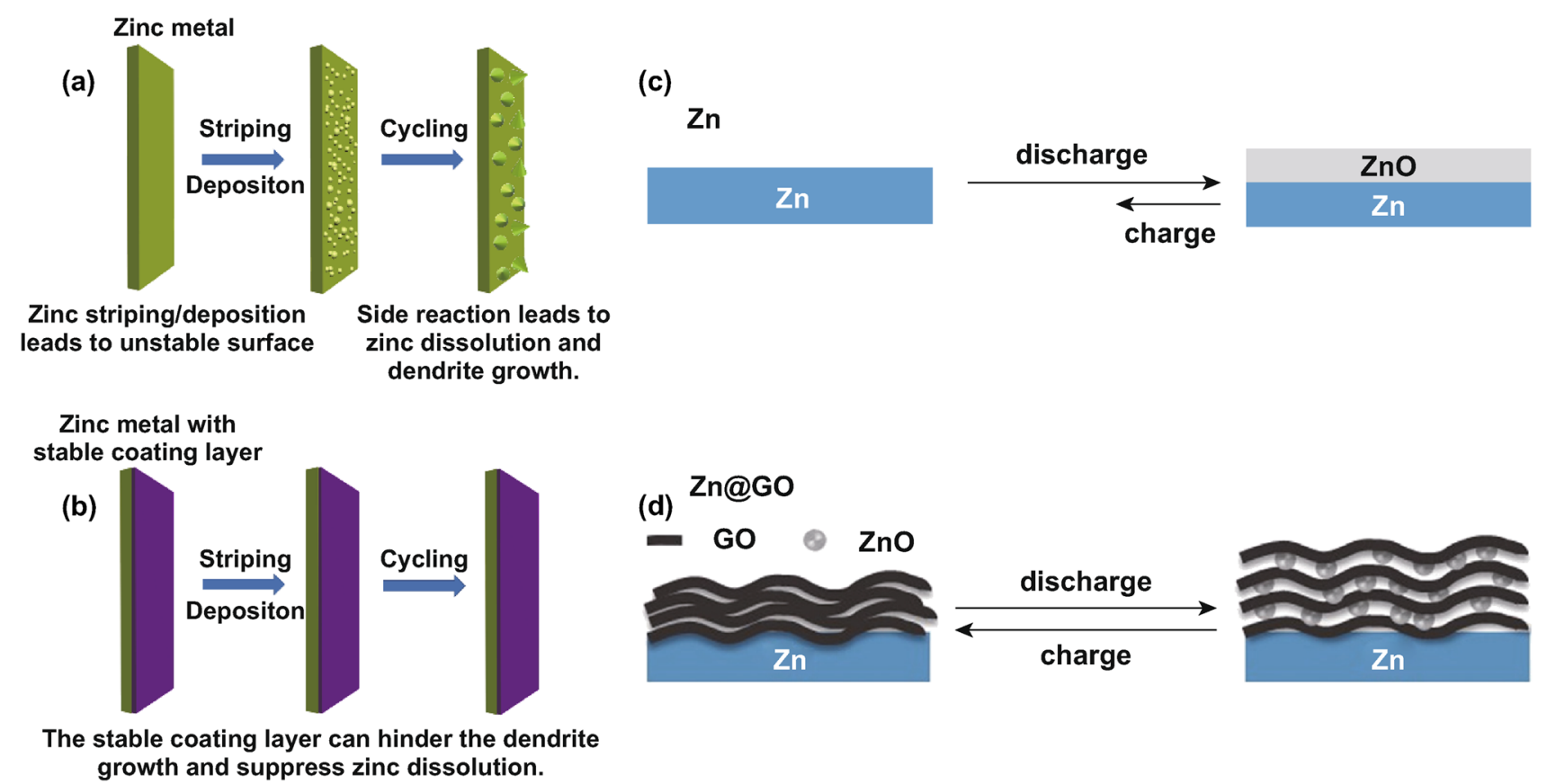

(d) Zn@GO

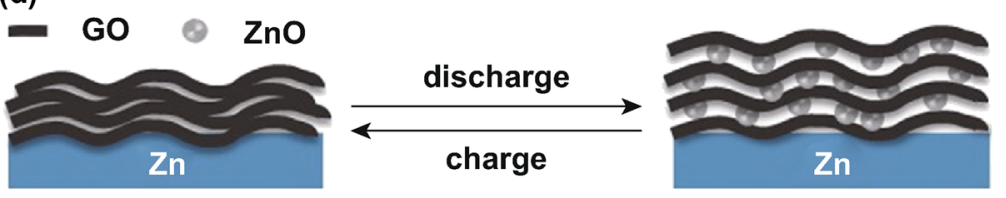

Fig. 12 Schematic illustration of the zinc metal anode with stable coating layer. a Plating and stripping of zinc ions lead to unstable surface. Side reaction during continuous cycling can lead to passivation and dendrite growth. b A thin coating layer leads to a stable deposition/stripping process, hindering dendrite growth, and by-product formation. Schematic of morphological changes about $\mathbf{c}$ the formation of $\mathrm{ZnO}$ passivation layer on $\mathrm{Zn}$ anode during charging and discharging. $\mathbf{d} \mathrm{GO}$ on $\mathrm{Zn}$ surface can suppress the formation of $\mathrm{ZnO}$ passivation and slow down the dissolution of $\mathrm{Zn}$ metal [124]. With permission from Elsevier 
and anode. Currently, most ZIB studies employ filter paper or glass fiber membrane as separators in the battery cells. The systematic explorations on the separator materials are still missing, and it would be helpful to have more research in this regard to realize large-scale utilization of ZIBs. Recently, Liu et al. have constructed a cross-linked polyacrylonitrile-based membrane that is mechanically robust and cost effective, for application as the separator in rechargeable ZIBs [127]. Based on the synthetic merits, Zn/Zn symmetric cells based on this separator exhibit superior long cyclability of over 350 cycles with efficient dendrite growth suppression and lower polarization, which provides an important solution for future design of separators.

\section{Conclusions}

In summary, we provide a timely review on the recent developments in zinc-ion batteries, including the cathode materials, liquid-based electrolytes, and solid-state electrolytes. The preparation methods of the electrode materials, fundamental electrochemical reaction mechanisms, corresponding battery performances, and their correlations are discussed in detail. Continuous efforts are being made for exploring a vast variety of cathode materials. However, there remain many essential electrochemical details that are yet to clarify. For example, the electrochemical reaction mechanisms of Mn-based cathodes in ZIBs are still disputable, with three different mechanisms of $\mathrm{Zn}^{2+}$ migration, proton migration, and $\mathrm{Zn}^{2+} / \mathrm{H}^{+}$co-migration being reported. Moreover, the combination of valence state change of manganese ion during cations insertion and corresponding typical voltage plateaus still need to be examined carefully, which may shed more light on the electrochemical mechanisms and thus provide effective guidance for constructing Mn-based electrode/ $\mathrm{Zn}$ batteries with improved performances. Compared to the Mn-based electrodes, V-based cathodes display a higher specific capacity and longer cycling performances, but the lower discharge plateaus $\sim 0.7 \mathrm{~V}$ is a distinct drawback. In addition, V-based materials may continuously dissolve in aqueous acidic $\mathrm{Zn}^{2+}$ electrolyte $\left(\mathrm{ZnSO}_{4}\right.$ or $\mathrm{Zn}\left(\mathrm{CF}_{3} \mathrm{SO}_{3}\right)_{2}$ electrolyte). Therefore, developing effective strategies to prevent the vanadium dissolution is necessary, such as adjustment of the electrolyte $\mathrm{pH}$ or growth of protective layers on the surface of the V-based cathodes. For the PBA cathodes in ZIBs, removing interstitial water content and reducing crystal defects help to increase the robustness of their crystalline structure and further improve their electrochemical performances.

As to the liquid-based electrolytes, their electrochemical behaviors and compatibility with both cathode and $\mathrm{Zn}$ anode are essential for the overall electrochemical properties. Typically, aqueous $\mathrm{Zn}\left(\mathrm{CF}_{3} \mathrm{SO}_{3}\right)_{2}$ and $\mathrm{ZnSO}_{4}$ electrolytes are the most commonly used solutions in ZIBs, owing to their better electrochemical performances than other zinc salts. It should be noted that $\mathrm{Zn}\left(\mathrm{CF}_{3} \mathrm{SO}_{3}\right)_{2}$ is much more expensive than $\mathrm{ZnSO}_{4}$ (with over 18 times higher price), which is not a cost effective electrolyte choice in large-scale ZIB production, while $\mathrm{ZnSO}_{4}$ is accompanied with the formation of unfavorable by-product of hydroxide sulfate. Therefore, it is imperative to investigate the by-product caused by $\mathrm{ZnSO}_{4}$ electrolyte and the interface fluctuation between the $\mathrm{Zn}$ anode and $\mathrm{ZnSO}_{4}$ electrolyte, which may facilitate industrial production of ZIBs based on low-cost $\mathrm{ZnSO}_{4}$ electrolytes. For the solid-state electrolyte, most reported polymer electrolytes suffer from low ionic conductivity, insufficient mechanical strength, and fast degradation. Therefore, studies on the chemical conjunction between $\mathrm{Zn}$-based electrolyte and polymer hosts and their joint electrochemical properties will play important roles in advancing solid-state electrolytes with high stability, broad voltage window, and improved long-term cycling performance. Furthermore, the systematic studies of solid-state polymer electrolytes operating in subzero or high temperature are lacking, which hinder the developments of ZIBs for harsh conditions, and more efforts should be made to explore and obtain electrolytes working in a wide temperature range. Despite much progress that has been achieved in the area of ZIBs, there remain challenges as summarized above. Additional fundamental studies are urgently needed, which are crucial for maturing the battery technology and realizing practical zinc-ion batteries for wide applications.

Overall, the combination of environment-friendly property, high safety, high energy density, and long cycling life makes ZIBs high potential candidates for future energy storage devices. Moreover, compared with current LIBs (about $\$ 300$ per $\mathrm{kWh}$ ), the price of ZIBs ( $\$ 65$ per $\mathrm{kWh}$ ) is much lower, which is even comparable with lead acid batteries. The low cost makes ZIBs very promising for practical large-scale applications. The current manufacturing can be leveraged to large-scale commercialization for ZIBs. However, the major challenges of ZIBs still reside in the high energy efficiency 
cathode, stable $\mathrm{Zn}$ anode, and cheap electrolytes. In the near future, adequate zinc anodes, metal oxide cathodes (probably $\mathrm{MnO}_{2}-, \mathrm{V}_{2} \mathrm{O}_{5}$-based materials), and electrolytes can be designed with more mature technology. The commercialization of rechargeable ZIBs will potentially be scaled up.

Acknowledgements W.W. Xu and Y. Wang acknowledge the Economic Development Assistantship and the Research Enhancement Awards program sponsored by LaSPACE for financial support. The authors also thank Jianwei Lai from Department of Mechanical Engineering and Prof. Qinglin Wu from School of Renewable Natural Resources in Louisiana State University for the discussions and suggestions.

Open Access This article is distributed under the terms of the Creative Commons Attribution 4.0 International License (http:// creativecommons.org/licenses/by/4.0/), which permits unrestricted use, distribution, and reproduction in any medium, provided you give appropriate credit to the original author(s) and the source, provide a link to the Creative Commons license, and indicate if changes were made.

\section{References}

1. J. Huang, Z. Guo, Y. Ma, D. Bin, Y. Wang, Y. Xia, Recent progress of rechargeable batteries using mild aqueous electrolytes. Small Methods 3(1), 1800272 (2018). https://doi. org/10.1002/smtd.201800272

2. J. Derraik, The pollution of the marine environment by plastic debris: a review. Mar. Pollut. Bull. 44(9), 842-852 (2002). https://doi.org/10.1016/S0025-326X(02)00220-5

3. M. Torres, M. Barros, S. Campos, E. Pinto, S. Rajamani, R. Sayre, P. Colepicolo, Biochemical biomarkers in algae and marine pollution: a review. Ecotoxicol. Environ. Saf. 71(1), 1-15 (2008). https://doi.org/10.1016/j.ecoenv.2008.05.009

4. I. Dincer, Renewable energy and sustainable development: a crucial review. Renew. Sustain. Energy Rev. 4(2), 157-175 (2000). https://doi.org/10.1016/S1364-0321(99)00011-8

5. C. McGlade, P. Ekins, The geographical distribution of fossil fuels unused when limiting global warming to $2{ }^{\circ} \mathrm{C}$. Nature 517(7533), 187-190 (2015). https://doi.org/10.1038/natur e14016

6. N. Abas, A. Kalair, N. Khan, Review of fossil fuels and future energy technologies. Futures 69, 31-49 (2015). https://doi. org/10.1016/j.futures.2015.03.003

7. V. Das, S. Padmanaban, K. Venkitusamy, R. Selvamuthukumaran, F. Blaabjerg, P. Siano, Recent advances and challenges of fuel cell based power system architectures and control-a review. Renew. Sustain. Energy Rev. 73, 10-18 (2017). https://doi.org/10.1016/j.rser.2017.01.148

8. P. Owusu, S. Asumadu-Sarkodie, A review of renewable energy sources, sustainability issues and climate change mitigation. Cogent Eng. 3(1), 1167990 (2016). https://doi. org/10.1080/23311916.2016.1167990
9. J. Lelieveld, J. Evans, M. Fnais, D. Giannadaki, A. Pozzer, The contribution of outdoor air pollution sources to premature mortality on a global scale. Nature 525(7569), 367-371 (2015). https://doi.org/10.1038/nature15371

10. M. Kampa, E. Castanas, Human health effects of air pollution. Environ. Pollut. 151(2), 362-367 (2008). https://doi. org/10.1016/j.envpol.2007.06.012

11. S. Yusoff, Renewable energy from palm oil-innovation on effective utilization of waste. J. Clean. Prod. 14(1), 87-93 (2006). https://doi.org/10.1016/j.jclepro.2004.07.005

12. F. Diaz-Gonzalez, A. Sumper, O. Bellmunt, R. Robles, A review of energy storage technologies for wind power applications. Renew. Sustain. Energy Rev. 16(4), 2154-2171 (2012). https://doi.org/10.1016/j.rser.2012.01.029

13. F. Wan, Z.Q. Niu, Design strategies of vanadium-based aqueous zinc-ion batteries. Angew. Chem. Int. Ed. 58, 2-12 (2019). https://doi.org/10.1002/anie.201903941

14. H. Chen, T. Cong, W. Yang, C. Tan, Y. Li, Y. Ding, Progress in electrical energy storage system: a critical review. Prog. Nat. Sci. 19(3), 291-312 (2009). https://doi.org/10.1016/j. pnsc.2008.07.014

15. G. Ren, G. Ma, N. Cong, Review of electrical energy storage system for vehicular applications. Renew. Sustain. Energy Rev. 41, 225-236 (2015). https://doi.org/10.1016/j. rser.2014.08.003

16. J. Goodenough, K. Park, The Li-ion rechargeable battery: a perspective. J. Am. Chem. Soc. 135(4), 1167-1176 (2013). https://doi.org/10.1021/ja3091438

17. Z. Ma, D.R. MacFarlane, M. Kar, Mg cathode materials and electrolytes for rechargeable $\mathrm{Mg}$ batteries: a Review. Batter. Supercaps 2(2), 115-127 (2019). https://doi.org/10.1002/ batt.201800102

18. Z.Q. Xie, J.W. Lai, X.P. Zhu, Y. Wang, Green synthesis of vanadate nanobelts at room temperature for superior aqueous rechargeable zinc-ion batteries. ACS Appl. Energy Mater. 1(11), 6401-6408 (2018). https://doi.org/10.1021/acsae m. 8 b01378

19. N. Zhang, F.Y. Cheng, Y.C. Liu, Q. Zhao, K.X. Lei, C.C. Chen, X.S. Liu, J. Chen, Cation-deficient spinel $\mathrm{ZnMn}_{2} \mathrm{O}_{4}$ cathode in $\mathrm{Zn}\left(\mathrm{CF}_{3} \mathrm{SO}_{3}\right)_{2}$ electrolyte for rechargeable aqueous Zn-ion battery. J. Am. Chem. Soc. 138(39), 12894-12901 (2016). https://doi.org/10.1021/jacs.6b05958

20. C.J. Rydh, M. Karlström, Life cycle inventory of recycling portable nickel-cadmium batteries. Resour. Conserv. Recycl. 34(4), 289-309 (2002). https://doi.org/10.1016/S0921 $-3449(01) 00114-8$

21. G. Majeau-Bettez, T.R. Hawkins, A. Strømman, Life cycle environmental assessment of lithium-ion and nickel metal hydride batteries for plug-in hybrid and battery electric vehicles. Environ. Sci. Technol. 45(10), 4548-4554 (2011). https ://doi.org/10.1021/es103607c

22. V. Etacheri, R. Marom, R. Elazari, G. Salitra, D. Aurbach, Challenges in the development of advanced Li-ion batteries: a review. Energy Environ. Sci. 4(9), 3243-3262 (2011). https ://doi.org/10.1039/C1EE01598B 
23. L. Lu, X. Han, J. Li, J. Hua, M. Ouyang, A review on the key issues for lithium-ion battery management in electric vehicles. J. Power Sources 226, 272-288 (2013). https://doi. org/10.1016/j.jpowsour.2012.10.060

24. N. Nitta, F. Wu, J.T. Lee, G. Yushin, Li-ion battery materials: present and future. Mater. Today 18(5), 252-264 (2015). https://doi.org/10.1016/j.mattod.2014.10.040

25. B. Scrosati, J. Garche, Lithium batteries: status, prospects and future. J. Power Sources 195(9), 2419-2430 (2010). https:// doi.org/10.1016/j.jpowsour.2009.11.048

26. M. Han, E. Gonzalo, G. Singh, T. Rojo, A comprehensive review of sodium layered oxides: powerful cathodes for $\mathrm{Na}-$ ion batteries. Energy Environ. Sci. 8(1), 81-102 (2015). https ://doi.org/10.1039/C4EE03192J

27. J. Pramudita, D. Sehrawat, D. Goonetilleke, N. Sharma, An initial review of the status of electrode materials for potassium-ion batteries. Adv. Energy Mater. 7(24), 1602911 (2017). https://doi.org/10.1002/aenm.201602911

28. G. Fang, J. Zhou, A. Pan, S. Liang, Recent advances in aqueous zinc-ion batteries. ACS Energy Lett. 3(10), 2480-2501 (2018). https://doi.org/10.1021/acsenergylett.8b01426

29. Q. Yang, Z.D. Huang, X.L. Li, Z.X. Liu, H.F. Li et al., A wholly degradable, rechargeable $\mathrm{Zn}-\mathrm{Ti}_{3} \mathrm{C}_{2}$ MXene capacitor with superior anti-self-discharge function. ACS Nano 13(7), 8275-8283 (2019). https://doi.org/10.1021/acsnano.9b03650

30. Y. Li, J. Fu, C. Zhong, T. Wu, Z. Chen, W. Hu, K. Amine, J. Lu, Batteries: recent advances in flexible zinc-based rechargeable batteries. Adv. Energy Mater. 9(1), 1970001 (2019). https://doi.org/10.1002/aenm.201970001

31. J. Ming, J. Guo, C. Xia, W. Wang, H.N. Alshareef, Zinc-ion batteries: materials, mechanisms, and applications. Mater. Sci. Eng. R 135, 58-84 (2019). https://doi.org/10.1016/j. mser.2018.10.002

32. C. Xu, B. Li, H. Du, F. Kang, Energetic zinc ion chemistry: the rechargeable zinc ion battery. Angew. Chem. Int. Ed. 51(4), 933-935 (2012). https://doi.org/10.1002/anie.20110 6307

33. B. Lee, H.R. Lee, H. Kim, K.Y. Chung, B.W. Cho, S.H. Oh, Elucidating the intercalation mechanism of zinc ions into $\alpha-\mathrm{MnO}_{2}$ for rechargeable zinc batteries. Chem. Commun. 51(45), 9265-9268 (2015). https://doi.org/10.1039/C5CC0 $2585 \mathrm{~K}$

34. Q. Yang, F.N. Mo, Z.X. Liu, L.T. Ma, X.L. Li et al., Activating $\mathrm{C}$-coordinated iron of iron hexacyanoferrate for $\mathrm{Zn}$ hybrid-ion batteries with 10000-cycle lifespan and superior rate capability. Adv. Mater. 31(32), 1901521 (2019). https:// doi.org/10.1002/adma.201901521

35. W.N. Xu, K.N. Zhao, W.C. Huo, Y.Z. Wang, G. Yao et al., Diethyl ether as self-healing electrolyte additive enabled long-life rechargeable aqueous zinc ion batteries. Nano Energy 62, 275-281 (2019). https://doi.org/10.1016/j.nanoe n.2019.05.042

36. F. Cheng, J. Chen, X. Gou, P. Shen, High-power alkaline $\mathrm{Zn}-\mathrm{MnO}_{2}$ batteries using $\gamma-\mathrm{MnO}_{2}$ nanowires/nanotubes and electrolytic zinc powder. Adv. Mater. 17(22), 2753-2756 (2005). https://doi.org/10.1002/adma.200500663
37. C. Yang, S. Lin, Improvement of high-rate capability of alkaline $\mathrm{Zn}-\mathrm{MnO}_{2}$ battery. J. Power Sources 112(1), 174-183 (2002). https://doi.org/10.1016/S0378-7753(02)00354-3

38. T. Yamamoto, T. Shoji, Rechargeable $\mathrm{ZnIZnSO} 4 \mid \mathrm{MnO}_{2}$-type cells. Inorg. Chim. Acta 117(2), L27-L28 (1986). https://doi. org/10.1016/S0020-1693(00)82175-1

39. C. Yuan, Y. Zhang, Y. Pan, X. Liu, G. Wang, D. Cao, Investigation of the intercalation of polyvalent cations $\left(\mathrm{Mg}^{2+}, \mathrm{Zn}^{2+}\right)$ into $\lambda-\mathrm{MnO}_{2}$ for rechargeable aqueous battery. Electrochim. Acta 116, 404-412 (2014). https://doi.org/10.1016/j.elect acta.2013.11.090

40. B. Wu, G. Zhang, M. Yan, T. Xiong, P. He, L. He, X. Xu, L. Mai, Graphene scroll-Coated- $\mathrm{MnO}_{2}$ nanowires as high-performance cathode materials for aqueous $\mathrm{Zn}$-ion battery. Small 14(13), 1703850 (2018). https://doi.org/10.1002/smll.20170 3850

41. L. Zhang, L. Chen, X. Zhou, Z. Liu, Morphology-dependent electrochemical performance of zinc hexacyanoferrate cathode for zinc-ion battery. Sci. Rep. 5, 18263 (2015). https:// doi.org/10.1038/srep18263

42. X. Dai, F. Wan, L. Zhang, H. Cao, Z. Niu, Freestanding graphene/ $/ \mathrm{VO}_{2}$ composite films for highly stable aqueous $\mathrm{Zn}$ ion batteries with superior rate performance. Energy Storage Mater. 17, 143-150 (2019). https://doi.org/10.1016/j. ensm.2018.07.022

43. G. Li, Z. Yang, Y. Jiang, C. Jin, W. Huang, X. Ding, Y. Huang, Towards polyvalent ion batteries: a zinc-ion battery based on NASICON structured. Nano Energy 25, 211-217 (2016). https://doi.org/10.1016/j.nanoen.2016.04.051

44. Q. Zhao, W. Huang, Z. Luo, L. Liu, Y. Lu et al., High-capacity aqueous zinc batteries using sustainable quinone electrodes. Sci. Adv. 4(3), 1761 (2018). https://doi.org/10.1126/ sciadv.aao1761

45. W. Zeng, L. Shu, Q. Li, S. Chen, F. Wang, X. Tao, Fiberbased wearable electronics: a review of materials, fabrication, devices, and applications. Adv. Mater. 26(31), 5310-5336 (2014). https://doi.org/10.1002/adma.201400633

46. J. Kim, R. Kumar, A. Bandodkar, J. Wang, Advanced materials for printed wearable electrochemical devices: a review. Adv. Electron. Mater. 3(1), 1600260 (2017). https://doi. org/10.1002/aelm.201600260

47. Z.Q. Wang, J.T. Hu, L. Han, Z.J. Wang, H.B. Wang et al., A MOF-based single-ion $\mathrm{Zn}^{2+}$ solid electrolyte leading to dendrite-free rechargeable Zn batteries. Nano Energy 56, 92-99 (2019). https://doi.org/10.1016/j.nanoen.2018.11.038

48. Z. Liu, F. Mo, H. Li, M. Zhu, Z. Wang, G. Liang, C. Zhi, Advances in flexible and wearable energy-storage textiles. Small Methods 2(11), 1800124 (2018). https://doi. org/10.1002/smtd.201800124

49. W. Lu, C. Xie, H. Zhang, X. Li, Zinc dendrite growth in zincbased batteries. Chemsuschem 11(23), 3996-4006 (2018). https://doi.org/10.1002/cssc.201801657

50. Z. Peng, Q.L. Wei, S.S. Tan, P. He, W. Luo, Q.Y. An, L.Q. Mai, Novel layered iron vanadate cathode for high-capacity aqueous rechargeable zinc batteries. Chem. Commun. 
54(32), 4041-4044 (2018). https://doi.org/10.1039/C8CC0 0987B

51. M. Silva, M.J. Smith, P. Lightfoot, Characterisation of a Zn triflate-based polymer electrolyte. Portugaliae Electrochim. Acta 17, 3-10 (1999)

52. F. Wan, L. Zhang, X. Wang, S. Bi, Z. Niu, J. Chen, An aqueous rechargeable zinc-organic battery with hybrid mechanism. Adv. Funct. Mater. 28(45), 1804975 (2018). https://doi.org/10.1002/adfm.201804975

53. H. Li, L. Ma, C. Han, Z. Wang, Z. Liu, Z. Tang, C. Zhi, Advanced rechargeable zinc-based batteries: recent progress and future perspectives. Nano Energy 62, 550-587 (2019). https://doi.org/10.1016/j.nanoen.2019.05.059

54. M. Song, H. Tan, D. Chao, H.J. Fan, Recent advances in Zn-ion batteries. Adv. Funct. Mater. 28(41), 1802564 (2018). https://doi.org/10.1002/adfm.201802564

55. N. Alias, A. Mohamad, Advances of aqueous rechargeable lithium-ion battery: a review. J. Power Sources 274, 237251 (2015). https://doi.org/10.1016/j.jpowsour.2014.10.009

56. H. Kim, J. Hong, K. Park, H. Kim, S. Kim, K. Kang, Aqueous rechargeable $\mathrm{Li}$ and $\mathrm{Na}$ ion batteries. Chem. Rev. 114(23), 11788-11827 (2014). https://doi.org/10.1021/ cr500232y

57. F. Beck, P. Rüetschi, Rechargeable batteries with aqueous electrolytes. Electrochim. Acta 45(15-16), 2467-2482 (2000). https://doi.org/10.1016/S0013-4686(00)00344-3

58. M. Alfaruqi, V. Mathew, J. Gim, S. Kim, J. Song, J.P. Baboo, S.H. Choi, J. Kim, Electrochemically induced structural transformation in a $\gamma-\mathrm{MnO}_{2}$ cathode of a high capacity zincion battery system. Chem. Mater. 27(10), 3609-3620 (2015). https://doi.org/10.1021/cm504717p

59. C. Xu, H. Du, B. Li, F. Kang, Y. Zeng, Reversible insertion properties of zinc ion into manganese dioxide and its application for energy storage. Electrochem. Solid-State Lett. 12(4), A61-A65 (2009). https://doi.org/10.1149/1.3065967

60. H. Pan, Y. Shao, P. Yan, Y. Cheng, K. Han et al., Reversible aqueous zinc/manganese oxide energy storage from conversion reactions. Nat. Energy 1(5), 16039 (2016). https://doi. org/10.1038/nenergy.2016.39

61. W. Sun, F. Wang, S. Hou, C. Yang, X. Fan et al., Zn/ $\mathrm{MnO}_{2}$ battery chemistry with $\mathrm{H}^{+}$and $\mathrm{Zn}^{2+}$ coinsertion. J. Am. Chem. Soc. 139(29), 9775-9778 (2017). https://doi. org/10.1021/jacs.7b04471

62. G.Z. Fang, C.Y. Zhu, M.H. Chen, J. Zhou, B.Y. Tang et al., Suppressing manganese dissolution in potassium manganate with rich oxygen defects engaged high-energy-density and durable aqueous zinc-ion battery. Adv. Funct. Mater. 29(15), 1808375 (2019). https://doi.org/10.1002/adfm.201808375

63. J. Huang, Z. Wang, M. Hou, X. Dong, Y. Liu, Y. Wang, Y. $\mathrm{Xia}$, Polyaniline-intercalated manganese dioxide nanolayers as a high-performance cathode material for an aqueous zinc-ion battery. Nat. Commun. 9, 2908 (2018). https://doi. org/10.1038/s41467-018-04949-4

64. J. Knight, S. Therese, A. Manthiram, Chemical extraction of $\mathrm{Zn}$ from $\mathrm{ZnMn}_{2} \mathrm{O}_{4}$-based spinels. J. Mater. Chem.
A 3(42), 21077-21082 (2015). https://doi.org/10.1039/ C5TA06482A

65. N. Zhang, Y. Dong, M. Jia, X. Bian, Y. Wang et al., Rechargeable aqueous $\mathrm{Zn}-\mathrm{V}_{2} \mathrm{O}_{5}$ battery with high energy density and long cycle life. ACS Energy Lett. 3(6), 1366-1372 (2018). https://doi.org/10.1021/acsenergylett.8b00565

66. M. Yan, P. He, Y. Chen, S. Wang, Q. Wei et al., Water-lubricated intercalation in $\mathrm{V}_{2} \mathrm{O}_{5} \cdot n \mathrm{H}_{2} \mathrm{O}$ for high-capacity and highrate aqueous rechargeable zinc batteries. Adv. Mater. 30(1), 1703725 (2018). https://doi.org/10.1002/adma.201703725

67. D. Kundu, B. Adams, V. Duffort, S. Vajargah, L. Nazar, A high-capacity and long-life aqueous rechargeable zinc battery using a metal oxide intercalation cathode. Nat. Energy. 1(10), 16119 (2016). https://doi.org/10.1038/nenergy.2016.119

68. J. Ding, Z. Du, L. Gu, B. Li, L. Wang, S. Wang, Y. Gong, $\mathrm{S}$. Yang, Ultrafast $\mathrm{Zn}^{2+}$ intercalation and deintercalation in vanadium dioxide. Adv. Mater. 30(26), 1800762 (2018). https ://doi.org/10.1002/adma.201800762

69. T. Wei, Q. Li, G. Yang, C.J. Wang, An electrochemically induced bilayered structure facilitates long-life zinc storage of vanadium dioxide. J. Mater. Chem. A 6(17), 8006-8012 (2018). https://doi.org/10.1039/C8TA02090F

70. J. Lai, H. Zhu, X. Zhu, H. Koritala, Y. Wang, Interlayerexpanded $\mathrm{V}_{6} \mathrm{O}_{13} \cdot n \mathrm{H}_{2} \mathrm{O}$ architecture constructed for advanced rechargeable aqueous zinc ion battery. ACS Appl. Energy Mater. 2(3), 1988-1996 (2019). https://doi.org/10.1021/acsae $\mathrm{m} .8 \mathrm{~b} 02054$

71. J. Shin, D. Choi, H. Lee, Y. Jung, J. Choi, Hydrated intercalation for high-performance aqueous zinc ion batteries. Adv. Energy Mater. 9(14), 1900083 (2019). https://doi. org/10.1002/aenm.201900083

72. C. Shen, X. Li, N. Li, K. Xie, J. Wang, X. Liu, B. Wei, Graphene-boosted, high-performance aqueous Zn-ion battery. ACS Appl. Mater. Interfaces 10(30), 25446-25453 (2018). https://doi.org/10.1021/acsami.8b07781

73. P. He, Y. Quan, X. Xu, M. Yan, W. Yang, Q. An, L. He, L. Mai, High-performance aqueous zinc-ion battery based on layered $\mathrm{H}_{2} \mathrm{~V}_{3} \mathrm{O}_{8}$ nanowire cathode. Small 13(47), 1702551 (2017). https://doi.org/10.1002/smll.201702551

74. Q. Pang, C. Sun, Y. Yu, K. Zhao, Z. Zhang et al., $\mathrm{H}_{2} \mathrm{~V}_{3} \mathrm{O}_{8}$ nanowire/graphene electrodes for aqueous rechargeable zinc ion batteries with high rate capability and large capacity. Adv. Energy Mater. 8(19), 1800144 (2018). https://doi. org/10.1002/aenm.201800144

75. Y. Yang, Y. Tang, G. Fang, L. Shan, J. Guo et al., Li ${ }^{+}$intercalated $\mathrm{V}_{2} \mathrm{O}_{5} \cdot n \mathrm{H}_{2} \mathrm{O}$ with enlarged layer spacing and fast ion diffusion as an aqueous zinc-ion battery cathode. Energy Environ. Sci. 11(11), 3157-3162 (2018). https://doi.org/10.1039/ C8EE01651H

76. M. Alfaruqi, V. Mathew, J. Song, S. Kim, S. Islam et al., Electrochemical zinc intercalation in lithium vanadium oxide: a high-capacity zinc-ion battery cathode. Chem. Mater. 29(4), 1684-1694 (2017). https://doi.org/10.1021/acs.chemm ater.6b05092

77. B. Sambandam, V. Soundharrajan, S. Kim, M. Alfaruqi, J. Jo, S. Kim, V. Mathew, Y. Sun, J. Kim, $\mathrm{K}_{2} \mathrm{~V}_{6} \mathrm{O}_{16} \cdot 2.7 \mathrm{H}_{2} \mathrm{O}$ 
nanorod cathode: an advanced intercalation system for high energy aqueous rechargeable $\mathrm{Zn}$-ion batteries. J. Mater. Chem. A 6(32), 15530-15539 (2018). https://doi. org/10.1039/C8TA02018C

78. P. He, G. Zhang, X. Liao, M. Yan, X. Xu, Q. An, J. Liu, L. Mai, Sodium ion stabilized vanadium oxide nanowire cathode for high-performance zinc-ion batteries. Adv. Energy Mater. 8(10), 1702463 (2018). https://doi.org/10.1002/ aenm.201702463

79. F. Wan, L. Zhang, X. Dai, X. Wang, Z. Niu, J. Chen, Aqueous rechargeable zinc/sodium vanadate batteries with enhanced performance from simultaneous insertion of dual carriers. Nat. Commun. 9, 1656 (2018). https://doi. org/10.1038/s41467-018-04060-8

80. P. Hu, T. Zhu, X. Wang, X. Wei, M. Yan et al., Highly durable $\mathrm{Na}_{2} \mathrm{~V}_{6} \mathrm{O}_{16} \cdot 1.63 \mathrm{H}_{2} \mathrm{O}$ nanowire cathode for aqueous zinc-ion battery. Nano Lett. 18(3), 1758-1763 (2018). https ://doi.org/10.1021/acs.nanolett.7b04889

81. Y. Cai, F. Liu, Z. Luo, G. Fang, J. Zhou, A. Pan, S. Liang, Pilotaxitic $\mathrm{Na}_{1.1} \mathrm{~V}_{3} \mathrm{O}_{7.9}$ nanoribbons/graphene as high-performance sodium ion battery and aqueous zinc ion battery cathode. Energy Storage Mater. 13, 168-174 (2018). https ://doi.org/10.1016/j.ensm.2018.01.009

82. C.F. Liu, Z. Neale, J.Q. Zheng, X.X. Jia, J.J. Huang et al., Expanded hydrated vanadate for high-performance aqueous zinc-ion batteries. Energy Environ. Sci. 12, 2273-2285 (2019). https://doi.org/10.1039/C9EE00956F

83. C. Xia, J. Guo, P. Li, X. Zhang, H. Alshareef, Highly stable aqueous zinc-ion storage using a layered calcium vanadium oxide bronze cathode. Angew. Chem. Int. Ed. 57(15), 3943-3948 (2018). https://doi.org/10.1002/anie.201713291

84. L. Shan, Y. Yang, W. Zhang, H. Chen, G. Fang, J. Zhou, S. Liang, Observation of combination displacement/intercalation reaction in aqueous zinc-ion battery. Energy Storage Mater. 18, 10-14 (2019). https://doi.org/10.1016/j. ensm.2018.08.008

85. B. Tang, J. Zhou, G. Fang, F. Liu, C. Zhu, C. Wang, A. Pan, S. Liang, Engineering the interplanar spacing of ammonium vanadates as a high-performance aqueous zinc-ion battery cathode. J. Mater. Chem. A. 7(3), 940-945 (2019). https://doi.org/10.1039/C8TA09338E

86. R. Trócoli, F. Mantia, An aqueous zinc-ion battery based on copper hexacyanoferrate. Chemsuschem 8(3), 481-485 (2015). https://doi.org/10.1002/cssc.201403143

87. Z. Jia, B. Wang, Y. Wang, Copper hexacyanoferrate with a well-defined open framework as a positive electrode for aqueous zinc ion batteries. Mater. Chem. Phys. 149, 601-606 (2015). https://doi.org/10.1016/j.matchemphy s.2014.11.014

88. G. Kasiri, R. Trócoli, A. Hashemi, F. Mantia, An electrochemical investigation of the aging of copper hexacyanoferrate during the operation in zinc-ion batteries. Electrochim. Acta 222, 74-83 (2016). https://doi.org/10.1016/j.elect acta.2016.10.155

89. L. Zhang, L. Chen, X. Zhou, Z. Liu, Towards high-voltage aqueous metal-ion batteries beyond $1.5 \mathrm{~V}$ : the zinc/ zinc hexacyanoferrate system. Adv. Energy Mater. 5(2), 1400930 (2015). https://doi.org/10.1002/aenm.201400930

90. F. Wang, E. Hu, W. Sun, T. Gao, X. Ji et al., A rechargeable aqueous $\mathrm{Zn}^{2+}$-battery with high power density and a long cycle-life. Energy Environ. Sci. 11(11), 3168-3175 (2018). https://doi.org/10.1039/C8EE01883A

91. G.L. Li, Z. Yang, Y. Jiang, W.X. Zhang, Y.H. Huang, Hybrid aqueous battery based on $\mathrm{Na}_{3} \mathrm{~V}_{2}\left(\mathrm{PO}_{4}\right)_{3} / \mathrm{C}$ cathode and zinc anode for potential large-scale energy storage. J. Power Sources 308, 52-57 (2016). https://doi. org/10.1016/j.jpowsour.2016.01.058

92. H. Zhao, C. Hu, H. Cheng, J. Fang, Y. Xie et al., Novel rechargeable $\mathrm{M}_{3} \mathrm{~V}_{2}\left(\mathrm{PO}_{4}\right)_{3} / /$ zinc $(\mathrm{M}=\mathrm{Li}, \mathrm{Na})$ hybrid aqueous batteries with excellent cycling performance. Sci. Rep. 6, 25809 (2016). https://doi.org/10.1038/srep25809

93. W. Li, K. Wang, S. Cheng, K. Jiang, A long-life aqueous $\mathrm{Zn}$-ion battery based on $\mathrm{Na}_{3} \mathrm{~V}_{2}\left(\mathrm{PO}_{4}\right)_{2} \mathrm{~F}_{3}$ cathode. Energy Storage Mater. 15, 14-21 (2018). https://doi.org/10.1016/j. ensm.2018.03.003

94. W. Liu, J. Hao, C. Xu, J. Mou, L. Dong et al., Investigation of zinc ion storage of transition metal oxides, sulfides, and borides in zinc ion battery systems. Chem. Commun. 53(51), 6872-6874 (2017). https://doi.org/10.1039/C7CC01064H

95. W. Xu, K. Zhao, Y. Wang, Electrochemical activated $\mathrm{MoO}_{2} /$ $\mathrm{Mo}_{2} \mathrm{~N}$ heterostructured nanobelts as superior zinc rechargeable battery cathode. Energy Storage Mater. 15, 374-379 (2018). https://doi.org/10.1016/j.ensm.2018.06.028

96. J.J. Wang, J.G. Wang, H.Y. Liu, Z.Y. You, C.G. Wei, F.Y. Kang, Electrochemical activation of commercial $\mathrm{MnO}$ microsized particles for high-performance aqueous zinc-ion batteries. J. Power Sources 438, 226951 (2019). https://doi. org/10.1016/j.jpowsour.2019.226951

97. W. Xu, C. Sun, K. Zhao, X. Cheng, S. Rawal, Y. Xu, Y. Wang, Defect engineering activating (Boosting) zinc storage capacity of $\mathrm{MoS}_{2}$. Energy Storage Mater. 16, 527-534 (2019). https ://doi.org/10.1016/j.ensm.2018.09.009

98. H. Li, Q. Yang, F. Mo, G. Liang, Z. Liu et al., $\mathrm{MoS}_{2}$ nanosheets with expanded interlayer spacing for rechargeable aqueous Zn-ion batteries. Energy Storage Mater. 19, 94-101 (2018). https://doi.org/10.1016/j.ensm.2018.10.005

99. C.X. Xie, H.M. Zhang, W.B. Xu, W. Wang, X.F. Li, A long cycle life, self-healing zinc-iodine flow battery with high power density. Angew. Chem. Int. Ed. 130(35), 11341-11346 (2018). https://doi.org/10.1002/ange.201803122

100. B. Li, Z.M. Nie, M. Vijayakumar, G.S. Li, J. Liu, V. Sprenkle, W. Wang, Ambipolar zinc-polyiodide electrolyte for a highenergy density aqueous redox flow battery. Nat. Commun. 6, 6303 (2015). https://doi.org/10.1038/ncomms7303

101. H.L. Pan, B. Li, D.H. Mei, Z.M. Nie, Y.Y. Shao et al., Controlling solid-liquid conversion reactions for a highly reversible aqueous zinc-iodine battery. ACS Energy Lett. 2(12), 2674-2680 (2017). https://doi.org/10.1021/acsenergyl ett. $7 b 00851$

102. C. Bai, F. Cai, L. Wang, S. Guo, X. Liu, Z. Yuan, A sustainable aqueous $\mathrm{Zn}-\mathrm{I}_{2}$ battery. Nano Res. 11(7), 3548-3554 (2018). https://doi.org/10.1007/s12274-017-1920-9 
103. M. Chae, J.W. Heo, H.H. Kwak, H. Lee, S. Hong, Organic electrolyte-based rechargeable zinc-ion batteries using potassium nickel hexacyanoferrate as a cathode material. J. Power Sources 337, 204-211 (2017). https://doi.org/10.1016/j.jpows our.2016.10.083

104. C. Pan, R. Zhang, R. Nuzzo, A. Gewirth, $\mathrm{ZnNi}_{x} \mathrm{Mn}_{x} \mathrm{Co}_{2-2 x} \mathrm{O}_{4}$ spinel as a high-voltage and high-capacity cathode material for nonaqueous Zn-ion batteries. Adv. Energy Mater. 8(22), 1800589 (2018). https://doi.org/10.1002/aenm.201800589

105. C.S. Pan, R.G. Nuzzo, A.A. Gewirth, $\mathrm{ZnAl}_{x} \mathrm{Co}_{2-x} \mathrm{O}_{4}$ Spinels as cathode materials for non-aqueous $\mathrm{Zn}$ batteries with an open circuit voltage of $\leq 2 \mathrm{~V}$. Chem. Mater. 29(21), 9351-9359 (2017). https://doi.org/10.1021/acs.chemmater.7b03340

106. D.P. Kundu, S.H. Vajargah, L.W. Wan, B. Adams, D. Prendergast, L.F. Nazar, Aqueous vs. nonaqueous Zn-ion batteries: consequences of the desolvation penalty at the interface. Energy Environ. Sci. 11(4), 881-892 (2018). https://doi.org/10.1039/ C8EE00378E

107. Y.X. Zeng, X.Y. Zhang, Y. Meng, M.H. Yu, J.N. Yi et al., Achieving ultrahigh energy density and long durability in a flexible rechargeable quasi-solid-state $\mathrm{Zn}-\mathrm{MnO}_{2}$ battery. Adv. Mater. 29(26), 1700274 (2017). https://doi.org/10.1002/ adma.201700274

108. H. Li, C. Han, Y. Huang, Y. Huang, M. Zhu et al., An extremely safe and wearable solid-state zinc ion battery based on a hierarchical structured polymer electrolyte. Energy Environ. Sci. 11(4), 941-951 (2018). https://doi.org/10.1039/C7EE03232C

109. Z. Wang, Z. Ruan, Z. Liu, Y. Wang, Z. Tang et al., A flexible rechargeable zinc-ion wire-shaped battery with shape memory function. J. Mater. Chem. A 6(18), 8549-8557 (2018). https:// doi.org/10.1039/C8TA01172A

110. S. Zhang, N. Yu, S. Zeng, S. Zhou, M. Chen, J. Di, Q. Li, An adaptive and stable bio-electrolyte for rechargeable $\mathrm{Zn}$-ion batteries. J. Mater. Chem. A 6(26), 12237-12243 (2018). https:// doi.org/10.1039/C8TA04298E

111. D. Chao, C. Zhu, M. Song, P. Liang, X. Zhang et al., A highrate and stable quasi-solid-state zinc-ion battery with novel $2 \mathrm{D}$ layered zinc orthovanadate array. Adv. Mater. 30(32), 1803181 (2018). https://doi.org/10.1002/adma.201803181

112. Y. Huang, J. Liu, J. Wang, M. Hu, F. Mo, G. Liang, C. Zhi, An intrinsically self-healing NiCollZn rechargeable battery with a self-Healable ferric-ion-crosslinking sodium polyacrylate hydrogel electrolyte. Angew. Chem. Int. Ed. 57(31), 9810-9813 (2018). https://doi.org/10.1002/anie.201805618

113. F. Mo, G. Liang, Q. Meng, Z. Liu, H. Li, J. Fan, C. Zhi, A flexible rechargeable aqueous zinc manganese-dioxide battery working at $-20^{\circ} \mathrm{C}$. Energy Environ. Sci. 12(2), 706-715 (2019). https://doi.org/10.1039/C8EE02892C

114. M.C.H. McKubre, D.D. Macdonald, The dissolution and passivation of zinc in concentrated aqueous hydroxide. J. Electrochem. Soc. 128(3), 524-530 (1981). https://doi. org/10.1149/1.2127450

115. P. Gu, M.B. Zheng, Q.X. Zhao, X. Xiao, H.G. Xue, H. Pang, Rechargeable zinc-air batteries: a promising way to green energy. J. Mater. Chem. A 5(17), 7651-7666 (2017). https:// doi.org/10.1039/C7TA01693J
116. H.F. Li, Z.X. Liu, G.J. Liang, Y. Huang, Y. Huang et al., Waterproof and tailorable elastic rechargeable yarn zinc ion batteries by a cross-linked polyacrylamide electrolyte. ACS Nano 12(4), 3140-3148 (2018). https://doi.org/10.1021/acsnano.7b09003

117. Y. Yan, Y.M. Zhang, Y.T. Wu, Z.Z. Wang, A. Mathur et al., A lasagna-inspired nanoscale $\mathrm{ZnO}$ anode design for highenergy rechargeable aqueous batteries. ACS Appl. Energy Mater. 1(11), 6345-6351 (2018). https://doi.org/10.1021/acsae m.8b01321

118. L.P. Wang, N.W. Li, T.S. Wang, Y.X. Yin, Y.G. Guo, C.R. Wang, Conductive graphite fiber as a stable host for zinc metal anodes. Electrochim. Acta 244, 172-177 (2017). https://doi. org/10.1016/j.electacta.2017.05.072

119. A.B. Hashemi, G. Kasiri, F.L. Mantia, The effect of polyethyleneimine as an electrolyte additive on zinc electrodeposition mechanism in aqueous zinc-ion batteries. Electrochim. Acta 258, 703-708 (2017). https://doi.org/10.1016/j.elect acta.2017.11.116

120. T.K.A. Hoang, T.N.L. Doan, J.H. Cho, J.Y.J. Su, C. Lee, C.Y. $\mathrm{Lu}, \mathrm{P}$. Chen, Sustainable gel electrolyte containing pyrazole as corrosion inhibitor and dendrite suppressor for aqueous $\mathrm{Zn} /$ $\mathrm{LiMn}_{2} \mathrm{O}_{4}$ battery. Chemsuschem 10(13), 2816-2822 (2017). https://doi.org/10.1002/cssc.201700441

121. F. Wang, O. Borodin, T. Gao, X. Fan, W. Sun et al., Highly reversible zinc metal anode for aqueous batteries. Nat. Mater. 17(6), 543-549 (2018). https://doi.org/10.1038/s4156 3-018-0063-z

122. F. Wan, Y. Zhang, L.L. Zhang, D.B. Liu, C.D. Wang, L. Song, Z.Q. Niu, J. Chen, Reversible oxygen redox chemistry in aqueous zinc-ion batteries. Angew. Chem. Int. Ed. 58(21), 70627067 (2019). https://doi.org/10.1002/anie.201902679

123. K.N. Zhao, C. Wang, Y. Yu, M. Yan, Q. Wei et al., Ultrathin surface coating enables stabilized zinc metal anode. Adv. Mater. Interfaces 5(16), 1800848 (2018). https://doi.org/10.1007/ s10008-017-3589-0

124. L.T. Kang, M.W. Cui, F.Y. Jiang, Y.F. Gao, H.J. Luo, J.J. Liu, W. Liang, C.Y. Zhi, Nanoporous $\mathrm{CaCO}_{3}$ coatings enabled uniform $\mathrm{Zn}$ stripping/plating for long-life zinc rechargeable aqueous batteries. Adv. Energy Mater. 8(25), 1801090 (2018). https ://doi.org/10.1002/aenm.201801090

125. Z. Zhou, Y. Zhang, P. Chen, Y. Wu, H. Yang et al., Graphene oxide-modified zinc anode for rechargeable aqueous batteries. Chem. Eng. Sci. 194, 142-147 (2019). https://doi.org/10.1016/j. ces.2018.06.048

126. K.E.K. Sun, T.K.A. Hoang, T.N.L. Doan, Y. Yu, X. Zhu, Y. Tian, P. Chen, Suppression of dendrite formation and corrosion on zinc anode of secondary aqueous batteries. ACS Appl. Mater. Interfaces 9(11), 9681-9687 (2017). https://doi. org/10.1021/acsami.6b16560

127. B. Lee, S. Cui, X. Xing, H. Liu, X. Yue, V. Petrova, H. Lim, R. Chen, P. Liu, Dendrite suppression membranes for rechargeable zinc batteries. ACS Appl. Mater. Interfaces 10(45), 3892838935 (2018). https://doi.org/10.1021/acsami.8b14022 